Portland State University

PDXScholar

Fall 11-21-2014

\title{
Agricultural Classification of Multi-Temporal MODIS Imagery in Northwest Argentina Using Kansas Crop Phenologies
}

Jarrett Alexander Keifer Portland State University

\section{Recommended Citation}

Keifer, Jarrett Alexander, "Agricultural Classification of Multi-Temporal MODIS Imagery in Northwest Argentina Using Kansas Crop Phenologies" (2014). Dissertations and Theses. Paper 2102.

https://doi.org/10.15760/etd.2100

This Thesis is brought to you for free and open access. It has been accepted for inclusion in Dissertations and Theses by an authorized administrator of PDXScholar. Please contact us if we can make this document more accessible: pdxscholar@pdx.edu. 
Agricultural Classification of Multi-Temporal MODIS Imagery in

Northwest Argentina Using Kansas Crop Phenologies

by

Jarrett Alexander Keifer

A thesis submitted in partial fulfillment of the requirements for the degree of

\title{
Master of Arts
}

in

Geography

\author{
Thesis Committee: \\ Jiunn-Der Duh, Chair \\ David Banis \\ Leopoldo Rodriguez
}

Portland State University

2014 
(C) 2014 Jarrett Alexander Keifer 


\begin{abstract}
Subtropical deforestation in Latin America is thought to be driven by demand for agricultural land, particularly to grow soybeans. However, existing remote sensing methods that can differentiate crop types to verify this hypothesis require high spatial or spectral resolution data, or extensive ground truth information to develop training sites, none of which are freely available for much of the world. I developed a new method of crop classification based on the phenological signatures of crops extracted from multi-temporal MODIS vegetation indices. I tested and refined this method using the USDA Cropland Data Layer from Kansas, USA as a reference. I then applied the method to classify crop types for a study site in Pellegrini, Santiago Del Estero, Argentina. The results show that this method is unable to effectively separate summer crops in Pellegrini, but can differentiate summer crops and nonsummer crops. Unmet assumptions about agricultural practices are primarily responsible for the ineffective summer crop classification, underlining the need for researchers to have a complete understanding of ground conditions when designing a remote sensing analysis.
\end{abstract}


A mi amor, $y$ nuestra vida juntos. 


\section{Acknowledgements}

I could not have completed this project without the help and support of many who have come along side me in this endeavor. Firstly, thanks to my advisor, Geoffrey Duh, for his guidance, insights, and many hours of dedicated assistance. I would not have even known what I was proposing to do without him making sense of my ramblings. Thank you to my thesis committee members Leopoldo Rodriguez and David Banis, to whom I am grateful for their contributions. Polo, that shovel saved me. Thank you to Martha Works, for her help understanding my topic from a cultural geography perspective. Thank you Karin Walker and to other staff in the department who helped me navigate the complex bureaucracy of PSU. Thanks to all in my cohort for their support and camaraderie, in particular Tony Hair for his putting up with my incessant, overly-technical geo-babble, and encouraging me to continue even when I wanted to stop.

I must also extend a big thank you to Joe Poracsky and the PSU Geography Department, whose generosity helped to make this project possible.

Thank you to all those outside of PSU for their encouragement and support through this project: my parents, La Familia Flores, Aaron and Catherine, Tom and Harmony, Josh and Rachel, Matt and Jesse, Renjy and Katy, Dean, Carlos...so many people supported me 
in this endeavor, I cannot possibly name everyone.

To the people of Pellegrini: Gracias a todos. No puedo creer como la gente me ayudaron, especialmente Roberto y Manuel Dantas, David Ruiz, Rafael Dip, y Martín Lasko. Es verdad, sin ustedes yo no haya tenido éxito. Muchas gracias. Espero que yo puede regresar a Nueva Esperanza otra vez. Es una lugar especial para mi, por la gente. Y Playmax, es la gravedad: no puedo resistir la atracción.

Lastly, but definitely not least, thank you to my wife Aida. You have stood by me through the whole of this process, encouraging and pushing me to continue even when it made life more difficult for you. Te debo. Te quiero, mi bella. 


\section{Contents}

$\begin{array}{ll}\text { Abstract } & \text { i }\end{array}$

$\begin{array}{ll}\text { Dedication } & \text { ii }\end{array}$

Acknowledgements $\quad$ iii

List of Tables viii

List of Figures $\quad$ ix

List of Abbreviations $\quad$ x

1 Introduction 1

2 Background $\quad 4$

2.1 Deforestation and the Ley de Bosques (Forest Act) in Argentina . . . . . . . . 4

2.2 Soy and its Effects . . . . . . . . . . . . . . . . . . 5

2.3 Composite Vegetation Indices and Time-Series Images ～. . . . . . . . . 7

2.4 Crop Phenologies and Phenological Classification . . . . . . . . . . . . . . 11

3 Study Areas $\quad 18$

3.1 Kansas, USA . . . . . . . . . . . . . . . . . . . . . . . . . . . . . 18

3.2 Pellegrini, Santiago del Estero, Argentina . . . . . . . . . . . . . . 22

4 Data and Methods $\quad 28$

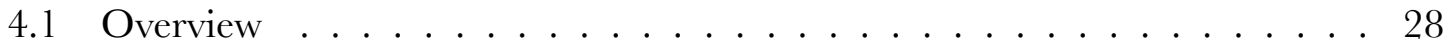

4.2 Field Methods and Data Collection in Pellegrini . . . . . . . . . . . . . . 30

4.3 Data Processing . . . . . . . . . . . . . . . . . . . . . 32

4.3.1 Resampling the CDL . . . . . . . . . . . . . . . 32 
4.3.2 Building the TSIs . . . . . . . . . . . . . . . . . 32

4.3 .3 Eliminating Mixels . . . . . . . . . . . . . . . . . . . 34

4.3.4 Extracting the Reference Temporal Signatures . . . . . . . . . . . . 34

4.3.5 Fitting the Reference Signatures to the TSIs and Creating the RMSE Rasters . . . . . . . . . . . . . . . . . . . . 37

4.3.6 Classifying the RMSE Rasters . . . . . . . . . . . . . . . . . . 38

5 Results $\quad 42$

5.1 Ground Truth and Agricultural Practices in Pellegrini . . . . . . . . . . . . 42

5.2 Elimination of Mixels . . . . . . . . . . . . . . . . . . 47

5.3 Extracted Reference Signatures . . . . . . . . . . . . . . . . . . . 47

5.4 Fitting and Classifying the TSIs . . . . . . . . . . . . . . . . . 50

6 Discussion $\quad 56$

6.1 Examining the Kansas Signatures . . . . . . . . . . . . . . 56

6.2 Breakdown of the Kansas Classification _ . . . . . . . . . . . . . . . 57

6.3 The Pellegrini Classification and Class Confusion . . . . . . . . . . . . . . 59

6.4 Clustering Pellegrini . . . . . . . . . . . . . . . . . . 62

6.5 More Ideas for Future Research _ . . . . . . . . . . . . . . . . 67

6.5.1 Temporal Signature Generation . . . . . . . . . . . . . 67

6.5 .2 Mixels . . . . . . . . . . . . . . . . . 68

6.5 .3 The Fitting Process . . . . . . . . . . . . . . . . . 69

6.5.4 Thresholding and Classification ............. 71

$\begin{array}{lll}7 & \text { Conclusion } & 74\end{array}$

$\begin{array}{ll}\text { References } & 77\end{array}$

$\begin{array}{lll}\text { Appendix A Reflecting on My Field Work } & 87\end{array}$

$\begin{array}{lll}\text { Appendix B Developing the Processing Tools } & 106\end{array}$

B.1 Review of the classification process . . . . . . . . . . . . . . 106

B.2 Creating Time Series Images . . . . . . . . . . . . . . . . . 107

B.3 Extracting Reference Temporal Signatures . . . . . . . . . . . . . . . . 108

B.4 The Fit Algorithm . . . . . . . . . . . . . . . . . . . . . . 109 
B.5 Creating a Classification From the RMSE Rasters . . . . . . . . . . . . . . 113

Appendix G A Breakdown of all Completed Testing 116

C.1 Round 1 Testing: Initial Classifications . . . . . . . . . . . . . 117

C.2 Round 2 Testing: Eliminating Mixels . . . . . . . . . . . . . . . . 124

C.3 Round 3 Testing: Refining the Reference Signatures . . . . . . . . . . . . . 139

C.4 Round 4 Testing: Different Time Ranges . . . . . . . . . . . . . . . . . . 150

C.5 Round 5: A Last Ditch Effort to Match the CDL . . . . . . . . . . . . . . 154

C.6 Discussion and Conclusions . . . . . . . . . . . . . . . . . 155

$\begin{array}{lll}\text { Appendix D Supplemental Files } & 157\end{array}$ 


\section{List of Tables}

2.1 Deforestation in Argentina, 2006 to $2011 \ldots \ldots$. . . . . . . . . . 5

3.1 Most extensive crops in Kansas, 2012 . . . . . . . . . . . . . . . . . . . 19

3.2 Kansas Study Site Planting Dates . . . . . . . . . . . . . . . . . . . . . 19

5.1 Summer 2014 Pellegrini Land Cover Classes, From Ground Truth . . . . . . 46

5.2 Key Dates for Summer Crops, Pellegrini, Argentina . . . . . . . . . . . . . . 46

5.3 Summer 2012 Kansas TSI Mixel and Pure Pixel Counts . . . . . . . . . . . . 47

5.4 Summer 2012 Kansas Study Site Classification Accuracy . . . . . . . . . . . . 50

5.5 Kansas Best Classification RMSE Thresholds . . . . . . . . . . . . . . . . 52

5.6 Summer 2014 Pellegrini Best Classification Accuracy ～. . . . . . . . . . . . 52

5.7 Pellegrini Best Glassification RMSE Thresholds . . . . . . . . . . . . . . . 53

6.1 Summer 2014 Pellegrini Best Classification Accuracy Checked Against All Pure Pixels ............................. 60

6.2 Pellegrini Corn and Soy Confusion with "Other" Land Cover Classes . . . . . 61 


\section{List of Figures}

2.1 Example VI Progression . . . . . . . . . . . . . . . . . . . 9

2.2 Example Transformations of a Crop's VI Curve . . . . . . . . . . . . . . . . 13

3.1 Kansas Study Site and the Communities of Halstead, Sedgwick, and Valley Center. . . . . . . . . . . . . . . . . 20

3.22012 Kansas Study Site Crop Cover . . . . . . . . . . . . . . . . . . 21

3.3 The Department of Pellegrini and the Greater Northwest of Argentina . . . . . 24

3.4 Land Cover Change in Pellegrini from 1973 to 2014 . . . . . . . . . . . . . . . 25

4.1 Five Winter Wheat Pixel Signatures and Their Mean Reference Signature . . . 36

5.1 Pellegrini Summer 2014 Collected and Digitized Ground Truth Dataset . . . . 43

5.2 Map of Estancia La Armonia, a Large Farm . . . . . . . . . . . . . . . . . 45

5.3 Clustering the Kansas TSI Image into Three Clusters for Each Crop . . . . . . 48

5.4 Crop Signatures Extracted from the Kansas TSI Crop Clusters . . . . . . . . . 49

5.6 Pellegrini Summer 2014 Classification . . . . . . . . . . . . . 54

6.1 Signature of an Unknown Non-Crop Pixel Confused for Corn and Soy in Pel-

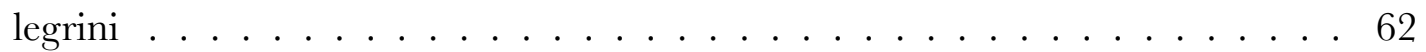

6.2 Corn, Soy, and Sorghum Signatures Extracted from the Pellegrini TSI . . . . . 63

6.3 Poroto and Pasture Signatures Extracted from the Pellegrini TSI . . . . . . . . 64

6.4 Forested, "Nothing," and "Other" Signatures Extracted from the Pellegrini TSI 65 


\section{List of Abbreviations}

CDL Cropland Data Layer

DOY Day of Year

EST Extract Signatures Tool

EVI Enhanced Vegetation Index

GDAL Geospatial Data Abstraction Library

GIL Global Interpreter Lock

GIS Geographic Information System

GM Genetically Modified

INTA Instituto Nacional de Tecnología Agropecuraía

(National Institute of Agricultural Technology)

LPDAAG Land Processes Distributed Active Archive Center

LULG Land Use/Land Cover

MODIS Moderate Resolution Imaging Spectroradiometer

NASA National Aeronautics and Space Administration

NDVI Normalized Difference Vegetation Index

OLI Operation Land Imager

OTBN Ordenamiento Territorial de los Bosques Nativos

(Land Management Order for Native Forests) 
RMSE Root Mean Square Error

RSG Reference Signature Generator

SS1 Study Site 1

SSE Sum of Square Errors

TM Thematic Mapper

TSF Two-Step Filter

TSI Time Series Image

USDA U.S. Department of Agriculture

VI Vegetation Index

WKID Well-Known ID 


\section{Chapter 1}

\section{Introduction}

Deforestation has long been a concern throughout tropical South America. However, this process of land use/land cover (LULC) change from forest to other uses has been increasingly recognized in subtropical South America as a significant source of environmental degradation. Understanding the complex dynamics of subtropical deforestation is crucial given the prominent role of forests in debates about climate change, conservation, and the protection of endangered species (Geist and Lambin 2002; Zak, Cabido, and Hodgson 2004; Bonnie 2000; Houghton 1994; Sala et al. 2000).

Currently, many perceive growing demand for agricultural land - particularly land for soybeans - to be one of the greatest pressures on South American subtropical forests (Pengue 2005; Grau, Gasparri, and Aide 2005; Altieri and Pengue 2006). Remote sensing has given researchers a tool to classify land cover and measure deforestation. However, existing multi-spectral and multi-temporal image classification techniques require extensive ground truth information for the accurate classification of common crop types using widelyavailable remotely-sensed data. Therefore, obtaining a complete picture of the dynamics of deforestation, including an understanding of agricultural pressures on forests, requires 
rarely-available high spatial or high spectral resolution data (Senay et al. 2000) or expensive field time gathering training site data. The development of a tool that can efficiently and effectively extract crop types using widely-available imagery would be of value for investigations of LULC change in areas under rapid agricultural expansion.

The primary goal of this thesis is to develop and test a phenological classification toolset that can identify and extract crop types from a multi-date vegetation index sequence assembled using free and publicly-accessible data from the National Aeronautics and Space Administration's (NASA) Moderate Resolution Imaging Spectroradiometer (MODIS) sensor. The toolset was tested using the U.S. Department of Agriculture's (USDA) Cropland Data Layer (CDL) from a test field in Kansas, USA. The CDL data provided delineation and crop identification of agricultural fields in the study area. Overlaid on the MODIS data, the CDL crop boundaries allowed the extraction of reference phenological signatures for various summer crops. Using the Kansas-derived reference signatures, imagery of the 2014 summer growing season in the Department of Pellegrini, Santiago del Estero, Argentina was then classified with the toolset. I further performed an accuracy assessment of the classification to determine the toolset's applicability in subtropical South America.

The body of this thesis is broken into seven chapters. The first chapter gives an overview and an introduction to the research. The second chapter provides background information on deforestation and soybean cultivation in Argentina and phenological classification techniques. The third introduces the two study areas where the processing methods, presented in Chapter 4, are applied. Chapter 5 reviews the results of said methods; Chapter 6 discusses the significance of the results, problems with the method and data, and ideas for 
future research. Chapter 7 closes the thesis with some concluding remarks.

Three appendices contain additional supporting information. Appendix A is a reflection of my time in Argentina doing the fieldwork for this project. Appendix B documents the toolset created to implement the processing methods of Chapter 4 and the development process. Preliminary testing of the tools is reviewed in Appendix C. Appendix D contains a list of the toolset source files included with the thesis, and instructions on how to install the toolset. 


\section{Chapter 2}

\section{Background}

\subsection{Deforestation and the Ley de Bosques (Forest Act) in Argentina}

The conversion of forestland to other uses has seriously impacted Argentina's forests. In 1915,30 percent of the country had forest cover, but in 2001 only 10 percent remained forested (Secretaría de Desarrollo Sustentable y Política Ambiental [Argentina] 2001). Over the period 1998 to 2002, Argentina lost over 940,000 hectares of forest cover (Secretaría de Ambiente y Desarrollo Sustentable [Argentina] 2007). This high rate of deforestation concerned policymakers. Law 26.331, or the Ley de Bosques (Forest Act), was passed in November 2007 in an effort to preserve remaining native forest. Areas of native forest are defined to be those with forest cover of at least 20 percent native species, and that have trees at least seven meters high. The law designates red, yellow, and green areas, each with different restrictions on clearing and use. Red is assigned to areas of "high conservation value," yellow is for areas that must be managed sustainably, and green allows "partial or total use" (Gulezian 2009: 25). Each provincial government is responsible for deciding how to classify their native forest areas, and each enacted the Ley de Bosques regulations under the Ordenamiento 
Table 2.1. Deforestation in Argentina, 2006 to 2011

\begin{tabular}{cc}
\hline Time Period & Hectares Deforested \\
\hline 2006 to Ley de Bosques (2007) & 573,296 \\
Ley de Bosques to OTBN (2009) & 473,001 \\
OTBN to 2011 & 459,108 \\
\hline Total & $1,505,405$ \\
\hline
\end{tabular}

Territorial de los Bosques Nativos (Land Management Order for Native Forests, OTBN).

As a part of Law 26.331, ongoing land cover studies are done to examine the effectiveness of the legislation. Between 2006 and the passing of the law in 2007, 573,296 hectares of native forest cover were lost (see Table 2.1). From the passing of the law and the classification of the OTBN areas in 2009, a further 473,001 hectares were deforested. From the enacting of the OTBN and 2011, some 459,108 hectares were found to have been lost (Secretería de Ambiente y Desarrollo Sustentable [Argentina] 2012). The continued deforestation suggests that, in the context of the native forest areas, the Ley de Bosques may have had a small effect in reducing deforestation. Yet the overall deforestation rate remains quite high. Consequently, some have begun to question the effectiveness of the law at slowing cutting (Valpreda 2012; Greenpeace Argentina 2013). Clearly, we need to develop a better understanding of the driving forces of deforestation in Argentina.

\subsection{Soy and its Effects}

The increase of soybean cultivation in Argentina has occurred at a rapid pace throughout the last two decades. Currently, Argentina is the third largest producer of soy in the world (U.S. Foreign Agricultural Service 2013). Necessarily, as soy production rises, so 
does its spatial extent and the intensity of cultivation methods. Currently, almost all of Argentina's soy production uses genetically modified (GM) varieties, specifically Monsanto's “Roundup Ready" beans (Greenpeace International 2005). The highly mechanized and input intensive nature of soybean cultivation has environmental consequences in addition to deforestation, such as pesticide runoff, glyphosate-resistant weeds, and soil depletion (Pengue 2005). The significant capital expense for necessary mechanical and chemical technologies consolidates land ownership into the hands of an elite few as small famers find themselves unable to compete with larger producers' economies of scale.

A number of studies have addressed soy and deforestation in Northwest Argentina, but only one has used methods capable of mapping crop types in deforested areas (Volante et al. 2005). However, that study, by the Argentine Instituto Nacional de Tecnología Agropecuraia (National Institute of Agricultural Technology, INTA), does not have well-documented methodology and has not been updated since 2005. Of the remainder, all used remote sensing techniques to classify only LULG and not specific crop types, leaving the effect of soy on LULC as an underlying assumption (Grau, Gasparri, and Aide 2005, 2008; Grau, Aide, and Gasparri 2005; Boletta et al. 2006; Gasparri and Grau 2009). While the extreme deforestation in Argentina is undeniable - and certainly soy plays a part - soy's role has not been examined in full, leaving unsubstantiated the perception of soy as the driving force in this process. We also do not know what effect, if any, the Ley de Bosques has had on agricultural production.

The goal of this research is to develop an image classification method capable of mapping agricultural crops by type, allowing soy to be explicitly identified on remotely sensed imagery. 
Accurate and efficient mapping of soy distributions and their changes over time will allow further investigation of the roles of soy in deforestation. The direct and indirect effects soy crops have had on deforestation can thus be understood conceptually and systemically at both regional and local scales, which could lead to the development of more effective policies for land management (Brown et al. 2007).

\subsection{Composite Vegetation Indices and Time-Series Images}

The differentiation of crop types in remotely-sensed imagery is not a straightforward process. The use of a vegetation index $(\mathrm{VI})$, such as the normalized difference vegetation index (NDVI) or the enhanced vegetation index (EVI), can help identify crops by their specific VI values in an image.

NDVI is a normalized ratio of the red and near-infrared bands, and can be expressed mathematically as:

$$
\mathcal{N D V I}=\frac{\rho_{\text {NIR }}-\rho_{\text {red }}}{\rho_{\text {NIR }}+\rho_{\text {red }}}
$$

where $\rho_{\text {NIR }}$ and $\rho_{\text {red }}$ are the measured surface reflectance in their respective bands. As a ratio, the index minimizes multiplicative noise, but has issues with non-linearity and additive noise (Huete et al. 2002).

With advances in calibration, atmospheric correction, and other noise removal techniques, which are integrated into the MODIS data processing workflow, a ratioing index is less necessary. The EVI was specifically developed for the MODIS platform to help correct some of the deficiencies of the NDVI. It has better sensitivity to high biomass, canopy struc- 
ture, and leaf area, and less susceptibility to atmospheric degradation. EVI is calculated as:

$$
E V I=G \frac{\rho_{\text {NIR }}-\rho_{\text {red }}}{\rho_{\text {NIR }}+C_{1} \times \rho_{\text {red }}-C_{2} \times \rho_{\text {blue }}+L}
$$

Again, each $\rho$ is the measured surface reflectance in the respective band, after complete or partial atmospheric correction. The blue band is used to "subtract" aerosol effects from the red band. Additionally, four coefficients are introduced: $G$ is the gain factor, $C_{1}$ and $C_{2}$ are used in the aerosol calculation, while $L$ "is the canopy background adjustment that addresses nonlinear, differential NIR and red radiant transfer through a canopy" (Huete et al. 2002: 196). The values of these coefficients as used in the MODIS EVI calculation are 2.5, 6.0, 7.5 , and 1.0 , respectively.

Some crops, such as soy and sugarcane, have very different spectral reflectance throughout their development and maturation. However others, such as soy and corn, can have very similar spectral reflectance, leading to overlapping VI ranges (Price 1994). Such overlap can make it impossible to determine a crop type with specificity using traditional approaches; even using hyperspectral data, few differentiating characteristics between crops' spectral signatures can hinder classification. To combat this ambiguity, imagery from multiple dates can be used to show VI values over time, allowing the development of a classifier based on crop phenologies rather than reflectance values on a single-date (Gu et al. 2010; Wardlow and Egbert 2002, 2005; Wardlow, Egbert, and Kastens 2007; Wardlow and Egbert 2008; Zhang et al. 2003). Figure 2.1 shows an example of how the VI values change over a growing season. 


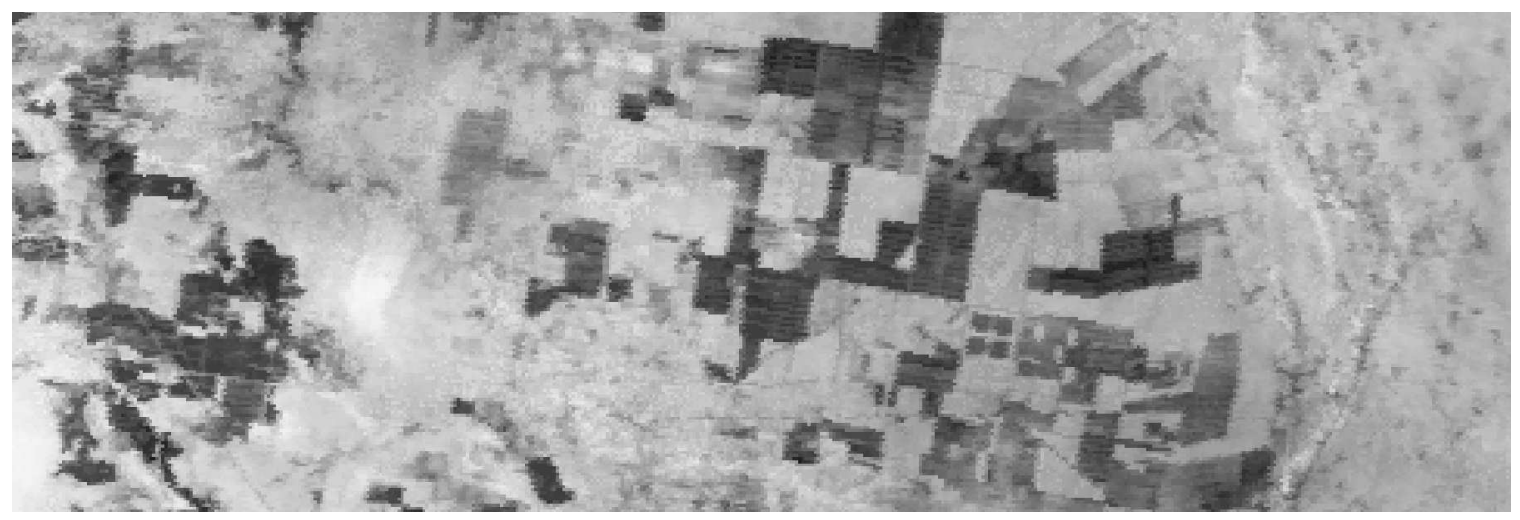

December 19, 2013

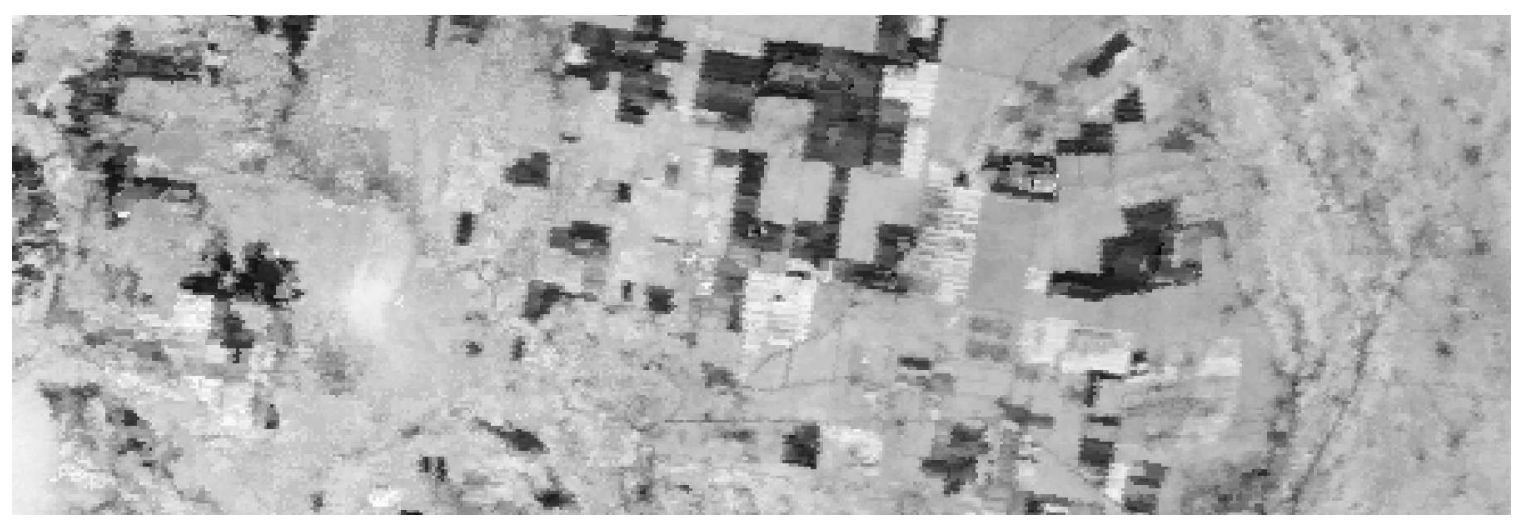

February 2, 2014

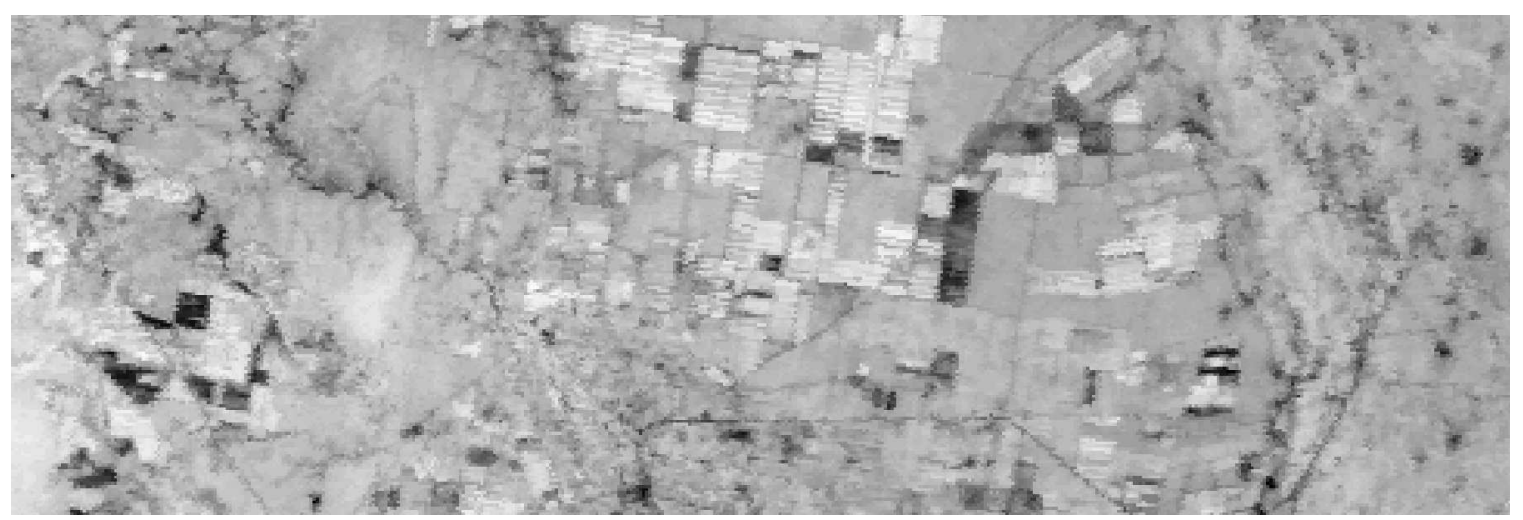

April 7, 2014

Figure 2.1. Example VI Progression

These MODIS NDVI images show the progression of VI values for a section of a MODIS tile containing the north half of Pellegrini and the surrounding area. The relatively constant medium-gray values of the forested areas stand in stark contrast to the fields, which predominately begin with low VI values (dark) in the first image, increasing as the crops mature to the greater VI values (bright) shown in the last image. 
MODIS 16-day VI composite imagery from both the Terra and Aqua Earth Observing System (EOS) satellites is available from the Land Processes Distributed Active Archive Center (LPDAAC). ${ }^{1}$ Each MODIS satellite images the entire Earth daily: the Terra satellite makes its passes north to south, while Aqua orbits south to north. Both cross the equator at noon. The daily temporal resolution is the greatest advantage of the MODIS platform. The likelihood of getting enough cloud-free data to develop a phenologic model is significantly increased over other common platforms like Landsat Thematic Mapper (TM) and Landsat Operational Land Imager (OLI), which have repeat coverage only every sixteen days. MODIS data, however, comes at the price of reduced spatial resolution: 231 meters compared to Landsat's 30-meter pixels. ${ }^{2}$ At this resolution, crop mapping is restricted to medium farms and larger - those with fields of at least 231 meters square, though often a field must be up to two times larger in at least one dimension to ensure a pure pixel can be isolated (pure pixels are those which are not mixels; see section C.2 on page 124 for details about problems with mixels). For the purposes of this investigation, however, this limitation is inconsequential, as small farms have a relatively minor impact on deforestation due to their size. Moreover, the crop of interest, GM soy, is only profitably grown using highly mechanized, input-intensive agricultural practices at very large scales (Kaimowitz and Smith 2001). Small fields do not have high enough yields to overcome the significant capital investment required.

LPDAAC creates the VI composites using the maximum VI value over the proceeding 16-day time period. Clouds, which have low VI values, are often eliminated completely over this composite period. The images are numbered by the day of the year (DOY) of the last 
date in the image's date range, so an image from DOY 17 is the composite of the images from 1 January through 17 January. ${ }^{3}$ Both NDVI and EVI are included in the MODIS VI products, and require no preprocessing for immediate use (unless cloud cover is pervasive in the area). A chronological series of these VIs can be assembled into a time series image (TSI), which can then be used for processing.

\subsection{Crop Phenologies and Phenological Classification}

$\mathrm{Gu}$ et al. outlined that phenological statistics regarding vegetation development can be derived from a MODIS VI time-series, including "start-of-season time, start-of-season NDVI, end-of-season time, end-of-season NDVI, maximum NDVI, maximum NDVI time, duration of season, amplitude of NDVI, and seasonal time integrated NDVI" (2010: 529). A principal component analysis can then be used to extract the meaningful variation in the data.

Similarly, Wardlow, Egbert, et al. (Wardlow and Egbert 2002, 2005; Wardlow, Egbert, and Kastens 2007; Wardlow and Egbert 2008) showed that a decision tree classifier can be used to classify vegetation time-series data into increasingly refined categories until specific crop types are isolated and classified. Beginning with a basic land cover classification (e.g. forest, urban, agriculture), crops in the agriculture class are broken down into winter and summer varieties using peaks in the vegetation index (winter wheat will peak earlier in the year than summer crops like corn and soy). Then, using training sites of known crop types defined by ground truth data, a final crop classification can be assigned by finding pixel values for key dates where like crops can be differentiated. That is, using the growing season 
in the Northern Hemisphere as an example, if from the training sites we know summer crop A has VI values between 0.7 and 0.8 on 26 June and between 0.5 and 0.6 on 29 August, while summer crop B is between 0.55 and 0.65 and 0.75 and 0.85 on the same dates, pixels in the summer crop class can be assigned one of these types by testing their pixel values on these dates. The authors found this method to have about an 85 percent overall accuracy (Wardlow and Egbert 2005). However, this method requires training sites with previously-determined crop types to produce a classification, which can be time consuming and expensive to acquire.

Masialeti, Egbert, and Wardlow (2010) found that VI values from one year have a significant correlation with values from other years. They compared the phenological curves of crops formed by the NDVI values from 2001 MODIS data (from Wardlow and Egbert 2005) with those from 2005 MODIS data. Generally, the shape of each crop's curve is maintained year-to-year, but three subtle transformations may occur depending on weather and other external variables: (1) a shift in the beginning of the curve (earlier or later planting), (2) a scaling of the maximum of the curve (better or worse crop development), and (3) a scaling of the spread of the curve (a longer or shorter growing season) (Figure 2.2). They surmised, with a means to account for the shift and scaling of the curve, one could use VI values from one year to classify those from another.

Even without a mechanism to account for interannual differences, Brown et al. (2007) used crop phenologies derived from multiple years of data to test four phenological classification methods. The authors fit the known phenologies to unknown phenologies from other years by comparing the VI values throughout the growing season. The degree of likeness 


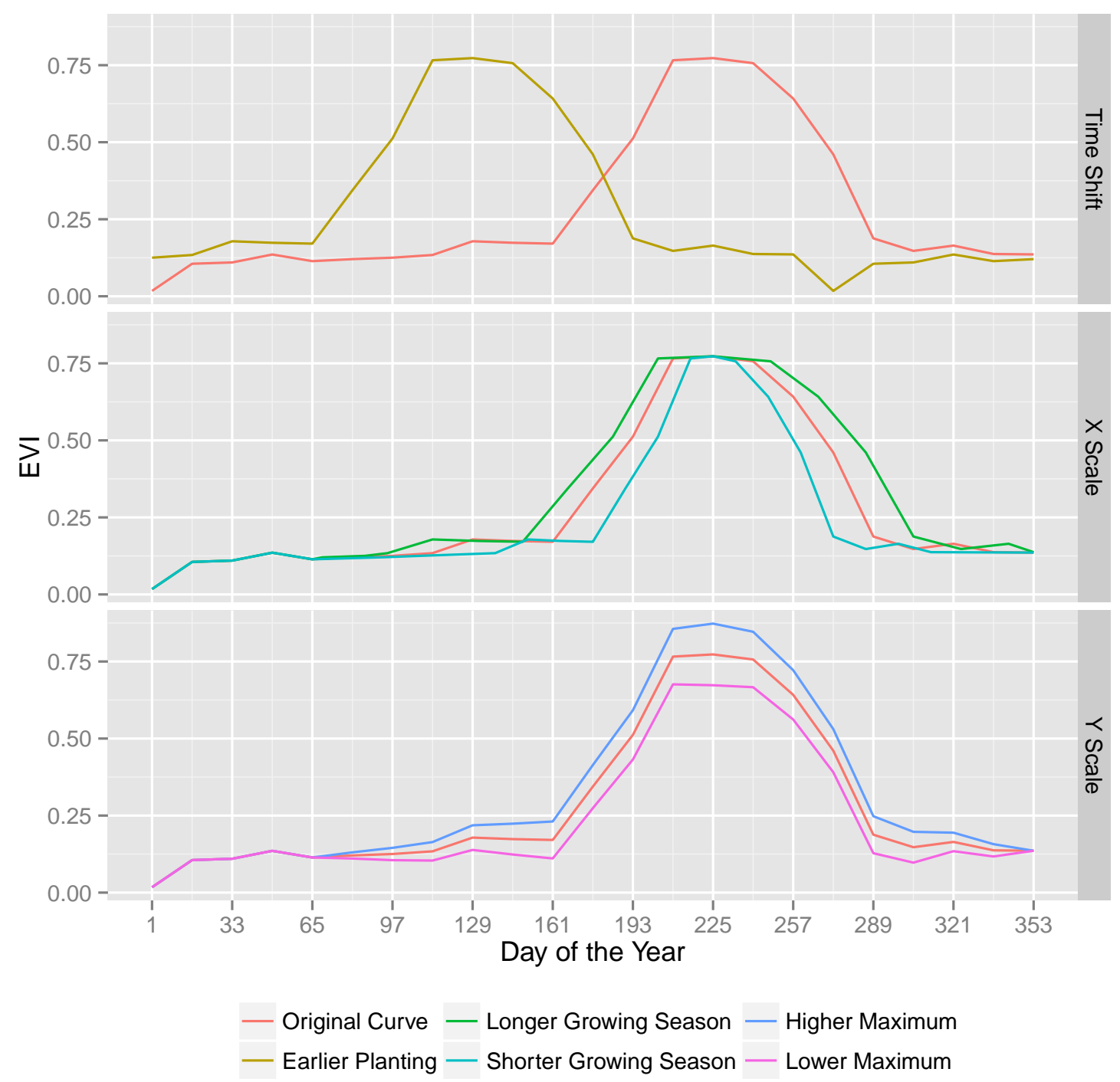

Figure 2.2. Example Transformations of a Crop's VI Curve

The original signature was derived from soy in southwestern Kansas. The other signatures were arbitrarily adjusted to illustrate each of the possible transformations (the diagrams were created for illustration purposes). 
between a known VI curve and the unknown VI curve determined the classification. They showed that the best of the four classification methods tested was to find the sum of the square errors between the known and unknown curves (the SSE method, Brown et al. pg. 131).

The similarities between the methods presented by Brown et al. and hyperspectral remote sensing techniques are striking. Hyperspectral techniques compare known spectral signatures from a signature library to the unknown pixel signatures in an image. One method, spectral feature fitting, uses a least-squares comparison reminiscent of SSE from Brown et al. (Exelis Visual Information Solutions 2013; Clark et al. 2003). The key difference between the two, besides comparing reflectance across time versus reflectance across the electromagnetic spectrum, is that spectral feature fitting does not require any training data from the processed image. All of the spectral signatures used for identification are from standardized spectral libraries, which contain the many spectra of different materials.

Accordingly, one goal of this study is to realize a method of vegetation classification for multi- or hyper-temporal imagery that does not require training data to be extracted from the imagery itself. The method would use standard libraries of phenological curves - temporal signatures - for different vegetation and non-vegetation land covers. A major challenge of this idea is that, unlike spectral signatures, temporal signatures are not necessarily consistent location to location nor year to year, as mentioned by Masialeti, Egbert, and Wardlow. Thus, a viable classification method must provide a way to transform the temporal signatures, within appropriate bounds, to match the horizontal scaling, vertical scaling, and time shifting of an unknown pixel before finding the degree of fit between the signature curve and the 
pixel curve.

Sakamoto et al. $(2005,2010)$ demonstrates a method using MODIS time-series data for use in finding key dates in a crop's phenology, enabling better crop management strategies. Specifically, the authors' two-step filter (TSF) method uses a wavelet transformation and a constrained minimization function to find a reference signature for a specific crop's phenological development, then fits that signature to known pixels of that crop type, finding the scaled dates of key transitions between developmental stages in the plants' growth. This TSF method demonstrates that reference signatures can be fit to a pixel's signature using a minimization function, accounting for the variations from the reference curve and the pixel curve. In other words, this minimization method provides the means to resolve scaling and time shift differences, allowing previously-known temporal signatures (e.g. not from training sites) to be fit to unknown pixel signatures in a TSI.

Specifically, from page 2151 of Sakamoto et al. (2010):

$$
R M S E=\left[\frac{1}{n} \sum_{x=j(1), j(2) \ldots}^{n}(f(x)-g(x))^{2}\right]^{\frac{1}{2}}
$$

where $n$ is the number of dates (bands) in the TSI, $f(x)$ is the temporal signature for a given pixel in a dataset, and $x$ is the DOY, as defined by $j(y)$ :

$$
\begin{aligned}
j(y) & =k(i \cdot s(y-1)) \\
\text { where } & k(z)= \begin{cases}z, & \text { if } z \leq 0 \\
z-((z \bmod 365) \bmod i-1), & \text { if } z>0\end{cases}
\end{aligned}
$$

such that $y$ is the band number in the TSI image, $s$ is the interval of the imagery and $d$ is the 
starting date of the imagery. $g(x)$ in Equation 2.3 is given by:

$$
g(x)=\text { yscale } \times h(x \text { scale } \times(x+\text { tshift }))
$$

Here, $x$ again is the DOY, yscale and xscale are coefficients controlling the vertical and horizontal scaling of a reference signature $h(x)$, and tshift is a constant representing the horizontal shift, in days, of $h(x)$. In other words, yscale adjusts the reference signature to match the growth condition (i.e. maximum VI value) of the pixel (again, given by $f(x)$ ); xscale adjusts the reference signature to match the pixel's growth cycle duration; and tshift, or time-shift, is the offset, in days, between the peak date of the reference signature and the peak date the pixel (see Figure 2.2). Thus, if we minimize Equation 2.3 bounding yscale, xscale, and tshift in $g(x)$ with reasonable values for each, we can calculate how well a given reference temporal signature $h(x)$ can be made to fit the pixel signature $f(x)$. Comparing a pixel's RMSE value from each of the reference signatures allows final classification; the signature with the lowest RMSE value has the best fit, and, of the tested signatures, provides the most probable identification. 


\section{Notes}

${ }^{1}$ For those interested in working with MODIS data, the web address of LPDAAC is https://lpdaac.usgs.gov/, though data are not directly available from their servers without an exact link. I found the best tool for searching the available data was NASA's Reverb|Echo web tool, at https://reverb.echo.nasa.gov/. Using this tool, one can get a list of links in a text file, and can use wget or curl to bulk download the files in the list.

${ }^{2}$ Though the literature typically denotes MODIS data as 250-meter, the composite vegetation indices are actually 231-meter. However, to stay consistent with conventions, I will refer to the data as 250-meter.

${ }^{3}$ Following this pattern exactly will make the first image from the following year be from 4 January, but the MODIS composite numbering "resets" at the end of each year. Thus the image interval at the end of the year is shortened, allowing the next image to be produced 1 January, though it still covers the proceeding 16 days. 


\section{Chapter 3}

\section{Study Areas}

This study used agricultural areas in Kansas, USA for testing and verification of the phenological classification method and applied the classification method to Pellegrini, Santiago del Estero, Argentina to test its effectiveness in subtropical South America.

\subsection{Kansas, USA}

The state of Kansas is one of the big agricultural producers of the U.S. As a plains state, it is relatively flat across much of its extent, making it well suited to large highly-mechanized agro-industrial operations. In 2012, the three most extensive crops in the state were wheat, corn, and soybeans (Table 3.1), which are also the most abundant crops in Pellegrini, Argentina. Additionally, Kansas has been the focus of a number of previous studies into the use of MODIS time-series for crop classification (Wardlow and Egbert 2002, 2005; Wardlow, Egbert, and Kastens 2007; Wardlow and Egbert 2008), and has a very detailed and easily-accessible crop cover dataset in the form of the USDA CDL. These factors make Kansas a natural choice for preliminary testing.

I delineated a small 100 MODIS pixel by 100 MODIS pixel study area just northwest of 
Table 3.1. Most extensive crops in Kansas, 2012 (adapted from U.S. Department of Agriculture 2013)

\begin{tabular}{lcc}
\hline Grop & Acreage (1,000 acres) & Production (1,000 units) \\
\hline Wheat & 9,100 & 382,200 \\
Corn & 3,950 & 379,200 \\
Soy & 3,810 & 83,820 \\
All Hay & 2,750 & 4,340 \\
All Forage & 2,750 & 4,545 \\
Sorghum & 2,100 & 81,900 \\
\hline
\end{tabular}

Wichita, Kansas. The communities of Valley Center, Sedgwick, and Halstead run linearly from the southeast corner to the northwest corner of the study site (Figure 3.1). I tested and verified the classification method in this area (see Appendix $\mathrm{G}$ on page 116 for a full overview of the Kansas testing), and I extracted the crop reference signatures used for the Argentina classification from this area. The typical planting dates for a variety of crops in this region are shown in Table 3.2. I chose this specific study site because of the mix of land covers in the 2012 CDL reference (Figure 3.2) included corn, soy, sorghum, winter wheat, winter wheat and soy double crop, urban development, grassland, forest, and others.

Table 3.2. Kansas Study Site Planting Dates (adapted from Shroyer et al. 1996)

\begin{tabular}{cc}
\hline Grop & Planting Date Range \\
\hline Wheat & 25 September to 20 October \\
Triticale & 1 September to 25 September \\
Winter Barley & 15 September to 10 October \\
Spring Barley & 25 February to 15 March \\
Spring Wheat & 25 February to 15 March \\
Spring Oats & 25 February to 15 March \\
Corn & 1 April to 10 May \\
Sorghum & 15 May to 20 June \\
Soybeans & 5 May to 10 June \\
\hline
\end{tabular}




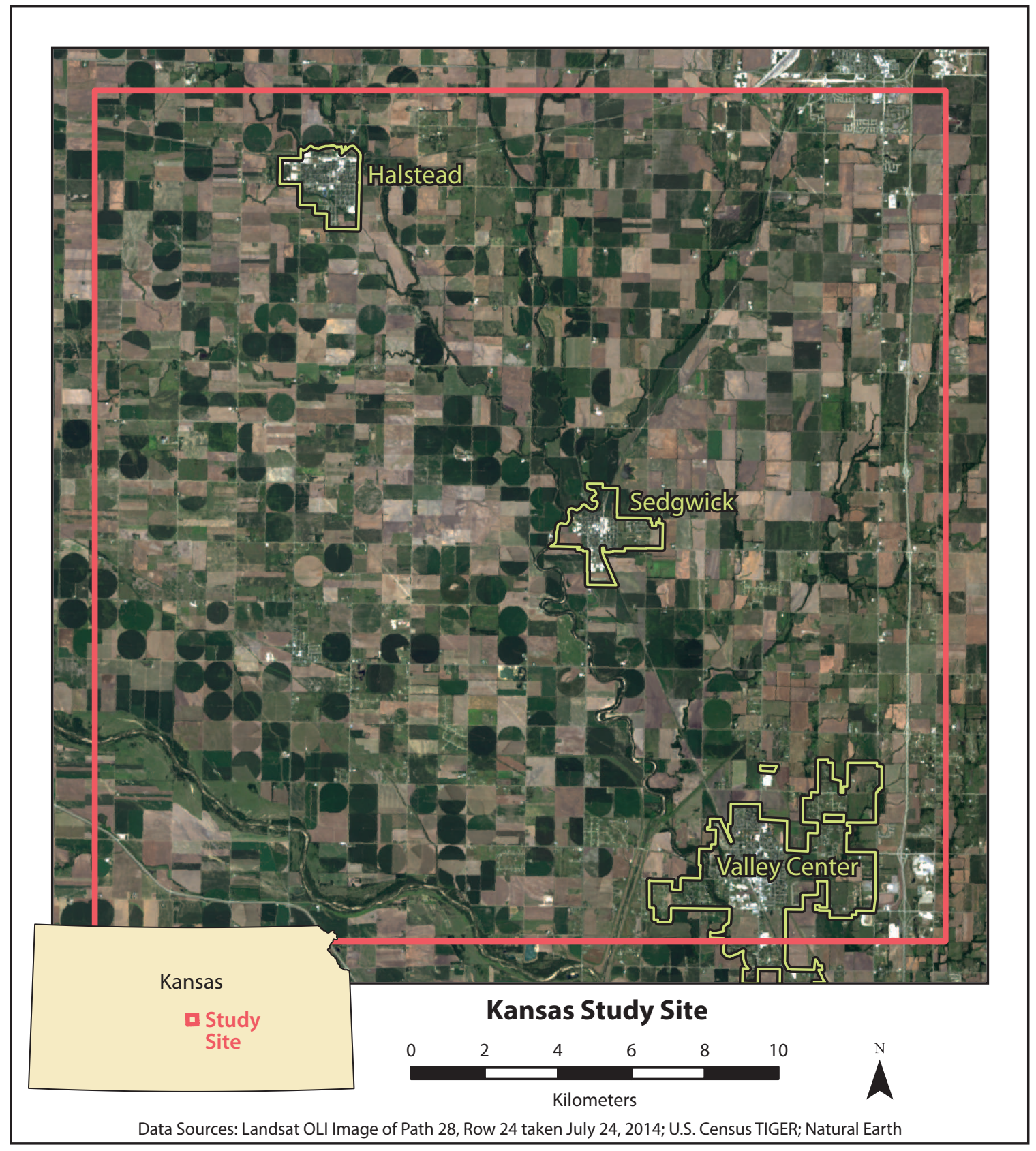

Figure 3.1. Kansas Study Site and the Communities of Halstead, Sedgwick, and Valley Center. 


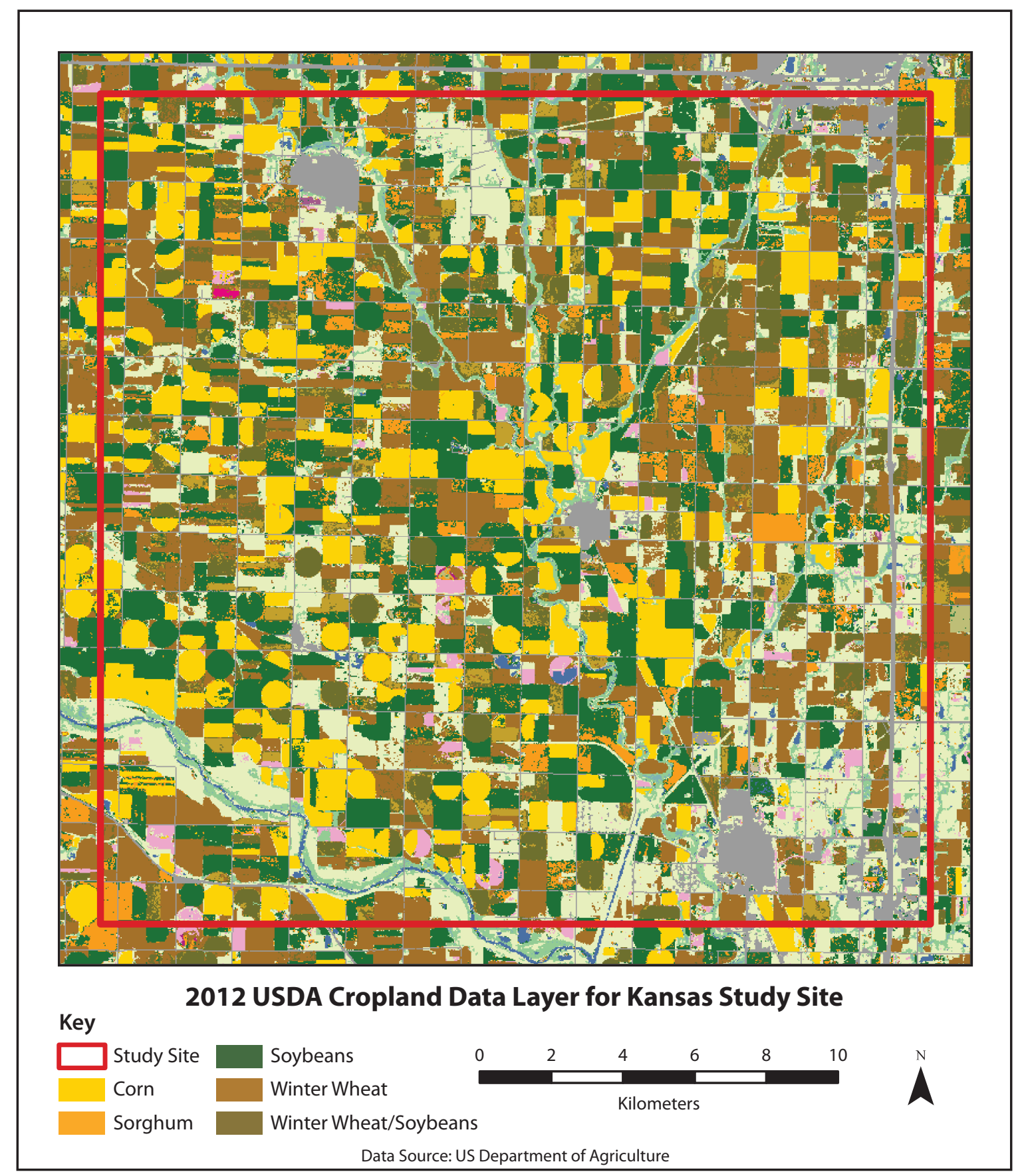

Figure 3.2. 2012 Kansas Study Site Crop Cover

Corn, soy, and winter wheat are the predominate crops in this area of Kansas, in line with the top three crops of the state as a whole. The sorghum sample size is comparatively small, but I found few areas with higher concentrations of sorghum. 


\subsection{Pellegrini, Santiago del Estero, Argentina}

Santiago del Estero, a province in Northwest Argentina, has an area of 136,351 square kilometers, which is about the same size as the state of Arkansas. The population was about 874,000 in 2010 (INDEC 2010b). The entire province is classified within the Parque Chaqueño (Chaco forest). Like the rest of Argentina forests, the remaining forested area has declined rapidly over the past fifteen years. During the period 1998 to 2002, 306,055 hectares were deforested (Secretaría de Ambiente y Desarrollo Sustentable [Argentina] 2007). From 2006 through 2011, a further 701,030 hectares of forest were lost, 283,669 of which were after the enacting of the OTBN in March of 2009 (Secretería de Ambiente y Desarrollo Sustentable [Argentina] 2012). Over both of these time periods, Santiago del Estero experienced the highest levels of deforestation in all of Argentina.

The Department of Pellegrini is an administrative area in the Northwest corner of the province of Santiago del Estero (Figure 3.3). ${ }^{1}$ The department has an area of 6,944 square kilometers, a size slightly larger than the state of Delaware. However, the 2010 population was only 20,514 (INDEC 2010a). The primary municipality of the department is Nueva Esperanza, with about 4,500 residents. Figure 3.4 shows Nueva Esperanza's location and the progression of deforestation in the department. Sometime between 1975 and 1993, an initial push for agricultural land began deforestation in the region. The frontier nature of Pellegrini seemed to limit further deforestation for some time. As can be seen from the satellite imagery, little changed between 1993 and 2001. And over the years 2001 to 2005, only 5,968 hectares were found to be deforested (Volante et al. 2005). However, recent 
demand for land has amplified the rate of clearing. Over the period 2006 to 2011, over 75,000 hectares were cleared, a deforestation rate much higher than previously witnessed (Secretería de Ambiente y Desarrollo Sustentable [Argentina] 2012). Some 39,480 of these hectares were cut after the enacting of the OTBN in 2009, when regulations should have slowed deforestation. Of the area cleared post-OTBN, 2,181 hectares were in red areas, the highest clearing of that designation in the nation. The vast majority of clearing was in yellow areas, totaling 29,796 hectares. Pellegrini's total deforestation during the period 2006 to 2011 was not the highest in Santiago del Estero, as both Moreno Department and Alberdi Department had higher total deforestation. However, as a percent of total land area, Pellegrini's deforestation occurred at a greater rate: 10.85 percent of Pellegrini's land area was cleared versus 10.45 percent and 7.91 percent of Moreno and Alberdi, respectively.

Volante et al. (2005) found Pellegrini's primary summer crop over the years 2000 to 2005 to be soy, averaging about 40,000 hectares cultivated per year. Corn was the second most frequent crop, occupying about 7,500 hectares per year. Poroto, a generic term for many types of common beans, was the third most popular, averaging a total cultivation of about 2,500 hectares per year. The primary winter crop was wheat, though cultivation varied wildly from less than 10,000 hectares in 2002 to over 31,000 hectares in 2004.

Specific planting dates for Pellegrini are not available, but crop calendars for Argentina as a whole do provide generalized information (U.S. Foreign Agricultural Service Office of Global Analysis 2008; Sacks et al. 2010; Soybean And Corn Advisor 2013). Corn is typically planted mid-September through the end of November, and sorghum follows about twenty days later. Soybeans are planted in two groups: early and late. Early soy is often 


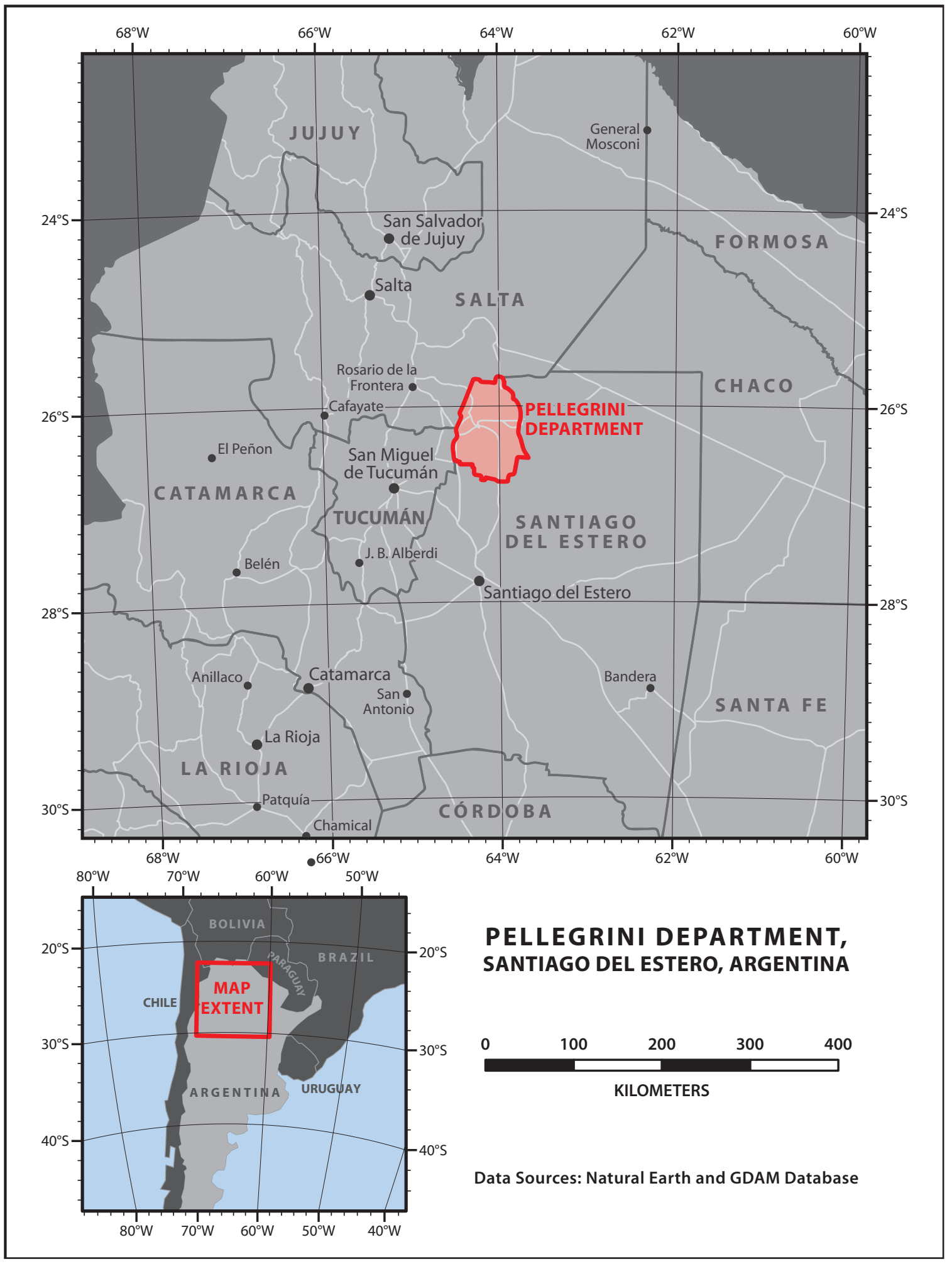

Figure 3.3. The Department of Pellegrini and the Greater Northwest of Argentina 


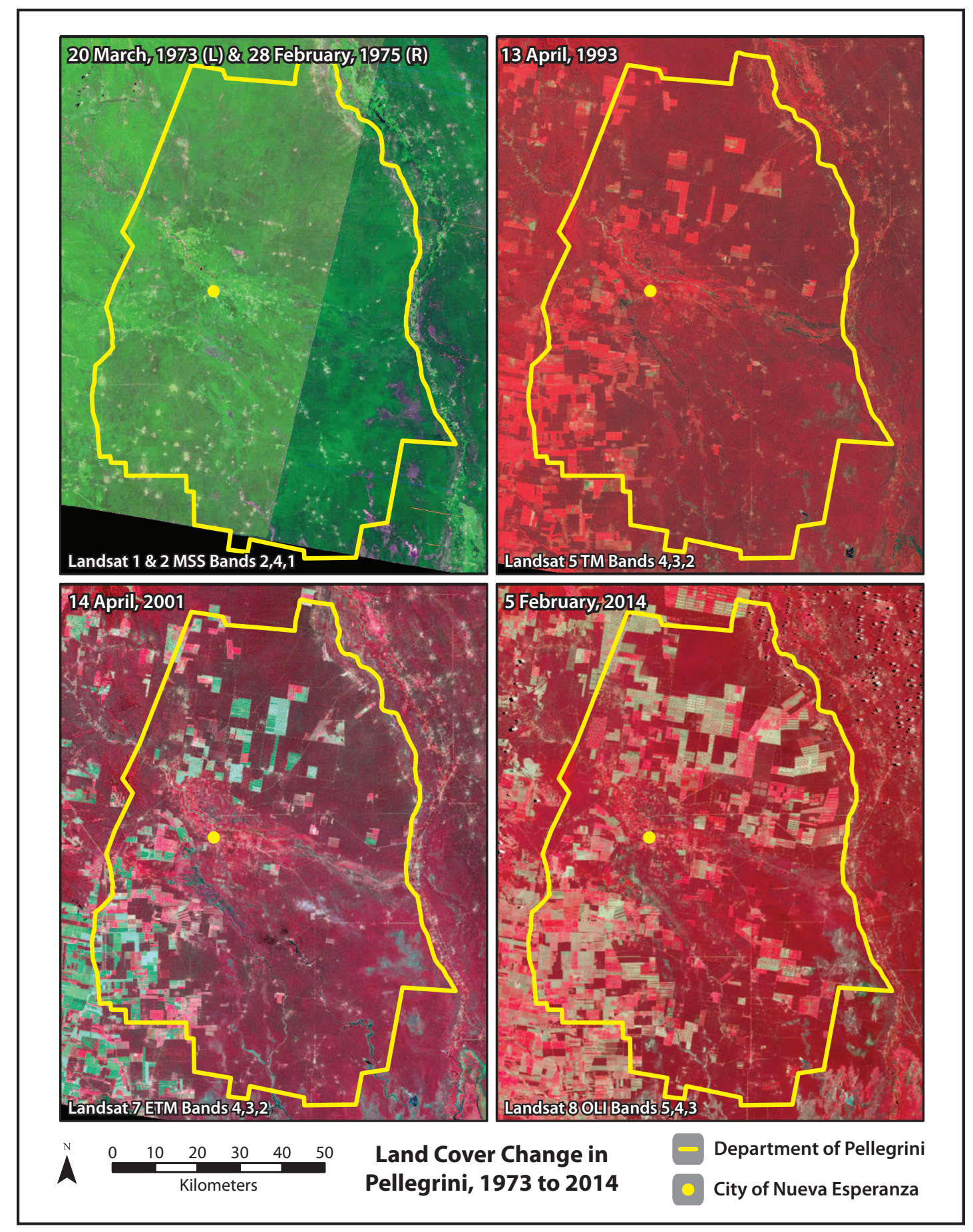

Figure 3.4. Land Cover Change in Pellegrini from 1973 to 2014

These images show the progression of deforestation in Pellegrini. The lack of deforestation in the 1973-1975 composite is striking. As early as 1993, deforestation is visible, primarily in the Southwest near Tucumán Province. Little changed between 1993 and 2001, but by 2014 much more deforestation is visible throughout the entire area. 
planted mid-November through the end of December, while late soy follows the harvesting of winter wheat, typically between the beginning of December through the middle of January. Compared to Table 3.2, these dates are approximately six months offset, congruent with Argentina's opposing location in the Southern Hemisphere. However, the Argentina planting date ranges are noticeably longer than those in Kansas. 


\section{Notes}

${ }^{1}$ The Pellegrini boundary shapefile I obtained does not accurately reflect the bounds of the department on the ground. Particularly along the lengthy and straight northwestern edge, careful inspection reveals a lack of registration between the vector geometry and the obvious boundary visible in the background image. When investigating some of my sample points along the northern and southern edges, I got strange looks and comments about how this or that field was not within Pellegrini, my supposed study area. I want to acknowledge that I realize my study area is not actually the Department of Pellegrini proper, but an inaccurate representation as defined by a shapefile from the Internet. I use this inaccurate representation to ensure consistency, to allow repeatability, and to simplify spatial analysis. 


\section{Chapter 4}

\section{Data and Methods}

\subsection{Overview}

This study has two purposes: (1) develop a set of tools to allow the classification of agricultural crops using a time series of imagery and known crop reference signatures, and (2) test the portability of said reference signatures. The known crop reference signatures were extracted from the Kansas study site, and their portability was tested by using them to classify the Argentina study site. The data used for this study consist of the following:

- 250-meter MODIS 16-day Composite Vegetation Index images

- 30-meter 2012 USDA Cropland Data Layer: agricultural land cover raster dataset

- 30-meter Landsat 8 Operational Land Imager satellite imagery

- Shapefile of the administrative boundary of the Department of Pellegrini

The MODIS VI composites were used as the source imagery for extracting phenological signatures and classifying the crop types. The CDL served as a ground truth for the Kansas study area. This dataset allowed identification of crop clusters when extracting signatures, and validation of the classification method. Landsat 8 OLI images of Pellegrini (path 230, row 78) from multiple dates were used during field data collection and subsequent digitizing. 
All three of these data are publicly available from U.S. agencies. The Pellegrini boundary, used to define the Argentina study area, is from the GDAM Global Administrative Areas Dataset, version 1.0 (available at http://www.gdam.org).

Additionally, for the Pellegrini classification, I used a 2014 Pellegrini Land Cover vector dataset with crop identifications. I produced this dataset as a result of my fieldwork. As mentioned above, the data were digitized from Landsat 8 images, and land cover identifications were collected in the field.

An outline of the processing workflow is below:

1. Reproject the MODIS composite imagery.

2. Assemble individual composite images into time series images: one for Kansas and one for Argentina.

3. Identify all the "pure" pixels - those containing a single land cover type (e.g. nonmixels) - in the Kansas TSI by overlaying the CDL with the MODIS pixel grid.

4. Use the GDL to isolate the pure corn, soy, and sorghum pixels in the Kansas TSI.

5. Identify the unique phenological groups in each set of isolated Kansas TSI pixels using k-means clustering.

6. Extract the pixel values for each unique phenological group from the Kansas TSI and find the mean value for each date to form the unique signatures for each crop.

7. Fit the Kansas signatures to the Kansas TSI using the TSF method from section 2.4.

8. Classify the Kansas RMSE rasters and assess the classification accuracy.

9. Fit the Kansas signatures to the Argentina TSI.

10. Classify the Argentina RMSE rasters and assess the accuracy.

This chapter is a look at the methods and fieldwork used to create the validation land cover dataset of Pellegrini, and the data processing steps used to generate the study results. 
Details about the specific tools in the classification toolset and the development process can be found in Appendix B. For a detailed explanation of all the testing proceeding this study, please see Appendix C. A thorough recounting of my field experience can be found in Appendix A.

\subsection{Field Methods and Data Collection in Pellegrini}

While ground truth data were easily obtained for the Kansas study site, getting a ground truth dataset for verification of the classification in Pellegrini was not so simple. Such a dataset did not exist, necessitating onsite data collection. I visited Argentina during the summer 2014 growing season to gather field observations of summer crop types and to talk to local farmers about typical agricultural practices, summer and winter crop varieties, and planting and harvesting dates.

To guide my ground truth collection, I generated 400 random sample points inside the Pellegrini shapefile boundary, and used a Landsat OLI image as a reference for land cover (image date 5 February 2014). Where a point fell within a MODIS mixel, I allowed it to be moved within a 3-by-3 pixel window centered on the point's original pixel. As much as possible, I aimed to keep the point within a pixel belonging to the feature type on which it originally fell. In certain limited cases, if a point fell quite obviously within a field but the center pixel and eight surrounding pixels were mixels and/or were not within the field, I allowed the point to be moved to the closest pure pixel in the same field. Of the 400 sample points, I had to move 106 within the 3-by-3 window, and ten to a non-neighboring pixel within the same field. 
From these adjusted points, I was able to establish 247 were forested using Landsat imagery. I did not need to visit these. For each of the remaining 153, I created map sheetsone for every point, centered on the point - showing the point on satellite imagery at three different scales: (1) an overview at 1:60,000 scale with the 5 February 2014 Landsat OLI image; (2) a closer view at 1:30,000 scale, with the Landsat OLI image and an overlay of the MODIS pixel grid; and (3) a large scale 1:4,500 view with older but higher spatial resolution imagery from Digital Globe. I also made eighteen smaller-scale "regional" maps at 1:150,000 scale from a 25-kilometer grid overlaid on Pellegrini, which I used to identify neighboring points and plan routes. Lastly, I made an overview map of the entire department at 1:475,000 scale. I printed all of these maps and put them in a binder, so I could take notes and record the crop types in the field. I also planned to collect data about fields without sample points; I wanted to record every field I came across to ensure the comprehensiveness of my ground truth dataset.

The primary means of gathering the crop identities for the ground truth was direct observation. When direct observation was not possible, I interviewed local farmers and land owners. In such cases, the interviewees were asked to identify their fields on the printed maps and describe their cultivars. Finally, if no knowledgable local could be found, visual interpretation of the Landsat imagery was attempted using the appearance of already-identified fields as reference. If an identification was uncertain, the point was removed from the sample set. All the collected data were recorded directly on the sample point maps and later manually digitized into a geographic information system (GIS).

Ancillary information about agricultural practices in the region was also collected when- 
ever possible. It was a key goal to identify each crop's date range for planting and harvesting in order to allow: (1) the proper selection of MODIS imagery dates, and, (2) appropriately setting the tshift bounds for Equation 2.5, enabling the temporal alignment of the Kansas reference signatures with the date range of the Pellegrini growing season.

\subsection{Data Processing}

\subsubsection{Resampling the CDL}

To use the CDL as a ground truth with the Kansas TSI, the 30-meter CDL pixels were resampled by majority to match the larger TSI pixels. This allowed a direct comparison between the crop values from the GDL and the pixel signatures in the TSI.

\subsubsection{Building the TSIs}

For this study, I chose to classify the 2012 Kansas summer growing season and the $2014^{1}$ Argentina summer growing season. I classified only summer crops instead of a full agricultural year because I lacked ground truth data for winter crops in Pellegrini. Both NDVI and EVI preprocessed data are available as MODIS products, but I did not test the latter. This decision was based on preliminary test results: NDVI outperformed EVI in this type of classification. For more information on this testing see section C.1 on page 117 .

I assembled the MODIS 16-day composite NDVI images into multi-date time-series images (TSI) covering the growth cycle of the summer crops. Each band in the TSIs is a 16-day composite NDVI image and the bands are ordered consecutively (see section B.2 on 
page 107 for the description of the Build Multidate Image Tool). The Kansas summer TSI covered the date range DOY 97 through DOY 273, and was made with data from the Terra satellite (LPDAAC product MOD13Q1, tile h10v05). Prior to creating the TSIs, each of the 16-day composites was reprojected from the native MODIS sinusoidal reference system using LPDAAC's MODIS Reprojection Tool (LDPAAG 2011). I reprojected the Kansas data into the Albers Equal Area Conic projection for the contiguous U.S. using the 1983 North American Datum (WKID: 5070) to match the reference system of the USDA CDL.

In Argentina, as it is in the Southern Hemisphere and the seasons are inverted to those of the Northern hemisphere, the growing season shifts, as must the date range for the VI time-series. The TSI for Pellegrini must begin at the end of the proceeding year to adequately capture the entirety of the summer phenologies. To accomplish this, the time-series image for summer 2014 began with the 16-day composite image from DOY 353 of 2013 (or DOY - 13 with reference to 2014) and ended with the image from DOY 161 of 2014 (MODIS grid tile h12v11). This specific date range was chosen based on information provided by local farmers to ensure coverage of the earliest planting and latest harvesting dates, as well as manual inspection of crop pixel signatures throughout the study area. Persistent clouds necessitated using an image from the Aqua satellite of DOY 105 (LPDAAC product MYD13Q1) in place of DOY 113 from Terra. Due to no viable imagery from Aqua or Terra, DOY 129 was interpolated via the arithmetic mean calculated from the DOY 105 Aqua image and the DOY 145 Terra image. The Argentina composite images were reprojected to the UTM Zone 20S reference system (WKID: 32720). 


\subsubsection{Eliminating Mixels}

After building the TSIs, the next processing step was to eliminate mixels from the Kansas TSI. Mixels, or pixels that contain more than one land cover type within the 250-by-250meter cell area, have mixed temporal signatures. Earlier testing showed that mixels can not be clearly classified (see section C.2 on page 124 for more information). To prevent errors, mixels had to be removed from the Kansas analysis. Pure pixels, the non-mixels in an image, were isolated using ArcGIS (ESRI 2012) by intersecting a vectorized version of the original 30-meter CDL ground truth with a vector grid of the TSI pixels. From the resulting geometry, all polygons with an area greater than 53,000 square meters (or 98 percent of a MODIS pixel) were selected as pure. I also manually selected two sorghum pixel features that were omitted due to intermixed soy pixels. I chose to add these pixels due to the low number of sorghum features retained, and because the CDL's intermixed soy pixels appeared to be errors.

All of the other polygon features were discarded. The remaining polygon features were converted to point features based on their centroids. These points were used to find the TSI pixel coordinates of the pure pixels in the subsequent processing steps, including extracting the reference signatures.

\subsubsection{Extracting the Reference Temporal Signatures}

As a reference library of temporal signatures does not yet exist, I had to extract my own signatures from the Kansas TSI. To do so, the pure TSI pixels of each key summer 
crop (corn, soy, and sorghum) as specified in the resampled CDL were isolated in separate rasters. Initial classification attempts revealed high variability in the crop temporal signatures. I obtained the best classification results when using more than one signature per crop. Given the existing literature about phenological classification, I do not actually believe crops have multiple signatures. I believe every crop as a theoretical ideal signature, which can be made to fit any actual signature using the xscale, yscale, and tshift transformations in Equation 2.5, barring any unusual effects of weather or other forces impacting crop development (a mid-season drought, for example, may cause a crop signature with double peaks due to the partial dying off and regeneration of the plants). However, given the CDL as my only source of ground truth, I had to assume it was accurate, despite any evidence to the contrary. Therefore, I strived to create a classification with the highest accuracy compared to the GDL.

To extract multiple signatures for each crop, the separated rasters were each clustered into three clusters using the ENVI (Exelis Visual Information Solutions 2014a) k-means tool. $\mathrm{K}$-means is an iterative unsupervised classification technique where data are clustered using the minimum distance to the nearest cluster centroid (Exelis Visual Information Solutions 2014b; Matteucci, n.d.). The centroids begin equally distributed throughout the data, but are recalculated on each iteration based on the shapes of the clusters in the previous iteration. The algorithm stops after the maximum number of iterations have been run, or when the cluster pixel counts change less than a given percent threshold. I chose to use a 1.0 percent change threshold over 100 maximum iterations. The TSI pixels in each cluster were then sampled and averaged. That is, the values from every pixel in a cluster on a given date were 


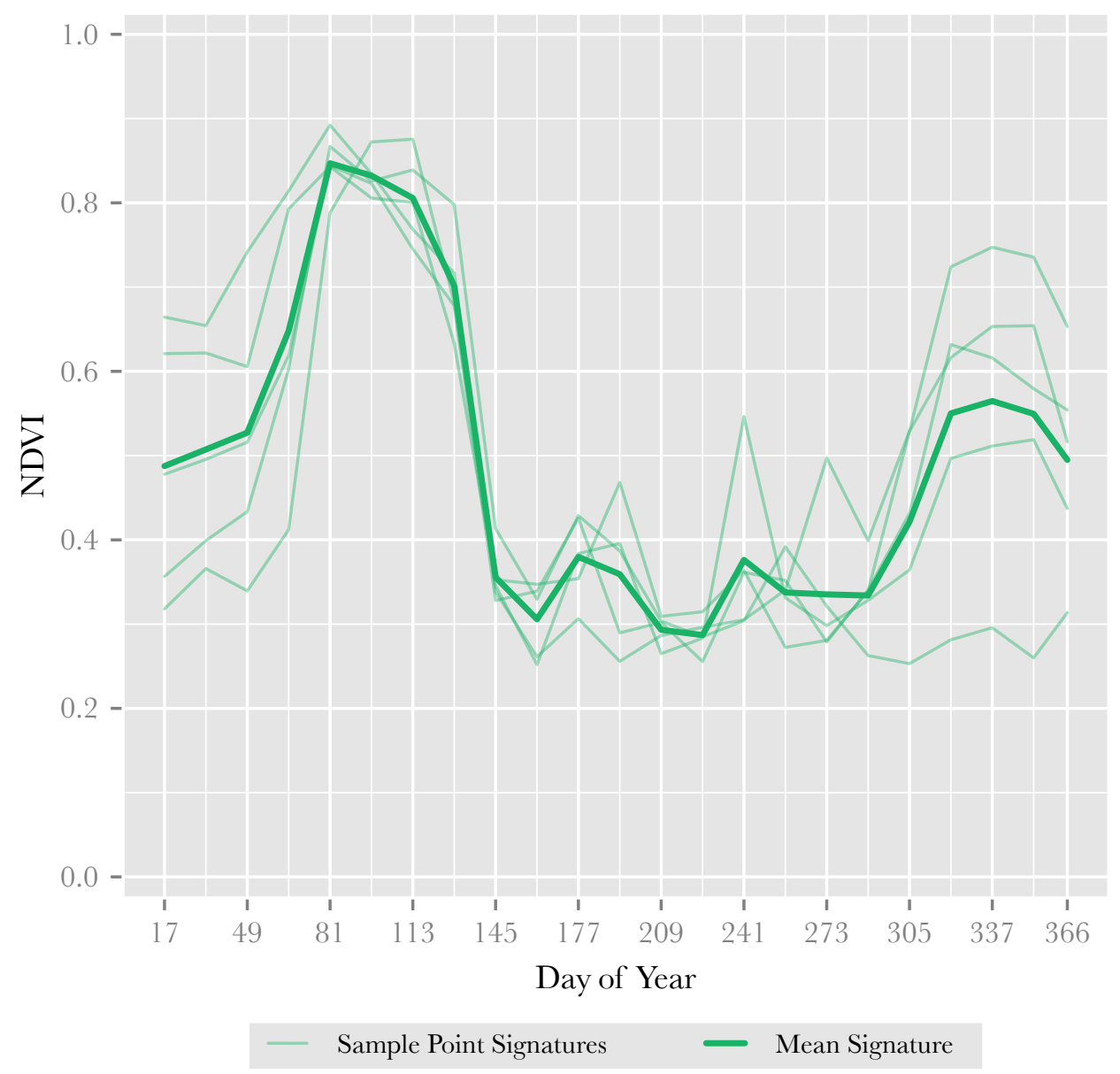

Figure 4.1. Five Winter Wheat Pixel Signatures and Their Mean Reference Signature

This example shows the averaging process used to derive reference temporal signatures from sampled pixels. At each date (band) in the TSI, the pixel values are extracted and averaged via their mean. The bold line shows the resulting signature created from the averages.

averaged together, providing the reference signature value for that date. This averaging is repeated for all dates in the TSI, and the result is the complete reference temporal signature representing that cluster (an illustration of an average signature from pixel signatures is shown in Figure 4.1). Completion of this process for all crop clusters creates the three primary signatures for each crop (see section B.3 on page 108 for information about the Extract Signatures Tool). 


\subsubsection{Fitting the Reference Signatures to the TSIs and Creating the RMSE Rasters}

To find the degree of fit between reference signatures and unknown pixels, I used the TSF comparison method without the wavelet filtering step. I implemented a tool based on Equation 2.3 (page 15) using the programming language Python (Python Software Foundation 2014). Details of the tool and its development can be found in section B.4 on page 109 . The tool iterates through each pixel in a TSI, comparing each reference signature with the pixel's values (i.e. MODIS NDVI values) and calculating the RMSE between the signature and the pixel's values. An output RMSE raster is created for each crop signature to record the RMSE values for each pixel. I omitted the wavelet filtering step because Sakamoto et al. used higher temporal resolution data than I had, and I did not think filtering would be as necessary or as effective with the 16-day interval of the MODIS VI composites I used.

The reference signatures extracted from the Kansas TSI clusters were fit to the Kansas TSI and the output RMSE rasters were classified and verified. Then, the same Kansas signatures were fit to the Pellegrini TSI within the study area. The output RMSE rasters from each crop type were then classified. For both Kansas and Pellegrini, the bounds for the xscale and yscale parameters, which account for differences in growing season length and plant health, respectively, were 0.6 to 1.4 . The tshift parameter, which temporally aligns the reference signature to a pixel's values, was bounded to -10 to +10 days for the Kansas fit processing. The tshift bounds for the Pellegrini fit processing were 120 to 140 days (still \pm 10 days, but shifted 130 days). These bounding ranges were chosen as the result of nonextensive testing. Given the different lengths of planting date ranges between the Kansas 
and Pellegrini sites, the tshift bounds likely need to be adjusted accordingly. I am certain this is one aspect of the method that requires further testing and optimization, and could have a large effect on classification results.

\subsubsection{Classifying the RMSE Rasters}

RMSE rasters quantify the likelihood of a pixel being the crop types represented by the associated reference signatures. To create a classification from these likelihoods, one must first find the useable RMSE values: even pixels that are obviously different than a reference signature will result in measurable RMSE values, they will simply be high RMSE values. Thus, the RMSE rasters need to be thresholded to eliminate such high RMSEs.

One can think of the threshold in a similar manner to weighting: a higher RMSE threshold will allow more pixels from that RMSE raster to be considered in the final classification. The correct threshold for a RMSE raster will vary depending on a variety of factors, including what types of crops are in the sample area, what crops are trying to be identified, and how homogeneous the pixels for that crop are in comparison to the reference signature used. The extent to which these and other factors influence the optimal threshold is not well understood and requires further study. Despite not knowing the exact effects of these factors on the optimal threshold value, it is clear that the optimal value will vary between RMSE rasters. That is, a single threshold value used across all RMSE rasters in a classification is unlikely to provide the highest possible accuracy.

Once the RMSE rasters are thresholded, one can make a classification by finding the best fit for every pixel. For example, if a given pixel had thresholded RMSE values for corn, 
soy, and wheat of 356.7, 531.5, and none (as the original RMSE was above the threshold used), respectively, the best fitting signature would be corn, and the pixel could be classified as corn. If a pixel did not have any RMSE values under the threshold used, then that pixel would not be classified (a classification as "other" would be equally correct).

As mentioned, how to calculate optimal RMSE threshold values is unknown. Therefore, to find the best threshold combination, I developed a tool to brute-force through many combinations of RMSE thresholds within a user-specified range, classifying the RMSE rasters and calculating the accuracy of each threshold combination. A raster of the classification with the best accuracy is retained. More details about the tool itself can be found in section B.5 on page 113. Unfortunately, this tool does require a ground truth dataset for the accuracy assessment. I am currently unable to create an optimized classification using this method without such a resource. An unoptimized classification can still be created manually without a ground truth.

For the Kansas classification, it was easy to iterate through different RMSE threshold ranges to find the highest accuracy classification. However, generating the Argentina classification was not as straightforward. As the tool must brute-force through every RMSE threshold combination, the time required to find the best threshold in a range is exponential, given by $s^{n} \cdot t$ where $s$ is the number of threshold steps, $n$ is the number of RMSE rasters, and $t$ the time of each iteration, in seconds. The Kansas classification took under 0.3 seconds per iteration; classifying the larger area of Pellegrini took substantially more time, somewhere between three and four seconds per iteration. The increased processing time ruled out using more than two or three threshold steps. Consequently, in the case of 
the Argentina classification, it was much more efficient to iterate through a range of RMSE threshold values using a single threshold value across all the RMSE rasters, then manually refine each raster's threshold value until the optimum combination was identified. That is, I found the threshold value that, when used on all the RMSE rasters, had the highest classification accuracy. Then, I manually increased or decreased the threshold value of each RMSE raster individually, until I could no longer improve the classification accuracy. 


\section{Notes}

${ }^{1}$ To clarify, I have chosen to refer to the summer growing season by the harvesting year, given that the Argentine summer technically ranges from 21 December to 20 March. This is the same date range as the Northern Hemisphere's winter season, which is typically referred to by the year in which it ends, i.e., winter 2014. I find other references to the growing seasons in Argentina to be somewhat confusing. Often, a year range is used, such as 20132014, to denote that the growing season actually begins in 2013. Sometimes, as planting dates in Argentina as a whole are primarily September through December, the proceeding year is used to refer to the entire growing season, which I find especially misleading. 


\section{Chapter 5}

\section{Results}

\subsection{Ground Truth and Agricultural Practices in Pellegrini}

I travelled to Pellegrini 12 March through 3 April 2014 during the summer growing season to collect crop data. Using field observation, interviews, and satellite image interpretation, I gathered identifications for 378 of 400 sample points randomly distributed throughout the department, as well as many additional fields I also came across. Areas of homogenous land cover were digitized from Landsat imagery, and the collected data were used to assign the land cover classifications of the the digitized polygons, where applicable (Figure 5.1).

Of my 400 sample points, I was able to visually classify 247 of the points as forested from Landsat OLI imagery before leaving for Argentina. Of the remaining 153, I identified 106 as actively-cultivated agriculture: thirty six points as corn, twenty four points as soy, two points as sorghum, seven points as poroto, and thirty seven points as pasture. Twenty two points were identified as "other," representing all non-forest, non-agricultural, and/or mixed-use land cover classes. Another three points, based on the literal descriptions communicated to 


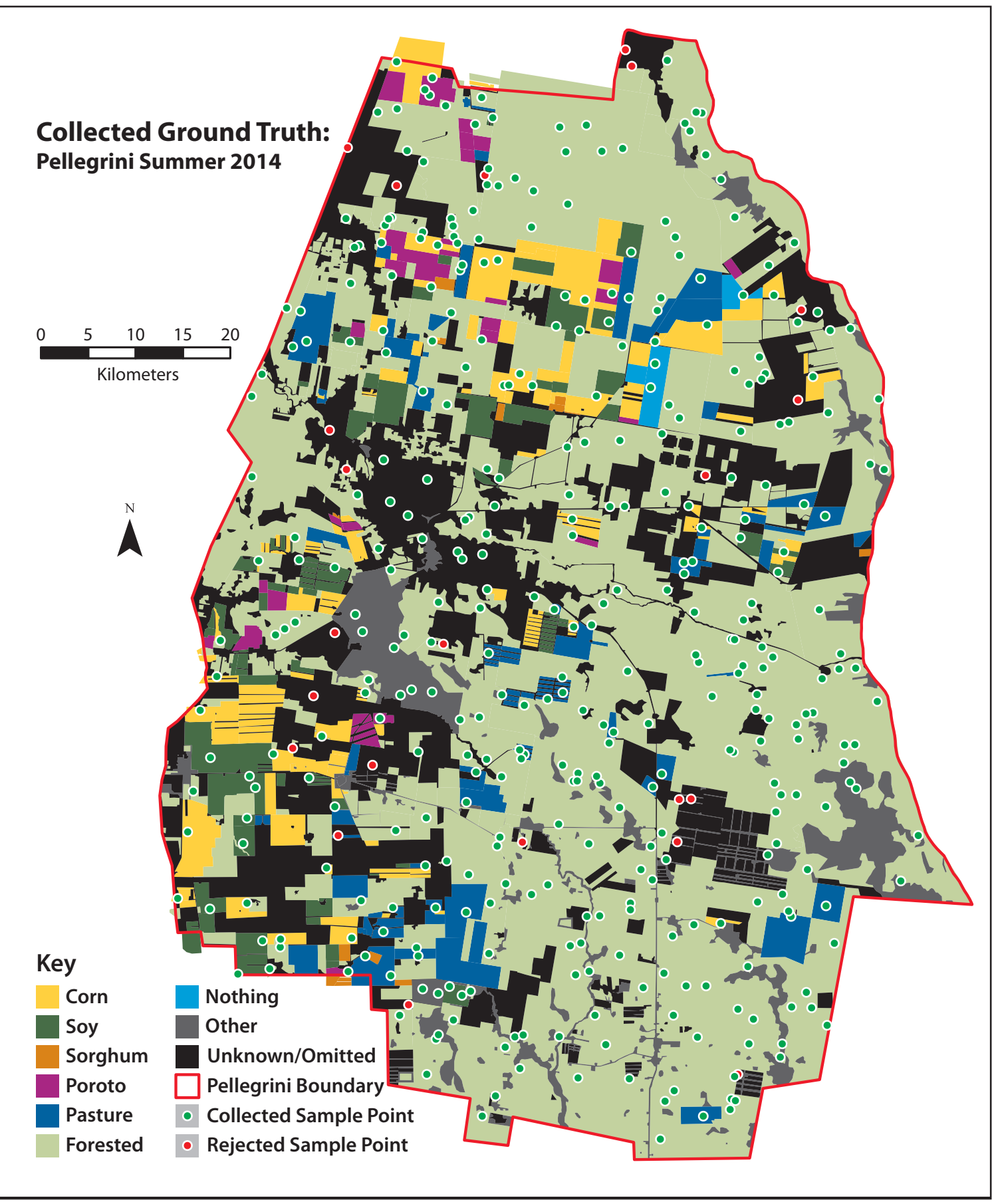

Figure 5.1. Pellegrini Summer 2014 Collected and Digitized Ground Truth Dataset 
me by land managers, were identified as "nothing." I am unsure if these fields were simply left fallow or are something else, but they were not under active cultivation at the time. Twenty two points could not be verified due to inaccessibility, uncertainty, or falling on a mixed-use area, and were removed from the final set of sample points used for the accuracy assessment.

I tried to get direct observations of all crop sample points to accurately record the crop types. However, this strategy proved to be difficult in many cases; I was able to visit only forty seven of the crop points. Often, fields were inaccessible due to road conditions or locked gates. Forty five crop observations came from interviews with farmers and land owners. In a few cases, I met agricultural engineers who showed me maps of the fields they managed (see Figure 5.2). The fourteen remaining crop point identifications were interpreted from Landsat imagery.

The total area of each land cover class is shown in Table 5.1. Compared to the 2000 through 2005 crop areas from Volante et al. (2005), corn seems to have expanded significantly in the area, while soy has retreated, despite the impression of the contrary in the country as a whole. I gathered from talks with farmers that the decline of soy in Pellegrini may be the result of increased expenses due to pests, fungus, poor soil, and transportation. Sorghum, a hectare count of which Volante et al. omitted for Pellegrini, did not occupy much land relative to the other crops. Across Argentina as a whole, sorghum experienced a significant decline in production from 1970 to 2003 (Paruelo, Guerschman, and Verón 2005). However, the 1,646 hectares I observed may indicate a reversal of sorghum's popularity. As cattle producers continue to expand feedlot operations in the country, sorghum 


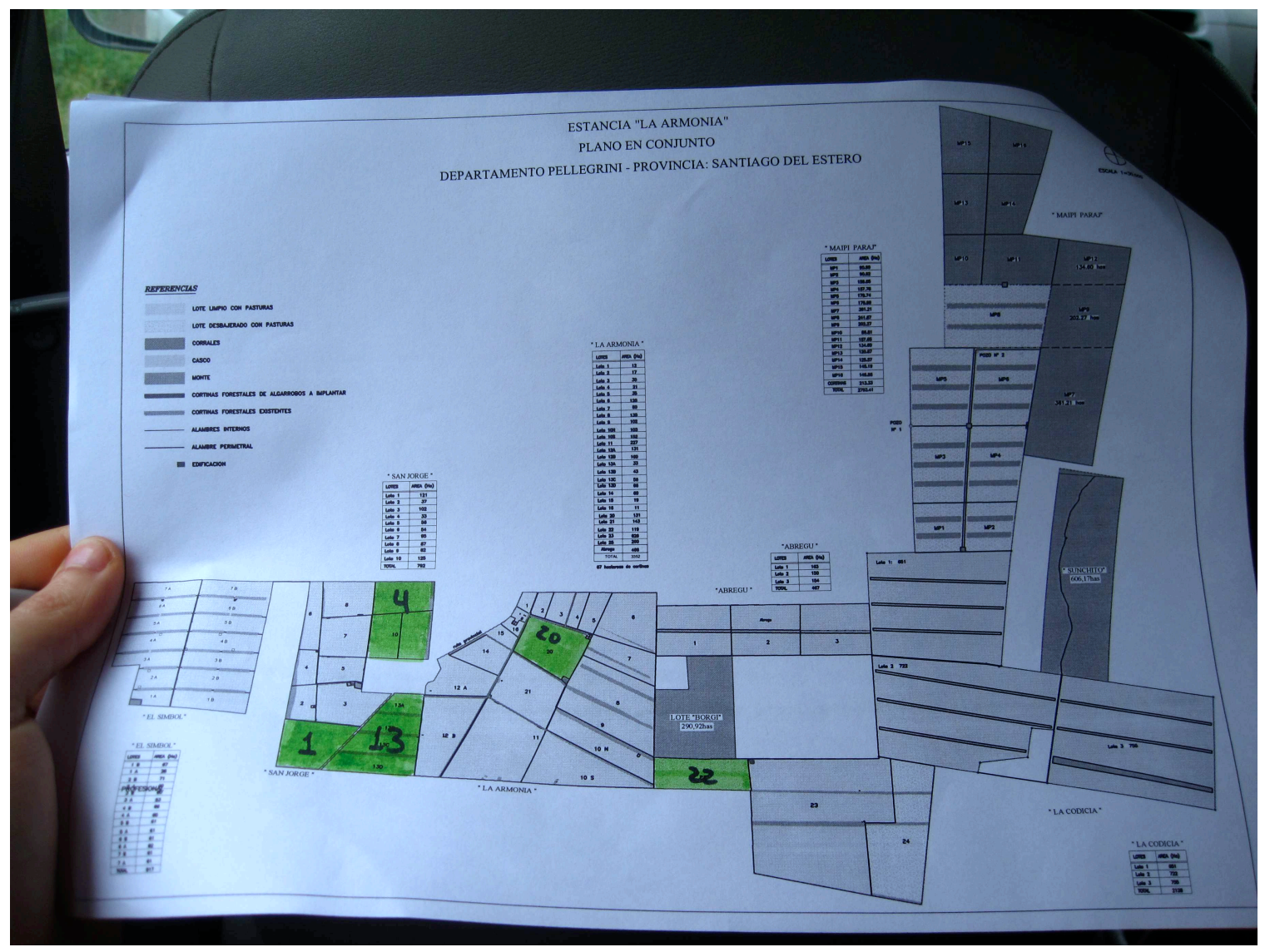

Figure 5.2. Map of Estancia La Armonia, a Large Farm

This map is exemplary of those used by the larger farming operations to plan land use. This farm, Estancia La Armonia, primarily raises cattle, so most all of the fields shown are pasture areas. The fields shown highlighted in green are sorghum, which I was told is used as part of the feed mixture in a small cattle feedlot operation.

will likely experience increased demand as cattle feed, suggesting the crop will be a bigger piece of the Pellegrini agricultural pie in coming years.

In conferring with local farmers and land owners, I found the typical planting and harvesting dates for the major summer crops of soy, corn, sorghum, and poroto, shown in Table 5.2. The dates I collected did not match those I found published for the country as a whole (see section 3.2, page 22). In fact, based on my data, soy is most frequently planted 
Table 5.1. Summer 2014 Pellegrini Land Cover Classes, From Ground Truth By Area, with Sample Point Counts

\begin{tabular}{lrr}
\hline Cover Type & Hectares & Sample Points \\
\hline Forested & 389,541 & 247 \\
Other & 42,229 & 22 \\
Corn & 41,488 & 36 \\
Pasture & 35,057 & 37 \\
Soy & 27,498 & 24 \\
Poroto & 9,539 & 7 \\
Nothing & 3,057 & 3 \\
Sorghum & 1,646 & 2 \\
\hline Unknown & 92,248 & 17 \\
Omitted & 52,052 & 5 \\
\hline Total & 694,346 & 400 \\
\hline
\end{tabular}

before corn, in contrast to Kansas and the rest of Argentina (see Table 3.2 on page 19 for Kansas dates). I was also told that the winter growing season is separate from the summer growing season. Unlike Kansas, where the beginning of the summer crops (namely corn's early development) overlaps with the end of winter wheat growth, the harvesting of Pellegrini's winter crops is typically completed before summer planting begins. Thus, where double cropping is limited in Kansas to a winter crop and a late-developing summer crop (overwhelmingly a winter wheat and soy or winter wheat and sorghum combination), any winter crop can be paired with any summer crop in Pellegrini.

Table 5.2. Key Dates for Summer Crops, Pellegrini, Argentina

\begin{tabular}{cccc}
\hline Grop & Ideal Planting Range & Latest Planting Date & $\begin{array}{c}\text { Harvesting } \\
\text { Begins }\end{array}$ \\
\hline Soy & 15 December to 15 January & End of February & 1 May \\
Corn & 15 January to 15 February & End of February & 1 June \\
Sorghum & 15 January to 15 February & End of February & 1 June \\
Poroto & 15 January to 20 February & Early March & 10 May \\
\hline
\end{tabular}


Table 5.3. Summer 2012 Kansas TSI Mixel and Pure Pixel Counts

\begin{tabular}{crr}
\hline & Count & Percent of Total \\
\hline Total Pixels & 10,000 & 100.00 \\
Pure Pixels & 1,359 & 13.59 \\
Corn & 414 & 4.14 \\
Soy & 354 & 3.54 \\
Sorghum & 16 & 0.16 \\
All Others & 575 & 5.75 \\
Mixels & 8,641 & 86.41 \\
\hline
\end{tabular}

\subsection{Elimination of Mixels}

I found 1,359 pure pixels in the 100 pixel by 100 pixel Kansas study area. The low percentage of pure pixels in the study area is a consequence of the large pixel size relative to field sizes, as well as a few irregular features cutting across the pixel grid. The distribution of pure pixels across the land classes is shown in Table 5.3.

\subsection{Extracted Reference Signatures}

Before extracting the reference signatures for each summer crop, the pixels for each crop had to be clustered. Figure 5.3 shows the spatial distribution of the three clusters for each crop. Given the small number of pixels, the k-means algorithm only found a single cluster for sorghum.

The temporal signatures of each of the clusters are plotted in Figure 5.4. Each of the crops have a somewhat similar appearance to one another, but each can be differentiated: corn peaks earlier in the year than soy or sorghum, soy has a rounder peak than corn, while sorghum has lower VI values and a slightly later growing season than soy. 


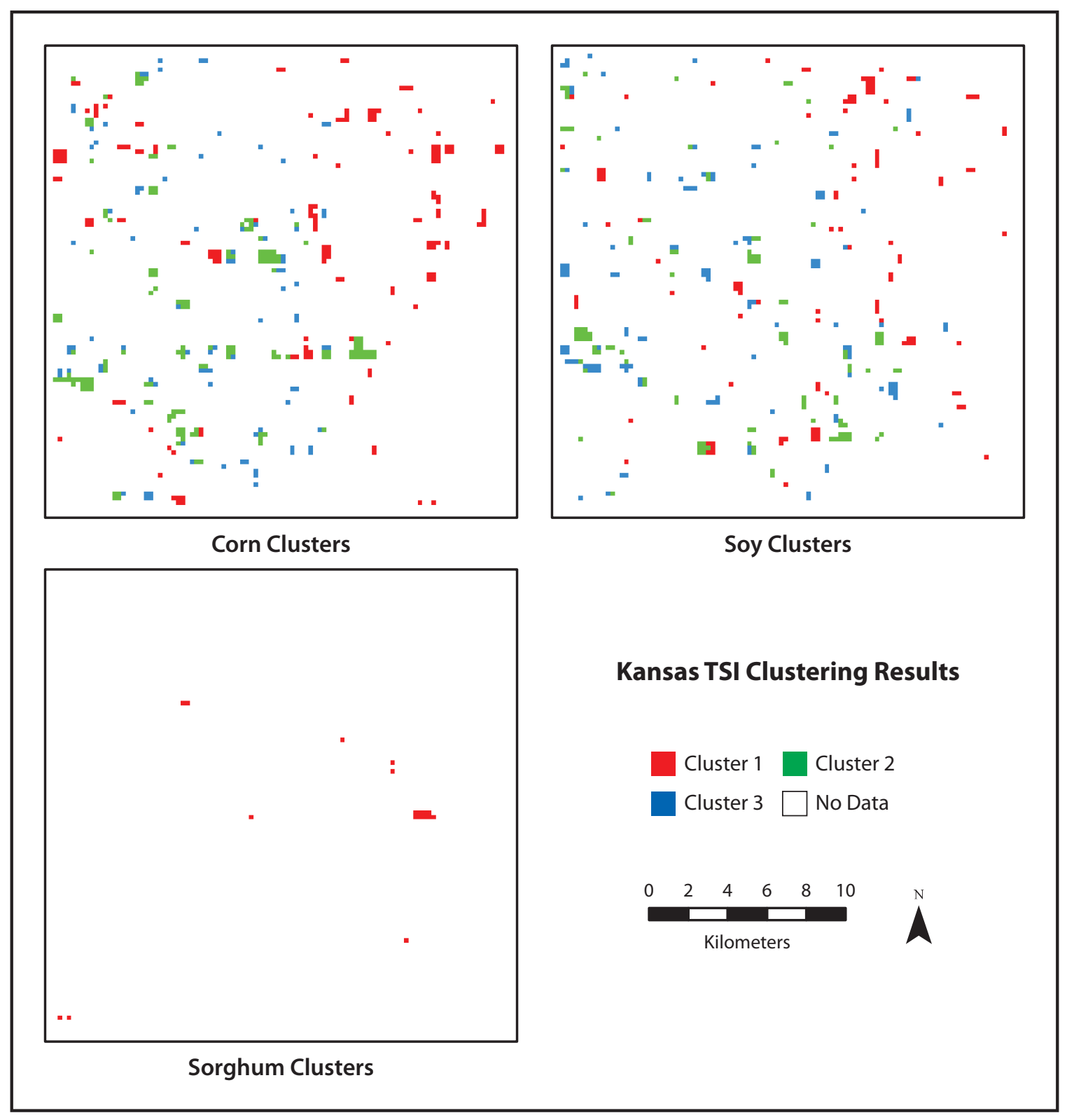

Figure 5.3. Clustering the Kansas TSI Image into Three Clusters for Each Crop 


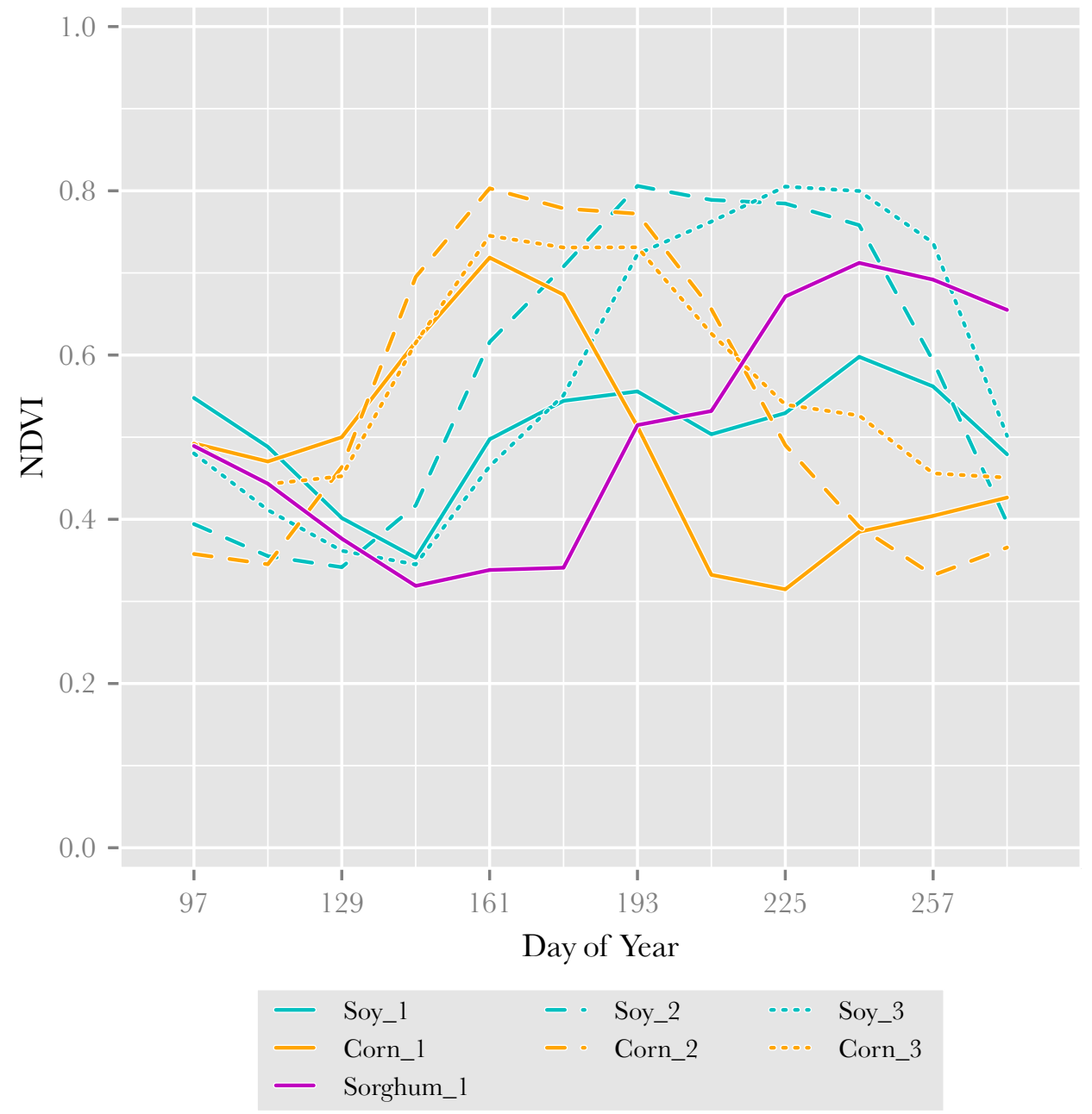

Figure 5.4. Crop Signatures Extracted from the Kansas TSI Crop Clusters

Shown are the seven crop signatures extracted from the Kansas study site's TSI using the k-means clusters. Notice how all three corn signatures occur earlier in the year than the soy or sorghum signatures, but otherwise look similar to the soy signatures. The temporal separation assists with classification. The Soy_1 signature is strange in appearance; it does not look anything like a typical soy signature. Over this date range, the Sorghum_1 signature loses much of its downslope at the end of its growth. 
Table 5.4. Summer 2012 Kansas Study Site Classification Accuracy

\begin{tabular}{|c|c|c|c|c|c|c|c|}
\hline \multicolumn{8}{|c|}{ Reference Data } \\
\hline & & Corn & Soy & Sorghum & Other & Total & User Acc. \\
\hline \multirow{6}{*}{ 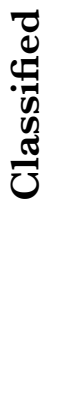 } & Corn & 369 & 65 & 5 & 17 & 456 & $80.92 \%$ \\
\hline & Soy & 32 & 273 & 10 & 47 & 362 & $75.41 \%$ \\
\hline & Sorghum & 0 & 0 & 2 & 6 & 8 & $25.00 \%$ \\
\hline & Other & 13 & 16 & 1 & 503 & 533 & $94.37 \%$ \\
\hline & Total & 414 & 354 & 18 & 573 & 1359 & \\
\hline & Producer Acc. & $89.13 \%$ & $77.12 \%$ & $11.11 \%$ & $\begin{array}{r}87.78 \% \\
\text { Overall }\end{array}$ & $\begin{array}{r}\text { Accura } \\
\mathrm{K}\end{array}$ & $\begin{array}{l}\text { y: } 84.40 \% \\
\text { appa: } 0.76\end{array}$ \\
\hline
\end{tabular}

\subsection{Fitting and Classifying the TSIs}

Fitting the seven crop reference signatures - three corn, three soy, and one sorghum - to the TSIs produced seven RMSE rasters for each TSI. The minimum RMSE values were typically in the range of 175 to 250, while the maximum RMSE values were often around $3000 .^{1}$

The Kansas classification achieved an overall accuracy of 84.4 percent, a map of which is shown in Figure 5.5; the confusion matrix is Table 5.4. To produce this classification, I began by iterating over a range of RMSE thresholds from 450 to 1150 by steps of 150 to identify a high accuracy threshold combination. I manually adjusted each of the thresholds in the resulting combination by steps of 50 until I found the maximum classification accuracy. The RMSE thresholds from that final combination are shown in Table 5.5.

The Argentina classification had a top overall accuracy of 87.8 percent (Table 5.6). Looking more closely at the results, the accuracy seems to be skewed upward by the high number of non-summer-crop sample points, which were correctly classified as "other." Within the 


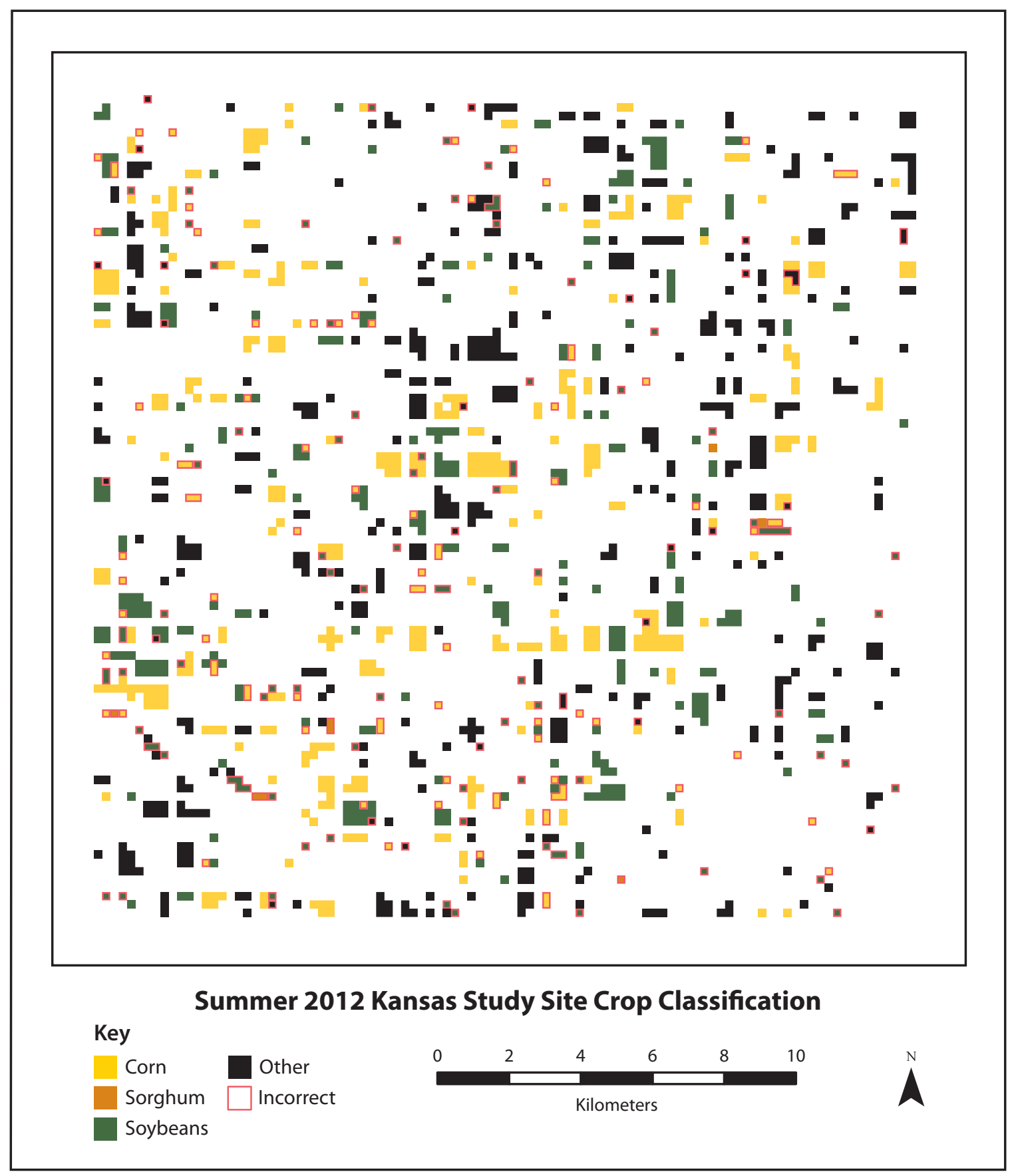

Figure 5.5. Kansas Summer 2012 Classification

These are the results of classifying the summer 2012 Kansas TSI using corn, soy, and sorghum signatures. Incorrectly classified pixels are shown outlined in red. Omitted mixels were not symbolized, and appear white like the background. 
Table 5.5. Kansas Best Classification RMSE Thresholds

\begin{tabular}{cc}
\hline Signature & Threshold Value \\
\hline Corn_1 & 1,000 \\
Corn_2 & 750 \\
Corn_3 & 500 \\
Soy_1 & 750 \\
Soy_2 & 1,300 \\
Soy_3 & 500 \\
Sorghum & 450 \\
\hline
\end{tabular}

summer crop sample points, the accuracy is much lower; only one of the twenty three soy points and zero of the two sorghum points were correctly classified. Corn fared better, but still underwhelmingly, as only 68.6 percent of its points were classified correctly. The RMSE thresholds used for this classification, in Table 5.7, show that the Corn_2 and Soy_3 signatures contributed to the classification most heavily, the Corn_1 and Soy_2 signatures contributed only a little, and the Corn_3, Soy_1, and the Sorghum_1 signatures did not contribute at all (hence zero sorghum points classified).

A map of the classification, shown in Figure 5.6, illustrates how well the classification stayed within summer crop fields, and did not classify much beyond. However, almost all

Table 5.6. Summer 2014 Pellegrini Best Classification Accuracy

\begin{tabular}{|c|c|c|c|c|c|c|c|}
\hline \multicolumn{8}{|c|}{ Reference Data } \\
\hline & & Corn & Soy & Sorghum & Other & Total & User Acc. \\
\hline \multirow{6}{*}{ 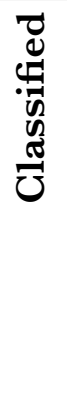 } & Corn & 24 & 13 & 0 & 8 & 45 & $53.33 \%$ \\
\hline & Soy & 0 & 2 & 1 & 2 & 5 & $40.00 \%$ \\
\hline & Sorghum & 0 & 0 & 0 & 0 & 0 & $0.00 \%$ \\
\hline & Other & 12 & 9 & 1 & 306 & 328 & $93.29 \%$ \\
\hline & Total & 36 & 24 & 2 & 316 & 378 & \\
\hline & Producer Acc. & $66.67 \%$ & $8.33 \%$ & $0.00 \%$ & $\begin{array}{r}96.84 \% \\
\text { Overall }\end{array}$ & $\begin{array}{r}\text { Accura } \\
\mathrm{K}\end{array}$ & $\begin{array}{l}\text { cy: } 87.83 \% \\
\text { appa: } 0.54\end{array}$ \\
\hline
\end{tabular}


Table 5.7. Pellegrini Best Classification RMSE Thresholds

\begin{tabular}{cc}
\hline Signature & Threshold Value \\
\hline Corn_1 & 550 \\
Corn_2 & 850 \\
Corn_3 & 0 \\
Soy_1 & 0 \\
Soy_2 & 600 \\
Soy_3 & 950 \\
Sorghum_1 & 0 \\
\hline
\end{tabular}

of the summer crop fields are classified as corn, reflecting the low summer crop accuracies shown in Table 5.6. 


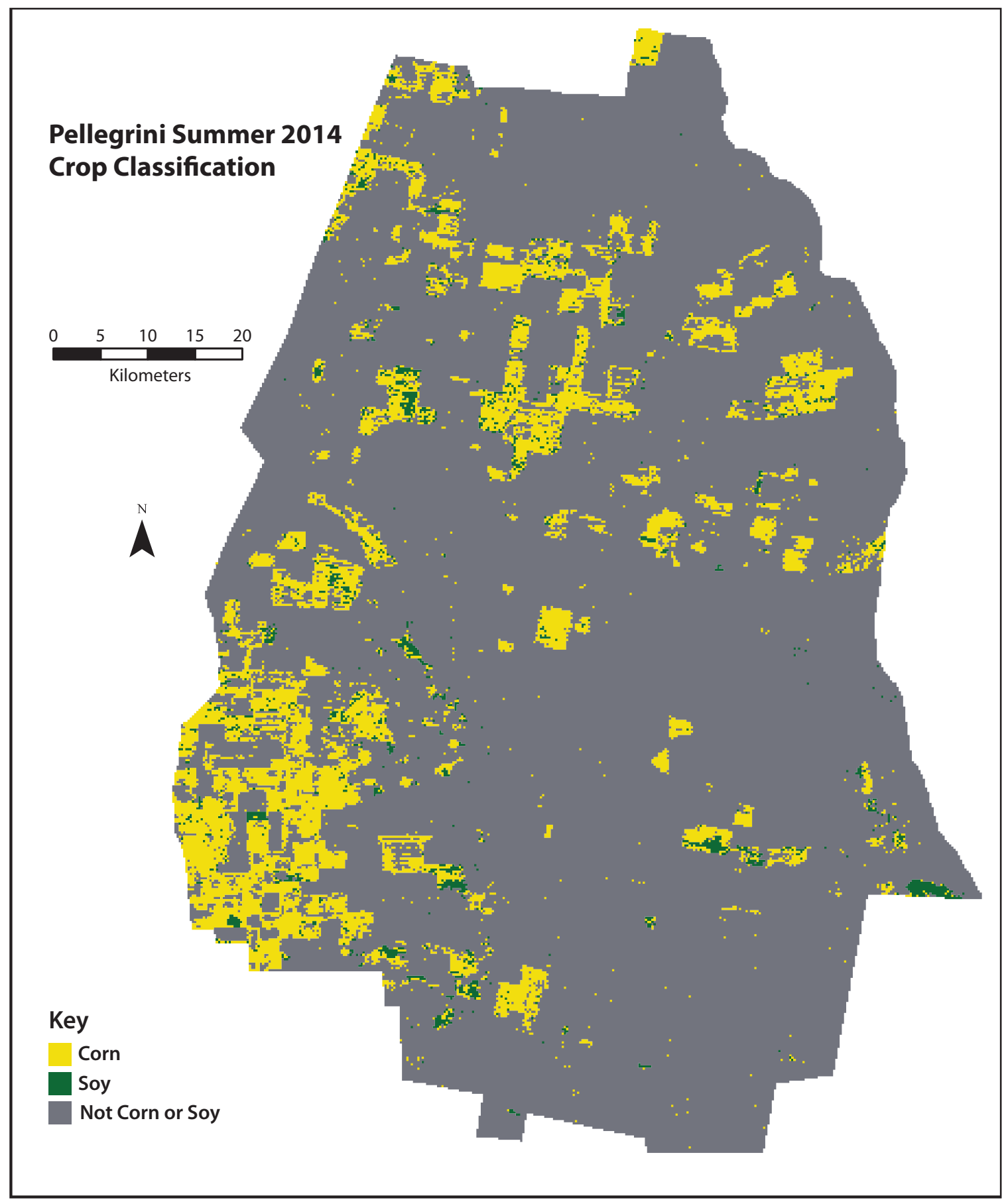

Figure 5.6. Pellegrini Summer 2014 Classification

Comparing this map to the ground truth in Figure 5.1 on page 43, one can see how well the classification was able to separate soy and corn fields from the other classes. However, these fields are overwhelmingly classified as corn, suggesting major class confusion between the two. 


\section{Notes}

${ }^{1}$ NDVI and EVI range between -0.2 and 1.0, so the RMSE values should be 0.0175 or 0.3000. However, the MODIS VIs are distributed as 16-bit signed integer rasters; to allow the VI values to be recorded with such a format, they are multiplied by 10,000 , hence the values shown here. I chose not to convert the measurements back to the proper decimal values to simplify processing, though the tools I developed should work either way. Users must take the responsibility be aware of the significance of the RMSE values and understand what values to expect based on their input data. 


\section{Chapter 6}

\section{Discussion}

\subsection{Examining the Kansas Signatures}

The Kansas signatures extracted from the k-means clusters (Figure 5.4) were not as variable as I was expecting. Based on initial testing results, presented in section C.3 beginning on page 139, I expected some of the cluster signatures would be much "stranger" looking. Aside from the Soy_1 signature and perhaps the Corn_1 signature to some degree, however, the cluster signatures were fairly typical in appearance. The Sorghum_1 signature appears more or less as expected over the TSI's date range, but does seem to be missing the late-season downslope.

Using the k-means algorithm to cluster each crop's pixels does not seem to have adequately captured the variability in the crop signatures as labeled by the CDL to allow the fit algorithm to match the CDL classification. That is, perhaps k-means separates pixels that would have similar RMSE values when fit with the same crop reference signature. Future research might want to consider clustering based on the RMSE value of each pixel to the

others; pixels with low RMSE values when compared to one another would be grouped 
together, as they are likely transformations of the same base temporal signature. Pixels with considerably different RMSE values would suggest different base temporal signatures.

Despite the fact the k-means might not capture similarity in the same way as the fit algorithm, it is worth noting that the k-means clusters generally do not divide fields: each pixel in a field is assigned the same cluster (Figure 5.3). This result shows that all pixels in a field typically have comparable signatures, at least using k-means as a measure of similarity. This result is further confirmation of the hypothesis that pixels of a crop grown under the same conditions should have the same development and therefore the same temporal signature.

\subsection{Breakdown of the Kansas Classification}

The initial verification of the Kansas reference signatures, done by classifying the TSI of the Kansas study area, demonstrates the method performs well when used to match the original source data (Table 5.4). The 84.4 percent overall accuracy and kappa value of 0.76 are well within the range considered acceptable for this type of classification, especially given the CDL's published accuracy of 88.4 percent (to which this classification is compared).

Some confusion between corn and soy, as well as soy and "other," pulled down the overall accuracy, as well as the producer and user accuracies of each of those classes. The similarities between the corn and soy signatures may cause late corn and early soy to be confused if the range of the offset of the maximum DOY of the reference signatures, tshift, allows overlap between the two. I believe much of the soy and "other" confusion was due to the Soy_1 reference signature (Figure 5.4). Examining the CDL classes of the best fit pixels in the RMSE raster showed a number of grassland pixels were well fit by that particular signature. 
However, omitting the Soy_1 signature seemed to allow one of the corn signatures to take many of the soy pixels, which I find strange due to the peculiar shape of the Soy_1 signature. In fact, the signature does not match the traditional soy signature, and makes me question the validity of the CDL in this case.

Classifying sorghum did not seem to be very effective; only two of the 18 sorghum pixels were accurately identified. The sorghum RMSE raster had the lowest threshold value at 450, but increasing the threshold only caused greater class confusion. Omitting the signature entirely had a slight negative effect on the overall accuracy: the "other" pixels it misclassifies would otherwise be misclassified as corn or soy. Adding another 16-day composite to the TSI to capture the tail-end of the sorghum signature may have alleviated the confusion. However, interference between winter crop germination and summer crop signatures would likely have resulted in worse classification errors (for more information see the "end-of-year bump" discussion in section C.4 beginning on page 150).

Moreover, the similarities between sorghum and soy signatures might cause confusion if the sorghum threshold were to be raised. However, it is also possible that the sorghum pixels were not accurately identified by the GDL. The GDL does not have clearly-delineated sorghum fields, but rather a mix of soy and sorghum. Thus, it appears that the USDA's classification method is unable to accurately differentiate between soy and sorghum in some cases. Consequently, sorghum pixels may have been included in the soy clusters, and vise versa. This would mix the temporal signatures and cause confusion in the results. Of course, the soy and sorghum signatures are rather similar in appearance, and it might be that my method is unable to distinguish them from one another. Even if the CDL has confusion 
between the two, this may still be case. Due to the low number of sorghum pixels, the validity of any conclusions about classifying this particular crop is questionable. A larger sample size and more testing are required.

The strange soy signature mentioned above, the sorghum problems, and additional CDL errors identified in preliminary testing (see section C.3 on page 147) make me distrust the CDL as a ground truth dataset. Lacking alternative data, I have proceeded through this investigation assuming the CDL is correct. The classification results using clustering do show that my tools work, as they were able to reproduce the CDL with decent accuracy. Some errors in my classification may be due to errors in the CDL. Even so, my accuracy is not necessarily representative of the method's performance; determining exactly how well the tools perform is difficult without more accurate ground truth data. I believe a ground truth without errors would allow classification using a single reference signature per crop. Clustering to find multiple crop signatures was necessary to work around the less reliable CDL data. ${ }^{1}$

\subsection{The Pellegrini Classification and Class Confusion}

As shown in Figure 5.6, classifying the Argentina TSI with the reference signatures from the k-means clustering of the Kansas TSI was able to effectively separate areas of the summer crops corn, soy, sorghum, and poroto from most other land cover classes, but identified those summer crop pixels predominately as corn. While Table 5.6 reflects this class confusion in the producer and user accuracies, the low sample count for corn, soy, and sorghum compared to all the other land covers deceptively skews the overall accuracy higher. Ta- 
Table 6.1. Summer 2014 Pellegrini Best Classification Accuracy Checked Against All Pure Pixels

\begin{tabular}{|c|c|c|c|c|c|c|c|}
\hline \multicolumn{8}{|c|}{ Reference Data } \\
\hline & & Corn & Soy & Sorghum & Other & Total & User Acc. \\
\hline \multirow{7}{*}{ 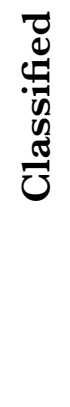 } & Corn & 3283 & 2076 & 61 & 1201 & 6621 & $49.58 \%$ \\
\hline & Soy & 189 & 313 & 36 & 458 & 996 & $31.43 \%$ \\
\hline & Sorghum & 0 & 0 & 0 & 0 & 0 & $0.00 \%$ \\
\hline & Other & 2234 & 1523 & 60 & 74387 & 78204 & $95.12 \%$ \\
\hline & Total & 5706 & 3912 & 157 & 76046 & 85821 & \\
\hline & Producer Acc. & $57.54 \%$ & $8.00 \%$ & $0.00 \%$ & $97.82 \%$ & & \\
\hline & & & & & Overal & Accura & $\begin{array}{l}\text { y: } 90.87 \% \\
\text { appa: } 0.51\end{array}$ \\
\hline
\end{tabular}

ble 6.1 is the confusion matrix for the same classification, but compared to the entire ground truth dataset, encompassing some 85,821 pixels, instead of the rather limited 378 random sample points. While the overall accuracy actually improves slightly with this new reference dataset, it must be noted that neither of these accuracy assessments is able to account for errors resulting from mixels. However, the increased number of samples better demonstrates the significant corn-soy confusion. For instance, of the 6,621 pixels classified as corn, 2,076 are soy. Errors of omission are also more prominent: 2,234 of the 5,706 corn pixels were left as "other." A similar proportion of soy pixels were also classified "other." Raising the RMSE thresholds on the RMSE rasters to decrease these omissions only increased the errors of commission, confusing "other" pixels for crops. The low kappa statistic of both accuracy assessments, 0.54 and 0.51 respectively, is reflective of the poor accuracies within the summer crops.

Considering that the "other" pixels contain a number of different classes, I found the frequency of corn and soy classifications within each of the "other" land cover classes. The 
results of this analysis (Table 6.2) show that the main sources of confusion were, from greatest to least, the true other land cover class, pasture, and poroto. However, when finding the percent of the land cover class pixels that were confused, poroto leads with over 26 percent of its pixels confused for either corn or soy. This confusion, and the confusion of some pasture areas as well, does make some sense, as these land covers, soy, and corn are all planted early in the year and reach peak maturation during the summer months. Depending on the type of pasture, it may or may not grow back after cutting; if it does not, the temporal signature may bear some resemblance to corn or soy. ${ }^{2}$

From their appearance in Landsat imagery, the main locations where the other class was confused for corn and soy seem to be bare earth, possibly due to high soil salinity. The areas have low-to-moderate reflectivity in the visual bands, high reflectivity in the mid-infrared, and low reflectivity in the near-infrared, and do not exhibit much change over time. However, the plots of a random sampling of pixels from the TSI show temporal signatures like that in Figure 6.1. I am currently unable to explain what is in these areas or why they are confused for corn and soy. I believe there may be some sort of summer grass cover or other seasonal vegetation, but it is hard to explain the lack of near-infrared reflectance

Table 6.2. Pellegrini Corn and Soy Confusion with "Other" Land Cover Classes

\begin{tabular}{cc|cc|cc}
\hline $\begin{array}{c}\text { Land } \\
\text { Cover }\end{array}$ & $\begin{array}{c}\text { Total } \\
\text { Pixels }\end{array}$ & $\begin{array}{c}\text { Confused as } \\
\text { Gorn }\end{array}$ & $\begin{array}{c}\text { Percent } \\
\text { of Total }\end{array}$ & $\begin{array}{c}\text { Confused as } \\
\text { Soy }\end{array}$ & $\begin{array}{c}\text { Percent } \\
\text { of Total }\end{array}$ \\
\hline Forested & 63,978 & 194 & 0.30 & 26 & 0.04 \\
Other & 5,393 & 306 & 5.67 & 322 & 5.97 \\
Pasture & 5,252 & 396 & 7.54 & 50 & 0.95 \\
Poroto & 1,369 & 303 & 22.13 & 59 & 4.31 \\
Nothing & 485 & 2 & 0.41 & 1 & 0.21 \\
\hline
\end{tabular}




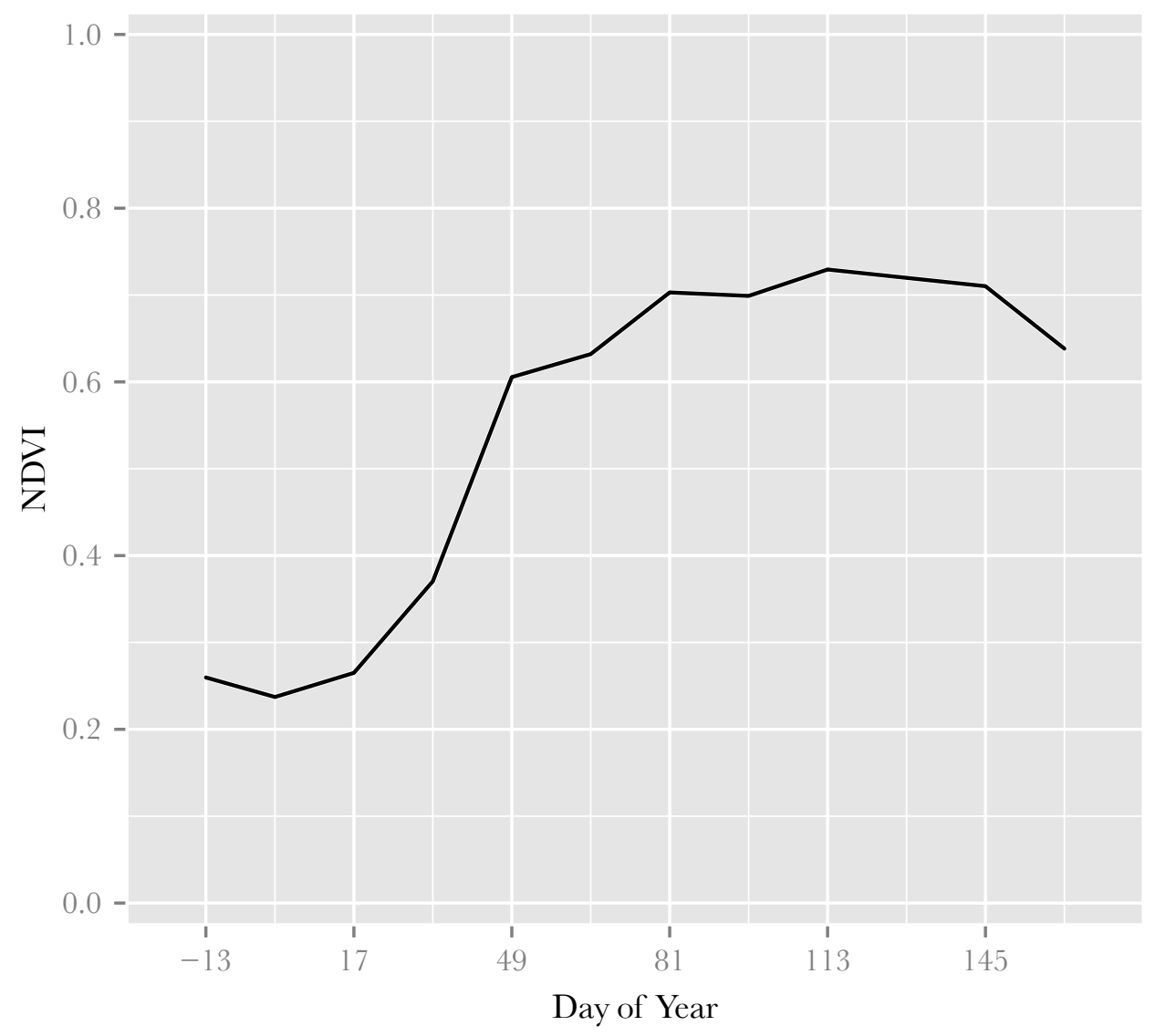

Figure 6.1. Signature of an Unknown Non-Crop Pixel Confused for Corn and Soy in Pellegrini

as observed in Landsat images from multiple dates throughout the summer. Perhaps some standing water coinciding with Landsat observations reduces the near-infrared reflectance, but the presence of vegetation results in high VI values on other dates, which are recorded in the MODIS composites.

\subsection{Clustering Pellegrini}

To further examine the class confusion in Pellegrini, I used the same k-means clustering as in Kansas to identify the three main signatures for each of the eight land cover classes 


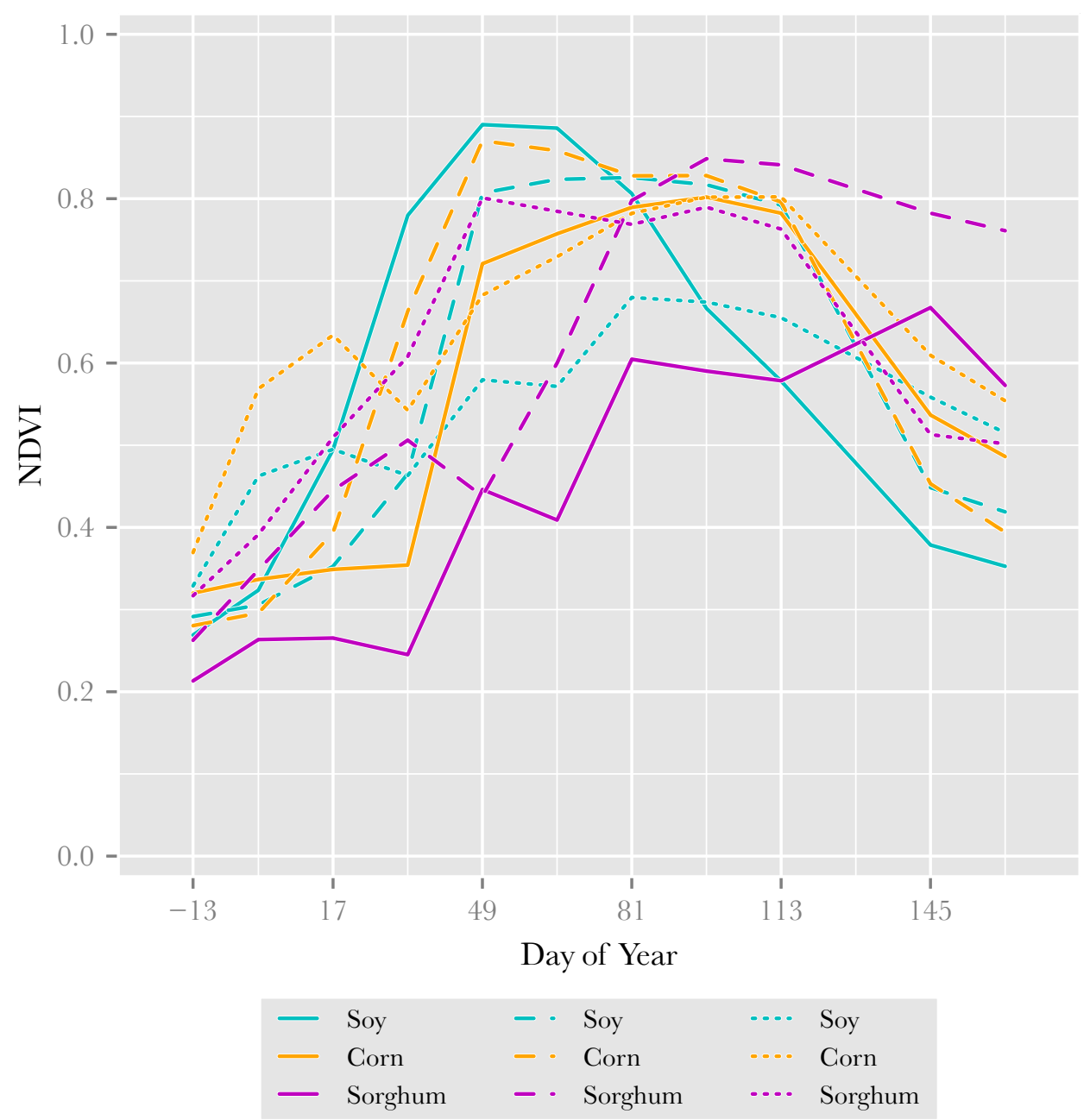

Figure 6.2. Corn, Soy, and Sorghum Signatures Extracted from the Pellegrini TSI

These are the signatures from the k-means crop clusters found in the Pellegrini TSI. While some strange exceptions like Soy_3, Sorghum_1, and Sorghum_3 deviate from the rest, the overwhelming similarities between signatures of different crops is striking. Unlike the crop signatures from Kansas, Pellegrini's crops are not temporally separated, but peak almost simultaneously.

in the ground truth dataset. The extracted corn, soy, and sorghum signatures are shown in Figure 6.2, while the poroto and pasture signatures are in Figure 6.3. The forest, nothing, and other signatures are shown in Figure 6.4.

The cause of the corn-soy confusion is immediately visible: both crops peak around the 


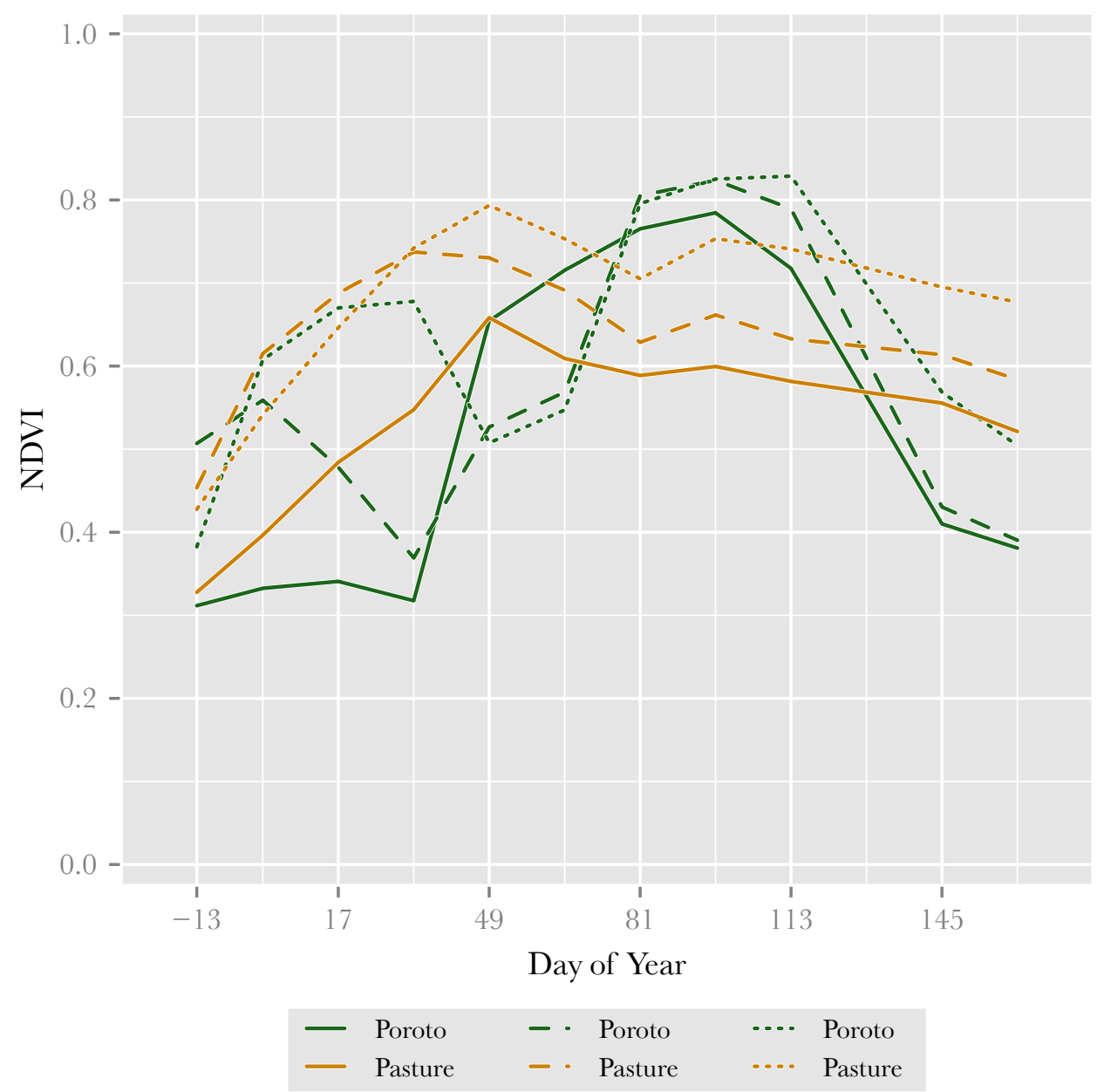

Figure 6.3. Poroto and Pasture Signatures Extracted from the Pellegrini TSI

same date. I did not expect this result, as the typical planting dates I collected suggest soy should peak earlier than corn. ${ }^{3}$ However, I also gathered that precipitation was the limiting factor in planting (confirmed by Sacks et al. 2010), and often farmers will wait until a certain amount of rain has fallen before planting. In fact, I was told the rains in the 2014 growing season were quite late, and on multiple occasions farmers told me they had planted a field late due to lack of rain. While I must admit I am not a farmer and do not know this for certain, the reason for waiting did not seem to be out of concern for plant health, in that too 


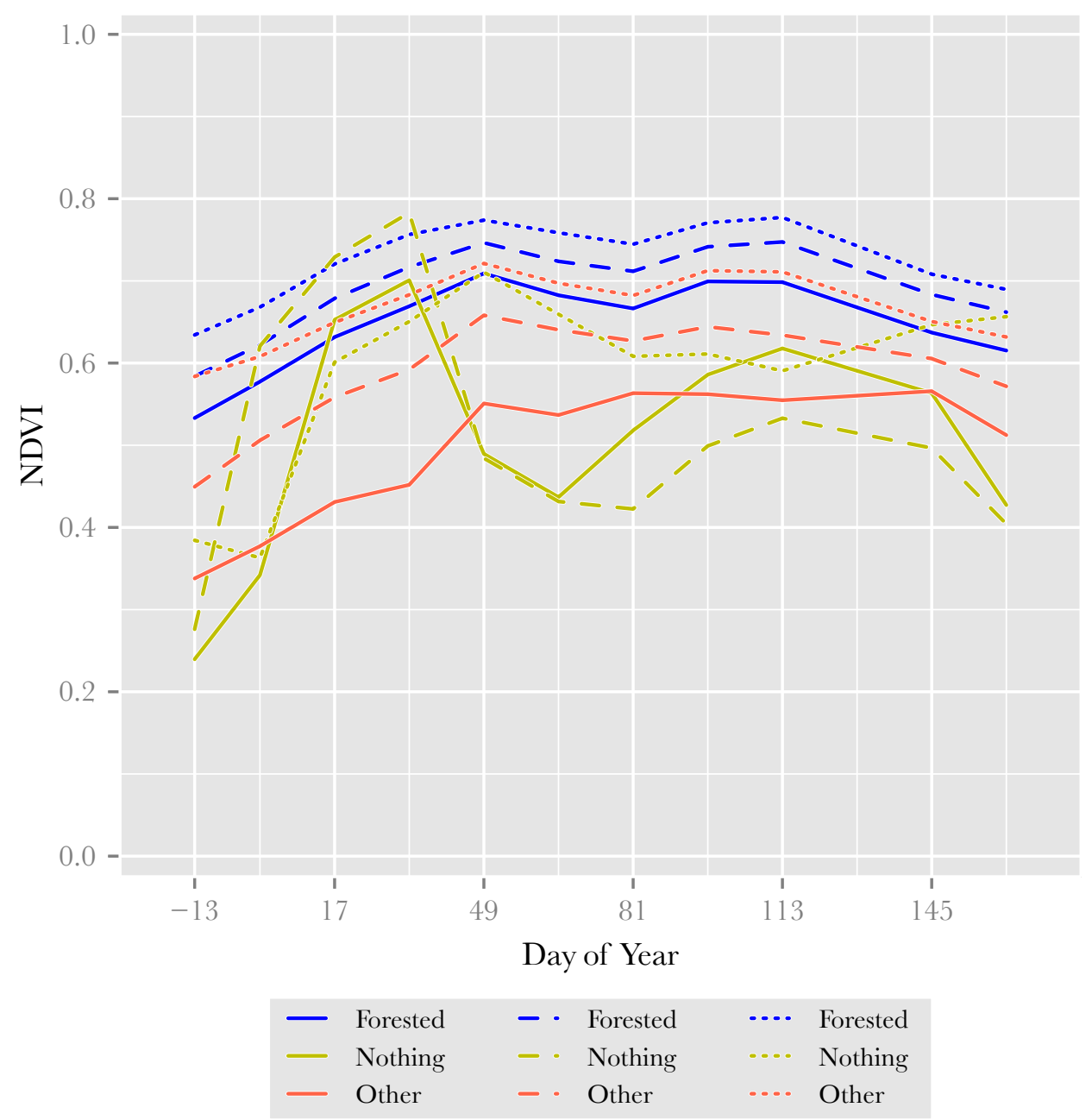

Figure 6.4. Forested, "Nothing," and "Other" Signatures Extracted from the Pellegrini TSI

early of planting would negatively impact the crop's health. Rather, the rationale seemed primarily economic: farmers do not want to pay to plant crops that will not grow if the rains never come.

I also observed fields of corn, soy, sorghum, and poroto in many different states of maturation, from the early, barely-germinated stage to the late, fruit-bearing stage. To me, the broad range of development is likely because water is the only limiting factor defining the 
typical planting dates. That is, the threat of changing temperatures does not affect planting decisions like in Kansas, and farmers have much more flexibility (this flexibility has been observed in other regions per Sacks et al. (2010)). Extremely early plantings can capitalize on early rains at the risk of crop failure. The rest of the plantings, both early and late, may germinate at different times, but should mature around the same date, their development being limited by the available water. My method should be able to accommodate an increased range of planting and maturation dates with looser bounds on the tshift parameter, allowing the reference signatures more freedom to temporally align themselves with the pixel values. However, there is one problem with that idea: my method handles similar-looking signatures, like corn and soy, by making the assumption that each should peak within a different time range. In Kansas, corn peaks before soy, and as such they can be differentiated. Planting dates for Argentina as a whole also suggest corn should peak before soy. However, in Pellegrini specifically, the weather conditions and consequent agricultural practices do not allow this assumption to be met. When both crops peak about the same date, their temporal signatures are not significantly different, leading to the class confusion exhibited.

I believe higher temporal resolution data might create more detailed temporal signatures, which could allow for more difference to be detected between different crops. Combining such data with certain noise-filtering methods (i.e., the TSF wavelet filtering) may allow signatures to be smoothed in ways that might accentuate differences between similar crops like corn and soy (see Doraiswamy, Akhmedov, and Stern (2006) and Sakamoto et al. (2010) for examples of higher temporal resolution data and filtering). 


\subsection{More Ideas for Future Research}

Given the practical constraints of this project, many aspects of this approach to classification have gone largely or completely untested, and some could have a profound impact on the classification accuracy and potential use-cases. I am sure that I have not thought of everything that could be tested or improved, but I have compiled the following list of ideas to help future researchers working with these tools, broken down by each step of the workflow.

\subsubsection{Temporal Signature Generation}

How does spatial and temporal variation in the sources used to generate a temporal signature (e.g. multiple study sites and multiple sample years, respectively) affect the accuracy of classifications produced with that signature? I initially tried to investigate this question, but my findings were largely inconclusive due to numerous problems (my initial testing is described in section C.1 on page 121). Now that I have refined the method somewhat, this question could be revisited. My hypothesis remains the same: the greater the variations averaged together to create a reference signature, the further that signature gets from an ideal reference which can be transformed effectively to fit pixels of that crop. That is, extracting signatures from a large geographical area, or across multiple years, will only create reference signatures that are less "true" than those created with less variation, spatially or temporally.

However, could another method of averaging the pixel signatures used to create a reference signature be less prone to these variations? In addition to the arithmetic mean of each dates' values, as presented in the methods, I have tried something like "fit averaging." 
The time shift and horizontal and vertical differences between two signatures can be found using the TSF equations. Dividing each of those transformations by two and applying them to one of the original signatures theoretically creates a new signature halfway between the two original signatures. However, in practice, this resulted in strange curve forms when the signatures averaged were not very similar. It may be that this method deserves a second test using the refined sample points, which all have similar shapes, as this approach may be particularly sensitive to outliers. It could also be that the program I used for this function has errors. Similarly, it would be worthwhile to test the effect of a geometric rather than arithmetic mean of the sampled pixels' values. Such a mean is less sensitive to outliers and may provide truer signatures. Additionally, other methods mat be more effective when generating reference signatures from disparate data.

\subsubsection{Mixels}

It seems to me that many methods could be more effective at negating the effects of mixels rather than my simple elimination. For instance, perhaps some method of signature unmixing could allow for sub-pixel classification. However, even using the basic elimination process, a few things should be tested. First, what is the purity threshold at which a mixel is too mixed? That is, what percentage of a whole pixel can still be accurately classified? I arbitrarily chose to eliminate all pixels less that 98 percent of a whole MODIS pixels. I assumed the possible 2 percent mixing was low enough that it would have no negative impact. Yet, perhaps I could have chosen many more mixed pixels with a higher mix threshold, or should have eliminated all pixels, even those so minimally mixed. An effective mix threshold 
may not be constant, however, as all land covers may not contribute equally to a mixel's temporal signature; this is also a subject for future investigations.

Another idea to work around mixels would be to integrate this classification method with more-traditional methods that use higher spatial resolution data. For example, thresholding the RMSE rasters at a low RMSE value would identify fields that have the highest probabilities of correct classification. Those identified pixels could then be converted into training sites for use with Wardlow and Egbert's decision tree classification method, or with a multispectral classifier. Another advantage of this idea is that it would eliminate the lessthan-ideal and lengthy threshold iteration.

\subsubsection{The Fitting Process}

As I mentioned in the methods section, the bounds chosen for the transformation parameters tshift, xscale, and yscale were not thoroughly tested, and likely have a large effect on the classification accuracy. Loosening the bounds would allow a reference temporal signature to to better fit pixel signatures that are dissimilar, but could increase confusion and errors of commission. Tightening the bounds would restrict the amount of possible signature transformation. Stricter transformation may reduce confusion, but could increase errors of omission. Also unclear is whether transformation parameter bounds should be the same across all crop signatures, or if each crop should have an independent set of bounds (perhaps due to differing variability in the signatures of different crops).

Another possible optimization is changing how curve similarity is calculated between reference signatures and pixel signatures. The current approach uses an arithmetic mean 
to calculate the RMSE, as given in Equation 2.3. Similarly, the geometric mean could be used:

$$
R M S E=\left[\left[\prod_{x=j(1), j(2) \ldots}^{n}(f(x)-g(x))^{2}\right]^{\frac{1}{2}}\right]^{\frac{1}{n}}
$$

I tried using the geometric mean for RMSE calculation in the fit algorithm, but I found it was too insensitive. RMSE values were unrealistically low. This mean seemed to allow reference signatures to fit to pixels that should not be classified (they are "other") in a similar threshold range to pixels which are legitimate. However, given subsequent optimizations to the overall classification process, formally testing this mean would be of value. The Find Fit Tool already has an option to use a geometric mean instead of an arithmetic mean, so testing would not require any programming changes.

A method of curve comparison beyond RMSE may be better suited to this analysis. I used RMSE because it was shown to work in Brown et al. (2007) and Sakamoto et al. (2010). However, another measure of curve likeness might perform better. I do not know what that method might be; ideas I want to investigate include Procrustes distance, dynamic time warping, and Frechet distance, though these may not all be applicable to this problem.

Also worth revisiting is the question of which VI performs best, or if there are certain conditions that favor specific VIs over others. My initial testing showed that NDVI worked better than EVI, but many improvements have been made to the method and program code since that testing was completed. Moreover, many other VIs could be tested for use with this method, and some may allow use cases outside agricultural classification. Similarly, this method may not be limited to use with just VIs; data other than VIs could allow for 
applications of the method beyond what I can imagine. What if the method were used multi-dimensionally, with multiple bands? Or with different data sources, i.e. higher spatial resolution data?

\subsubsection{Thresholding and Classification}

The thresholding and classification step is the part of this method I dislike the most. My original intention was to create a method for classifying crops without ground truth. Due to the complex thresholding process, optimal classifications are impossible to create without iterative accuracy assessments, which require ground truth. I hope that future research may devise a way to remove this limitation from the optimization process. The accuracy impact of achieving the absolute optimum classification over less-optimized classification is unknown. Is not well understood is if the optimal RMSE threshold varies between crop types. The wide spread of optimal RMSE thresholds that I've identified across the classifications I've created suggests that the best RMSE threshold values are unique to every circumstance and quite variable. However, it is also possible that a single threshold value used across all the RMSE rasters could result in classifications of reasonable accuracies.

While I cannot draw any solid conclusions, I did make a test classification of the summer 2012 Kansas TSI using the k-means clustering discussed in subsection 4.3.4 (page 34) using ten clusters per crop, rather than three. This clustering produced thirty clusters: ten each for corn and soy, nine for wheat-soy double cropped, and one for sorghum. Processing thirty RMSE rasters with the classification/accuracy tool using just two RMSE value thresholds would theoretically take $0.35 \times 2^{30}$ seconds, or almost twelve years, to complete on my 
computer. Rather than wait for that process to complete, I decided to use a single threshold across all the RMSE rasters and see what would result.

I stepped through RMSE value thresholds of 400 to 850 by increments of 50 . The highest accuracy classification, 71.7 percent, occurred at with a RMSE threshold of 650 across all the RMSE raster. Omitting the wheat-containing reference signatures boosted the classification accuracy to 79.2 percent at the same 650 threshold value. A last test without the sorghum signature proved to be the highest accuracy at 81.0 percent, again with the same RMSE threshold of 650.

If a single threshold value proves to be too inaccurate, finding a faster way to iterate through the RMSE thresholds combinations is an important task. One challenge of thresholding are local maxima. In other words, the accuracy may peak with a certain threshold combination, but that peak may only be a local maximum, and a different threshold combination may allow an even higher accuracy. One idea would be to investigate numerical optimization methods that could use the range of values in a RMSE raster to calculate an optimal threshold for that raster. If optimal RMSE thresholds could be approximated numerically, then no ground truth would be needed to create the classification. 


\section{Notes}

${ }^{1}$ My experience working with the CDL has revealed a number of problems. Additionally, others have expressed reservations to me about the published accuracies. That said, the CDL is a fantastically ambitious - and free - dataset, and I do not want to suggest that the USDA has failed. Even if the data have problems, the USDA are classifying the entire continental United States, which has extremely variable conditions and an incredible variety of land covers. That the USDA can achieve any reasonable classification at all is impressive.

${ }^{2}$ I heard a few names for the different types of pasture grasses that were being grown in the area, but I believe the two most prevalent are known locally as gatom pani and grama. I have not been able to determine if gatom pani has an English name; it is possible that I did not get the correct spelling. Blue Grama Grass (Bouteloua gracilis) is a common forage grass native to North America, though I am unsure if it is the same plant grown in Pellegrini. I did not learn much about any other pasture grasses cultivated in the area, or about typical harvesting practices.

${ }^{3}$ Even if soy had peaked earlier than corn, I would not have been able to achieve an accurate classification with the current tools, as corn-before-soy is a key assumption. That is, a single tshift parameter is specified for all reference signatures. It would be possible to rewrite the tool to allow different tshift values for different signatures, which might have sufficed if soy did peak before corn, but does not help when the peaks are coincident. 


\section{Chapter 7}

\section{Conclusion}

Deforestation in Argentina continues despite regulations intended to put an end to the loss of native forests. Popular perception holds the rapid expansion of soybeans throughout the country responsible for the rush on agricultural land and consequent pressure on forests. Because of this, I wanted to develop a remote sensing toolset that would allow better study of agricultural crops in the region by classifying crops by specific types.

I believe I have successfully developed such a toolset. However, my results do not show that it can be used effectively to classify crop types globally and under any conditions, as I had originally hoped.

Agricultural practices are key assumptions in the design of any crop classifier. The importance of a complete understanding of agricultural practices in the study area must not be underestimated. Such an understanding allows one to choose an appropriate classification method given the growing conditions. When differences in crop planting and management violate the classifier's assumptions, the classifier and all other similarly-assuming classifiers break down. In the case of my work in Pellegrini, the assumptions of my classifier did not match the growing conditions, and the classifier was unable to differentiate between the 
summer crops I wished to identify.

The testing I've completed has largely been to demonstrate that the tools I have developed are functional and that this "hypertemporal" signature-fitting approach may be effective for certain remote sensing applications. Based on the many outstanding research questions, a lot of work remains to increase the understanding of how different parameters affect fitting and classification. This study is just the beginning of a large body of potential research, which I believe will only increase in importance as earth-observing sensors become more numerous and high spatial and temporal resolution data become more commonplace.

Rigorous testing and optimization of the classification tools and workflow developed in this study may eliminate some of the current assumptions about agricultural practice. I believe such work can only improve classification accuracies and the conditions under which this classifier is useful. I hope that other researchers will continue investigating these techniques. I am encouraged by the results of this study and see these methods to hold promise for those investigating agriculture and LULC change. Having said this, I must admit my recognition of the importance of this work has changed somewhat.

I initially thought that classifying specific crops is necessary to understanding the full dynamics of deforestation. While I still believe that to be true, my perception has shifted because if my experience in Argentina, and the data I have gathered. Knowing which crops are highest in demand and expanding most rapidly is often enough to get a picture of the pressures driving agricultural expansion; knowing what is being grown in a field in any given year is not as important as I thought. Why? Farmers can change their crops annually, so where soy is occurring one year, corn or sorghum or some other crop entirely may be grown 
the next, as the shift from soy to corn in Pellegrini may demonstrate. Nonetheless, accurate land-cover maps generated by remote sensing methods could be used for LULC change studies and modeling that would provide more comprehensive insights into the actual drivers of LULC change.

Moreover, I have a newfound understanding of the influence of economics in LULC change. Popular wisdom in Argentina recommends two investments for securing wealth: buy dollars, or buy land. Correspondingly, agricultural land prices are extremely high (MercoPress 2010); I was quoted $\$ 20,000$ USD per hectare for land around Nueva Esperanza. Prices in the more productive Pampas region are higher still. Anecdotally, one Pellegrini land owner, who resides in Rosario, told me he bought 3,000 hectares in Pellegrini for the same price fifty hectares of land outside Rosario was selling for.

Even so, many large parcels in the area were for sale; I cannot count the number of times I was offered a "good deal" by some land owner looking to cash in and get out. I was left with the impression that the deforestation, the mad land grab, is not about agriculture. It is about desperately securing wealth in the unstable Argentine economy, where inflation runs rampant and a shadow economy rules all. It is an investment bubble. And it just so happens to be threatening the ecological health of the country, and the planet as a whole. Perhaps it will burst, and the cutting will cease. But by then will it be too late? Will a consequent fall in production simply begin to inflate a new bubble somewhere else? 


\section{References}

Altieri, M. A., and W. Pengue. 2006. GM soybean: Latin America's new colonizer. Seedling (January): 13-17.

Boletta, P. E., A. C. Ravelo, A. M. Planchuelo, and M. Grilli. 2006. Assessing deforestation in the Argentine Chaco. Forest Ecology and Management 228:108-114.

Bonnie, R. 2000. Counting the cost of deforestation. Science 288 (5472): 1763-1764.

Brown, J. C., W. E. Jepson, J. H. Kastens, B. D. Wardlow, J. M. Lomas, and K. P. Price. 2007. Multitemporal, moderate-spatial-resolution remote sensing of modern agricultural production and land modification in the Brazilian Amazon. GIScience $\mathbb{E}^{2}$ Remote Sensing 44 (2): 117-148.

Clark, R. N., G. A. Swayze, K. E. Livo, R. F. Kokaly, S. J. Sutley, J. B. Dalton, R. R. McDougal, and C. A. Gent. 2003. Imaging spectroscopy: Earth and planetary remote sensing with the USGS Tetracorder and expert systems. Fournal of Geophysical Research 108 (E12): 1-44. http://speclab.cr.usgs.gov/PAPERS/tetracorder/ (last accessed 11 August 2014). 
Doraiswamy, P. C., B. Akhmedov, and A. J. Stern. 2006. Improved techniques for crop classification using MODIS imagery. In International Geoscience and Remote Sensing Symposium, 2084-2087. Piscataway, NJ: The Institute of Electrical and Electronics Engineers.

Eastman, J. R. 2012. IDRISI Selva Manual. Worcester, MA: Clark University, January.

ESRI. 2012. ArcGIS for Desktop Advanced (version 10.1 SP1) [computer software]. Redlands, CA. http://www.esri.com/software/arcgis/arcgis-for-desktop (last accessed 1 September 2014).

Exelis Visual Information Solutions. 2014a. ENVI (version 5.0) [computer software]. Boulder, GO. http://www.exelisvis.com/ProductsServices/ENVIProducts.aspx.

- 2013. Selected hyperspectral mapping methods. ENVI Classic Tutorial. http://www.exelisvis.com/portals/0/pdfs/envi/mapping_methods.pdf (last accessed 12 August 2014).

- 2014b. K-Means. Using ENVI. http://www.exelisvis.com/docs/KMeansClassification.html (last accessed 1 September 2014).

Gasparri, N. I., and H. R. Grau. 2009. Deforestation and fragmentation of Chaco dry forest in Northwest Argentina. Forest Ecology and Management 258 (6): 913-921.

Geist, H. J., and E. F. Lambin. 2002. Proximate causes and underlying driving forces of tropical deforestation. BioScience 52 (2): 143-150. 
Grau, H. R., T. M. Aide, and N. I. Gasparri. 2005. Globalization and soybean expansion into semiarid ecosystems of Argentina. AMBIO: A fournal of the Human Environment 34 (3): 265-266.

Grau, H. R., N. I. Gasparri, and T. M. Aide. 2005. Agriculture expansion and deforestation in seasonally dry forests of Northwest Argentina. Environmental Conservation 32 (2): 140.

- 2008. Balancing food production and nature conservation in the neotropical dry forests of Northern Argentina. Global Change Biology 14 (5): 985-997.

Greenpeace International. 2005. The expanding soybean frontier: Argentina's dangerous reliance on genetically engineered soybean. Greenpeace Briefing (January). http://www.greenpeace.org/international/Global/international/planet2/report/2005/11/the-expanding-soybean-frontier.pdf (last accessed 27 October 2013).

Greenpeace Argentina. 2013. Ley de Bosques: 5 años con pocos avances [The Forest Act: Five years with few advances]. January. http://www.greenpeace.org/argentina/es/informes/Ley-deBosques-5-anos-con-pocos-avances/ (last accessed 2 September 2014).

Gu, Y., J. F. Brown, T. Miura, W. J. Van Leeuwen, and B. C. Reed. 2010. Phenological classification of the United States: A geographic framework for extending multi-sensor time-series data. Remote Sensing 2 (2): 526-544.

Gulezian, S. E. 2009. Environmental politics in Argentina: The Ley de Bosques. Honors thesis, University of Vermont. 
Houghton, R. A. . A. 1994. The worldwide extent of land-use change. BioScience 44 (5): 305-313.

Huete, A., K. Didan, T. Miura, E. P. Rodriguez, X. Gao, and L. G. Ferreira. 2002. Overview of the radiometric and biophysical performance of the MODIS vegetation indices. Remote Sensing of Environment 83 (1): 195-213.

Instituto Nacional de Estadística y Censos. 2010a. Provincia de Santiago del Estero, departamento Pellegrini: Población total por sexo e índice de masculinidad, según edad en años simples y grupos quinquenales de edad, año 2010 [Department of Pellegrini, Santiago del Estero Province: Total population, sex, and index of masculinity, by age in single years and groups of five]. Censo Nacional de Población, Hogaresy Viviendas 2010 [National Census of Population and Housing 2010]. http://www.censo2010.indec.gov.ar/CuadrosDefinitivos/P2-D_86_133.pdf (last accessed 14 May 2013). 2010b. Provincia de Santiago del Estero: Población total por sexo e índice de masculinidad, según edad en años simples y grupos quinquenales de edad, año 2010 [Santiago del Estero Province: Total population, sex, and index of masculinity, by age in single years and groups of five]. Censo Nacional de Población, Hogares y Viviendas 2010 [National Census of Population and Housing 2010]. http://www.censo2010.indec.gov.ar/CuadrosDefinitivos/P2-P_Santiago_del_estero.pdf (last accessed 14 May 2013). 
Kaimowitz, D., and J. Smith. 2001. Soybean technology and the loss of natural vegetation in Brazil and Bolivia. In Agricultural Technologies and Tropical Deforestation, ed. by A. Angelsen and D. Kaimowitz, 195-211. New York: CAB International. http://www.cifor.org/publications/pdf_files/books/ckaimowitz0101e0.pdf (last accessed 1 September 2014).

Land Processes Distributed Active Archive Center. 2011. MODIS Reprojection Tool (version 4.1) [computer software]. Sioux Falls, SD. https://lpdaac.usgs.gov/tools/modis_reprojection_tool (last accessed 28 August 2014).

Masialeti, I., S. Egbert, and B. D. Wardlow. 2010. A comparative analysis of phenological curves for major crops in Kansas. GIScience \& Remote Sensing 47 (2): 241-259.

Matteucci, M. n.d. K-Means Clustering. A Tutorial on Clustering Algorithms. http://home.deib.polimi.it/matteucc/Clustering/tutorial_html/kmeans.html (last accessed 1 September 2014).

MercoPress. 2010. Prime farmland in Argentina costs almost as much as in United States (October). http://en.mercopress.com/2010/10/21/prime-farmland-in-argentina-costsalmost-as-much-as-in-united-states (last accessed 21 August 2014).

Paruelo, J. M., J. P. Guerschman, and S. R. Verón. 2005. Expansión agrícola y cambios en el uso del suelo [Agricultural expansion and changes in land use]. Ciencia Hoy [Science Today] 15 (87): 14-23. (Last accessed 21 August 2014). 
Pengue, W. A. 2005. Transgenic crops in Argentina: The ecological and social debt. Bulletin of Science, Technology E̊ Society 25 (4): 314-322.

Price, J. C. 1994. How unique are spectral signatures? Remote Sensing of Environment 49 (3): $181-186$.

Python Software Foundation. 2014. Python Programming Language (version 2.7.8) [computer programming language]. Beaverton, OR. https://www.python.org/.

Sacks, W. J., D. Deryng, J. A. Foley, and N. Ramankutty. 2010. Crop planting dates: An analysis of global patterns. Global Ecology and Biogeography 19:607-620.

Sakamoto, T., B. D. Wardlow, A. A. Gitelson, S. B. Verma, A. E. Suyker, and T. J. Arkebauer. 2010. A two-step filtering approach for detecting maize and soybean phenology with time-series MODIS data. Remote Sensing of Environment 114 (10): $2146-2159$.

Sakamoto, T., M. Yokozawa, H. Toritani, M. Shibayama, N. Ishitsuka, and H. Ohno. 2005. A crop phenology detection method using time-series MODIS data. Remote Sensing of Environment 96 (3-4): 366-374.

Sala, O. E., F. S. Chapin, J. J. Armesto, E. Berlow, J. Bloomfield, R. Dirzo, E. Huber-Sanwald, L. F. Huenneke, R. B. Jackson, and A. Kinzig. 2000. Global biodiversity scenarios for the year 2100. Science 287 (5459): 1770-1774. 
Secretaría de Ambiente y Desarrollo Sustentable [Argentina]. 2007. Informe Sobre Deforestación en Argentina [Bulletin on Deforestation in Argentina]. http://www.ambiente.gov.ar/archivos/web/UMSEF/File/deforestacin_argentina_v2.pdf (last accessed 29 October 2013).

Secretaría de Desarrollo Sustentable y Política Ambiental [Argentina]. 2001. Primer Inventario Nacional de Bosques Nativos [First National Inventory of Native Forests]. http://aplicaciones.medioambiente.gov.ar/archivos/web/UMSEF/File/PINBN/nueva_ version_manuales/pinbn_manual_cartografia_sig.pdf (last accessed 13 May 2013).

Secretería de Ambiente y Desarrollo Sustentable [Argentina]. 2012. Monitoreo de la Superficie de Bosque Nativo de la República Argentina, Período 2006-2011: Regiones Forestales Parque Chaqueño, Selva Misionera, y Selva Tucumano Boliviana [Monitoring the Land Cover of Native Forests in the Argentine Republic, Period 2006-2011: Forest Regions of the Chaco, Misionera Forest, and Tucumano-Boliviana Forest]. http://www.ambiente.gov.ar/archivos/web/UMSEF/file/ LeyBN/monitoreo_bn_2006_2011_ley26331.pdf (last accessed 27 October 2013).

Senay, G. B., J. G. Lyon, A. D. Ward, and S. E. Nokes. 2000. Using high spatial resolution multispectral data to classify corn and soybean crops. Photogrammetric Engineering $\mathcal{E}^{\circ}$ Remote Sensing 66 (3): 319-327.

Shroyer, J. P., C. Thompson, R. Brown, P. D. Ohlenbusch, D. L. Fjell, S. Staggenborg, S. Duncan, and G. L. Kilgore. 1996. Kansas Crop Planting Guide. Lawrence, KS: Kansas State University, November. http://www.ksre.ksu.edu/bookstore/pubs//818.pdf (last accessed 19 August 2014). 
Soybean And Corn Advisor. 2013. Argentina monthy crop calendar. http://www.soybeansandcorn.com/Argentina-Crop-Cycles (last accessed 1 September 2014).

U.S. Department of Agriculture. 2013. Crops: Kansas agricultural statistics. USDA National Agriculture Staticstics Service Monthly Crop Production Reports (January). http://www.nass.usda. gov/Statistics_by_State/Kansas/Publications/Crops/Production/2013/cropjan.pdf (last accessed 25 November 2013).

U.S. Foreign Agricultural Service. 2013. World agricultural production. World Agricultural Production Circular Series (April). http://www.fas.usda.gov/psdonline/circulars/production.pdf (last accessed 27 October 2013).

U.S. Foreign Agricultural Service Office of Global Analysis. 2008. Crop calendar of Argentina. Foreign Agricultural Service Crop Explorer. http://www.pecad.fas.usda.gov/cropexplorer/al/ar_cropcal.htm (last accessed 1 September 2014).

Valpreda, J. R. 2012. The protection of natural forests in Argentina: Effective actions or words on paper? INK-Ideas, Numbers, and Knowledge 1 (1). http://ink-journal.com/index.php/ink/article/view/9\#.Unr-s5TF2fu (last accessed 6 November 2013). 
Volante, J. N., H. P. Paoli, A. R. Bianchi, Y. E. Noe, and H. J. Elena. 2005. Análisis de la Dinámica del Uso del Suelo Agrícola del Noroeste Argentino Mediante Teledetección y SIG. Período 2000-2005. [Analysis of the Dynamics of Agricultural Land Use in Northwest Argentina Using Remote Sensing and GIS. Period 2000-2005.] Instituto Nacional de Tecnología Agropecuaria. http://inta.gob.ar/documentos/analisis-de-la-dinamica-del-uso-del-sueloagricola-del-noroeste-argentino-mediante-teledeteccion-y-sig.-periodo-20002005/at_multi_download/file/Analisis_de_la_dinamica_del_uso_del_suelo.pdf (last accessed 13 May 2013).

Wardlow, B. D., and S. L. Egbert. 2002. Discriminating cropping patterns for the U.S. Central Great Plains region using time-series MODIS 250-meter NDVI data-Preliminary results. In Pecora 15 and Land Satellite Information IV Conferencenformation IV conference, 10-15.

. 2005. State-level crop mapping in the U.S. Central Great Plains agroecosystem using MODIS 250-meter NDVI data. In Pecora 16 Symposium, 25-27.

- 2008. Large-area crop mapping using time-series MODIS 250m NDVI data: An assessment for the U.S. Central Great Plains. Remote Sensing of Environment 112 (3): 1096-1116.

Wardlow, B. D., S. L. Egbert, and J. Kastens. 2007. Analysis of time-series MODIS 250m vegetation index data for crop classification in the U.S. Central Great Plains. Remote Sensing of Environment 108 (3): 290-310. 
Zak, M. R., M. Cabido, and J. G. Hodgson. 2004. Do subtropical seasonal forests in the Gran Chaco, Argentina, have a future? Biological Conservation 120 (4): 589-598.

Zhang, X., M. A. Friedl, C. B. Schaaf, A. H. Strahler, J. C. Hodges, F. Gao, B. C. Reed, and A. Huete. 2003. Monitoring vegetation phenology using MODIS. Remote Sensing of Environment 84 (3): 471-475. 


\section{Appendix A}

\section{Reflecting on My Field Work}

In order to complete an accuracy assessment of the classification I was to produce of agriculture in Pellegrini, I knew I needed ground truth data with which I could compare my results. As I suspected would be the case, I was unable to find any extant datasets, so I knew I would have to visit Pellegrini to gather such data.

After extensively reviewing satellite imagery of the area, I found that the fields were very large and appeared to have many roads connecting them, so I did not expect access to be problematic. While the size of the department, 6,944 square kilometers, is about the size of Delaware, I thought I would be able to cover ground fairly quickly, and allocated three weeks in Pellegrini to gather all my data.

I did have concerns to how the local people would take to my project. I would be immediately suspicious of some foreigner coming in to my town and wanting to know everything about the agricultural practices in the area. I'd be doubly suspicious when said foreigner wanted to visit every field. I actually practiced the Spanish to say, "Don't shoot! I am leaving, there is no problem." Perhaps this is just an American thing, but I was expecting at some point to be confronted maliciously with a gun. After all, I am not necessarily in favor 
of the agriculture that is taking over the area. While I would try to present my views as neutrally as possible, I anticipated conflict would be inevitable.

I arranged for a small rental car in San Miguel de Tucumán, Tucumán, a city about 150 kilometers southwest of Nueva Esperanza. I knew the roads would not be great, but I figured I should be able to get through just about anything with the rental car, except mud. Nueva Esperanza was to be my base. I planned visit areas furthest from town first, as I expected those to the most difficult to access, leaving the easier areas for last.

Just getting to Nueva Esperanza was a challenge in itself. Due to the budget fare the airline provided me in exchange for my miles, it took me some thirty six hours to get to Buenos Aires. Once there, I had to make my way around town to gather some supplies and change money. I had a short night in a hostel, as I awoke early to make a flight from Buenos Aires to San Miguel de Tucumán. Picking up my rental car at the airport in Tucumán, my stress level increased significantly: I now had to make my way around the city not as a passenger, but as a driver. Argentine traffic laws do exist, but I am not sure anyone knows what they are.

Another problem was gas. Even something as simple as purchasing fuel for one's vehicle can become a new and stressful experience in a foreign country. I was unsure what to expect; I once visited Guatemala, where drivers would pull up to seemingly random buildings around town, an attendant would appear from nowhere with a container of gasoline and a makeshift funnel made from the top of a plastic bottle, and a transaction would transpire. It turned out that the process was not so rudimentary nor much different from buying fuel back home, and my concern was mostly unwarranted. Yet, the first time I filled up, I myself 
was filled with stress.

After driving throughout Tucumán gathering supplies and getting gas, it was time for me to head to Nueva Esperanza. Despite using two maps and my GPS to navigate my way to the correct highway, I found myself on the wrong road out of town. I spent an inordinate amount of time following a long string of slow moving cars along what seemed more to be a series of main streets through a corridor of small towns than a highway. Fortunately, the road eventually led to the route I initially intended to take, and I began to make more rapid progress towards Nueva Esperanza. Unfortunately, my rapid progress quickly slowed upon reaching road construction, which persisted the next 70 kilometers or so.

My first full day in Nueva Esperanza, I planned out a long route to investigate. After talking with some workers at my hotel about security concerns, I decided I should visit the police comisaria to ask if I was going to have any problems with land owners or locals before venturing off alone. The moment I opened my mouth in the comisaría I became the attention of everyone in building. I used the best Spanish I could muster to try to tell them what I was there to do and why, but they kept passing me from person to person. Eventually, based on the questions they were asking - questions I was sure I had already answered - I realized they could not understand me. And I was struggling mightily myself to understand them.

After some two and a half hours and what must have been forty people trying to interview me, the police were finally able to track down an English teacher who taught in the local schools. With his assistance, I was able to communicate the details of my project. The police wrote up an official document vouching for my identity and purpose in case anyone took 


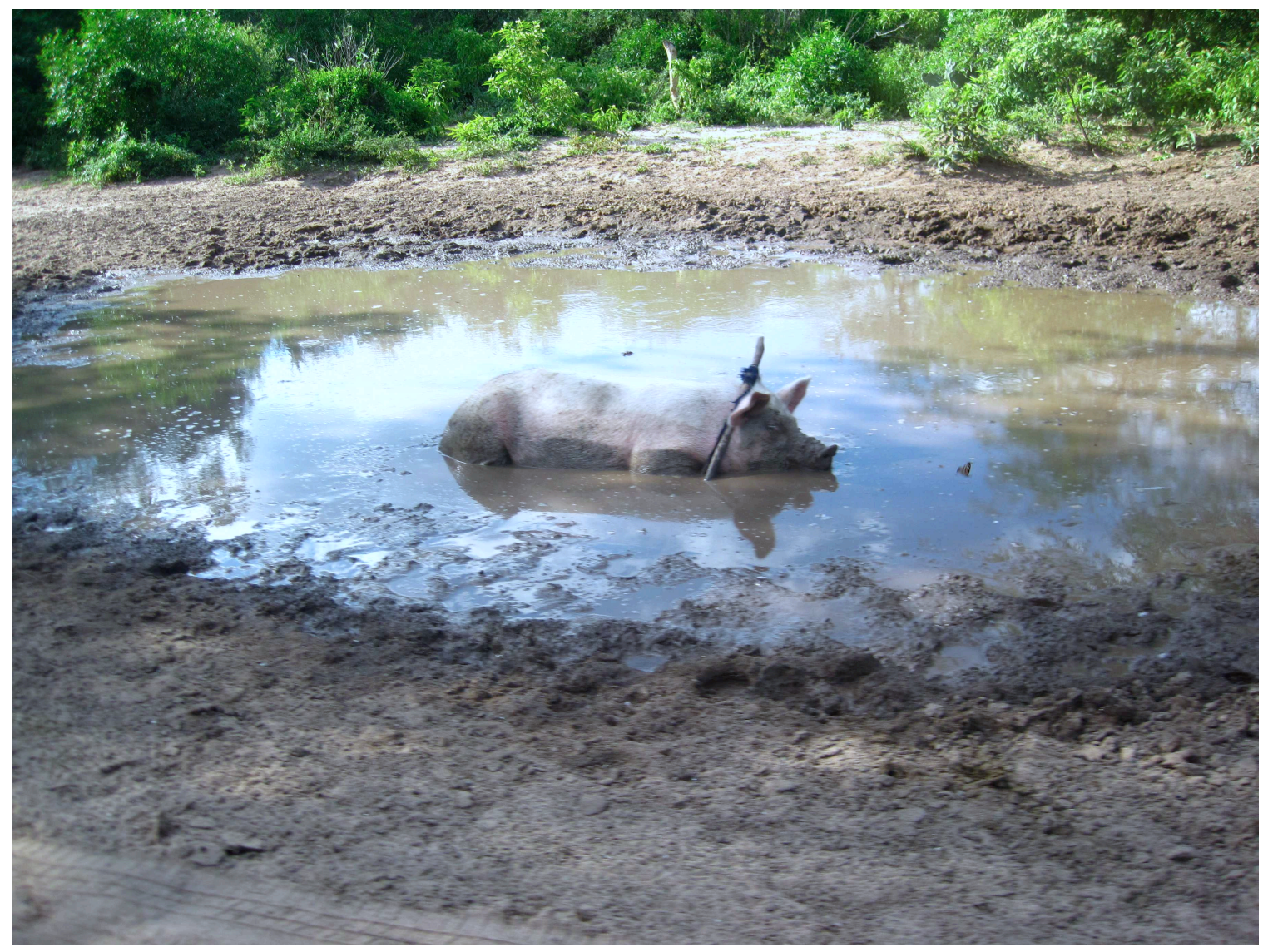

Figure A.1. Road Conditions in Pellegrini

My first day was hot, and recent rain had left large mud puddles in the middle of the road. Many pigs roam freely, and this one had found a cool place to hang out in the afternoon heat.

issue with my presence in the department. Everyone assured me that I would not have any problems with the people. Not once during my trip did I need the document.

In spite of the late hour I left the police station that first day, I naïvely attempted to complete the long route I had laid out for myself. My early progress was actually quite good; while I did not check off many points, I was able to visit quite a number of fields in a short amount of time. This only served to errantly bolster my self-confidence.

In line with my plan to visit the furthest points first, I was making my way to the far 
northwest corner of Pellegrini. About an hour and a half from Nueva Esperanza, I came to the border with the province of Salta. Looking at the Landsat imagery, I could clearly make out a long, straight road following this line. That this road was not marked on any other maps should have been a clue about what was ahead.

After a few minutes of searching and considering the numerous side paths along the main road, I determined the correct track to follow and proceeded north along it. I had a thought about the sandiness of the road, but figured as long as I maintained my momentum I would have no troubles. I did not consider the hour, which was closing in on 5:00 PM. Nor did I consider the fact that, due to my lengthly visit with the police, I had eaten only breakfast that day, hardily consisting of a lone banana.

A few minutes down the road, the situation quickly worsened. Deep ruts suddenly appeared in the middle of the road. I did my best to straddle the car over the left one with my left tires on the side of the road and my right tires in the middle. This maneuver quickly failed. Before I could react, the small, low car dropped down into the ruts. I stepped on the gas, hoping momentum would keep me from getting stuck. The sound of the sand scraping at the underside of the car was unbearable. I spotted a break in the vegetation on the left side of the road. Pointing the wheel at it, I hoped the car would break the clutches of the ruts with a sharp enough turn. Luckily, this time my maneuvering was successful, and I found myself parked on the only hard patch of clear ground in the visible surroundings.

I got out of the car and surveyed the situation. The deep, sandy ruts continued in both directions along the road. Being only a few minutes from the main road and realizing the lateness of the hour, I figured the only reasonable course of action would be to return to 
Nueva Esperanza. I contemplated driving through the small brush along the side of the road to get back to where the ruts were shallower, but my tires would be quickly deflated by the large thorns common to so many of the Chaco's plants. My only regress was to venture back the way I came.

Careful of the thorniest of plants, I turned my car around, orienting it in the proper direction. I knew I needed to do two things if I were to make it back to the main road without problems: go fast, and stay out of the ruts. I was able to do neither.

I pushed hard on the throttle, but given the gearing of the Chevy and its abysmally-small power plant, quick of the line it was not. Adding the fact that I was wholly unsuccessful at keeping out of the ruts, I managed all of three or four meters before losing all forward momentum. I tried rocking the car by repeatedly shifting between first and reverse, but only got the car more firmly planted in the sand.

Thanks to the sound advice of Polo, one of my committee members, I had actually purchased a shovel the day before in Tucumán. To say that at this point the shove came in handy would be an understatement.

I proceeded to dig out all the sand underneath the car upon which it was high centered, as well as a short path both in front and behind the car, and attempted another run at freedom. I repeated these steps numerous times with no success. Each time I felt that much closer to collapse due to my plummeting blood sugar.

Sometime into this cycle of failing to free the car, a woman approached on a motorbike with her two kids. I stood there, staring at her as she drew closer, hoping she would stop and tell me she would be right back with someone to help me out. Instead, she stopped 


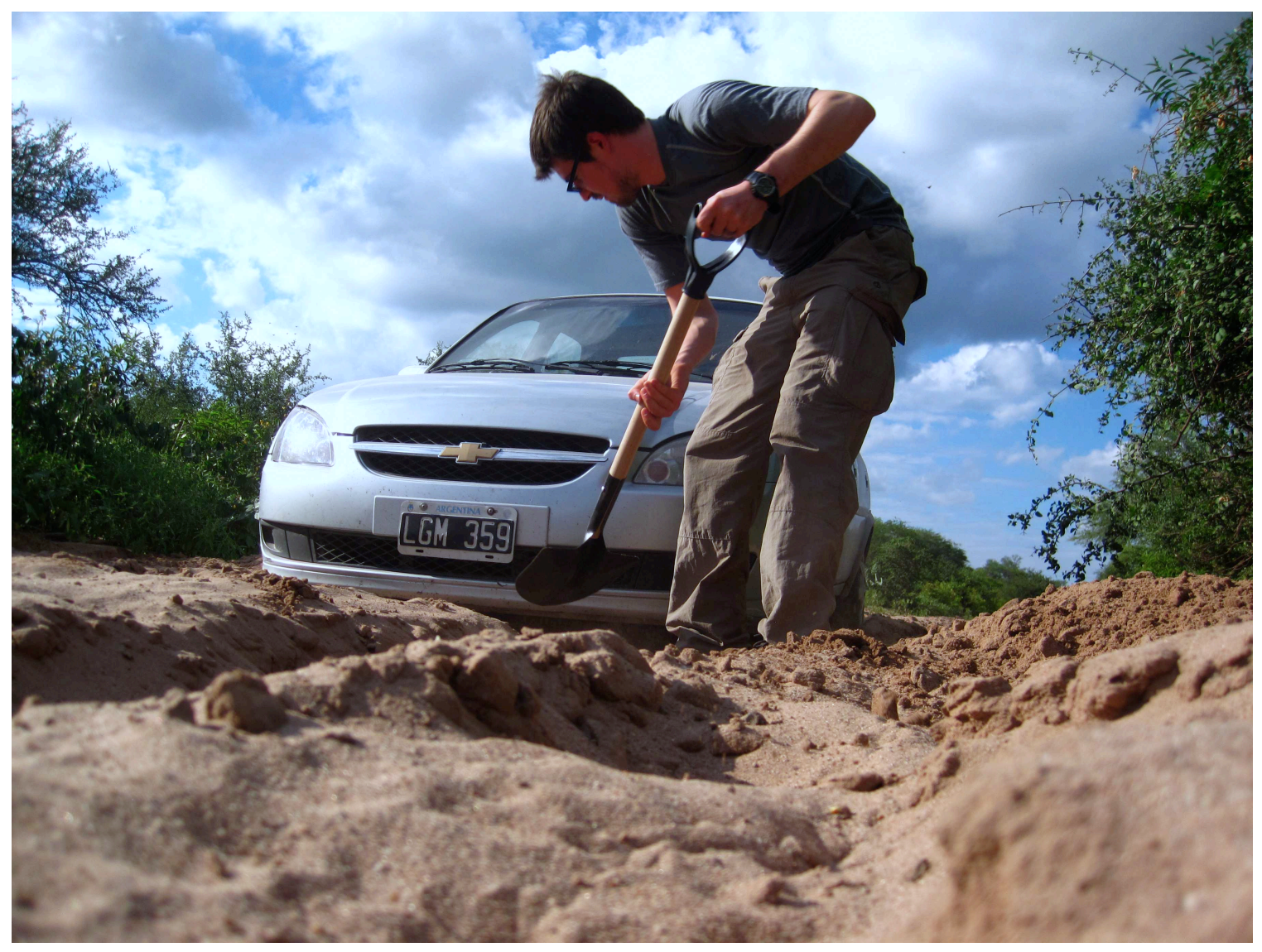

Figure A.2. Attempting to Dig the Sand out from Under the Car

and began looking at me as if amused, and I proceeded to explain my predicament as best I could. She told me in the most unhopeful manner that she would send someone my way, if she could even find someone capable of helping me. I still wonder what became of that woman and her two kids.

Eventually, I became wise to my insanity, and decided I needed to try another course of action. I recognized my problem was acceleration: each time I tried to accelerate, my tires would dig into the sand, and the ruts would present themselves as that much deeper. In order to escape the situation, I needed to be able to get my car to speed before I encountered any ruts. 


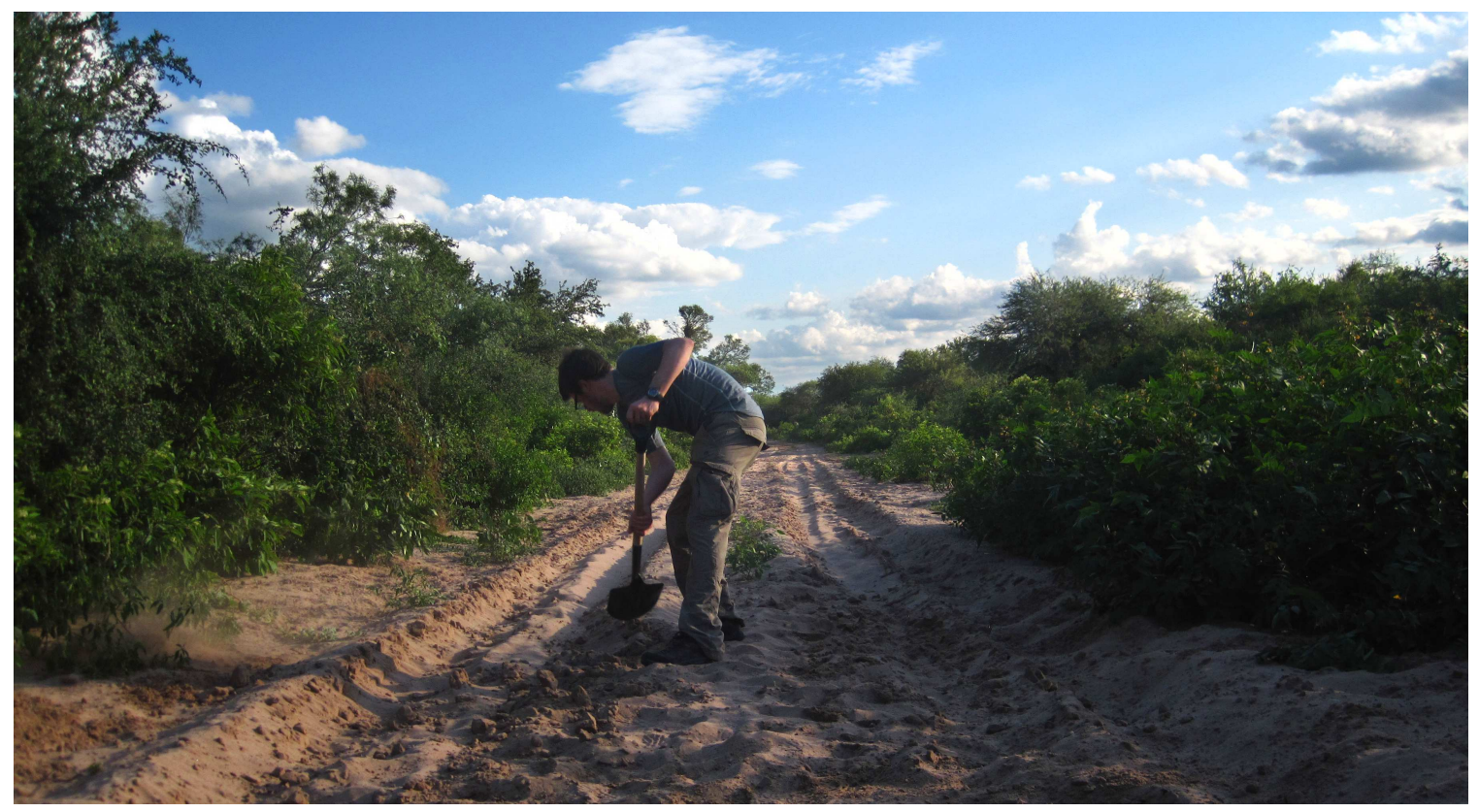

Figure A.3. Regrading the Road

I quickly went to work regrading a 30-meter length of road. By this point I was on the verge of passing out, but I knew I could not take a break. Even if it had dawned on me that I could have eaten one of my cup of noodles raw (the only food I had in the car due to an obvious misjudgment in preparation), I could not have stopped to do so. I needed to get myself out before dark or I would be stuck there all night.

After what must have been two hours of hard work in the energy-sucking heat, I finally cleared what I hoped would be a long enough section of road to get me free. Returning to my car, I resigned myself to spending the night out there, my cynicism taking hold and condemning me to an attitude of hopelessness. Yet, in spite of my natural inclination for pessimism, I found my car floating over the sand, making its way toward freedom. I did not let off the accelerator until I was sure I had loosed myself of the clutches of the sand.

At this point I felt as though my whole plan was falling apart. I had planned to visit some 


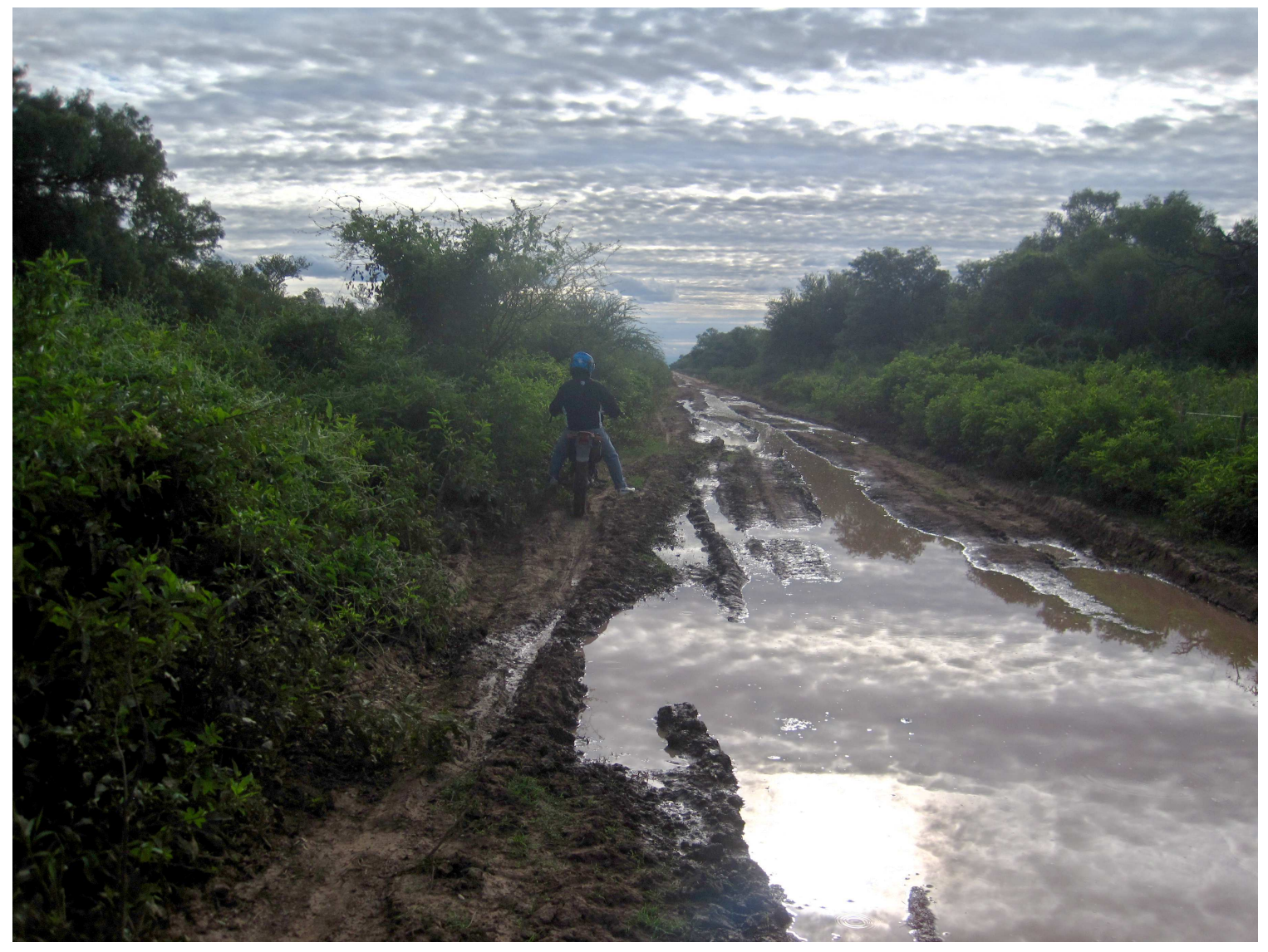

Figure A.4. One of the Many Muddy Road only Passable by Motorcycle

twenty-five points that afternoon, yet I only made it to four. I thought I could depend on myself to get around, but I realized my car was woefully incapable of passing all but the most traveled of roads. Moreover, many of the "roads" I had spotted on the satellite imagery and was depending on to get to my points were not in fact roads, but private paths behind fences, gates, and rows of bushes, accessible only to those with the permission of the landowner.

Even the accessible roads were beyond my worst nightmare. Perhaps my definition of bad was flawed; when people warned me before my trip that the roads would be bad, I just said I'd be fine. I've driven on bad roads, what could be the problem? This is not to say I did not expect to have any problems with the roads, but to see the condition of the main 
roads - all potholed, rutted, sandy, and muddy - and to get stuck on my first day out, was a humbling and troubling experience.

I needed help.

The road conditions were not the only reason either. My interactions with the police officers at the comisaría should have been a clue to the difficulties I would have with communication. Argentine Spanish is particularly difficult on its own (if one has learned Mexican and Central American Spanish as I have), but the Spanish in Pellegrini is another dialect entirely. Take Argentine Spanish, add indigenous terms and the accent and idioms of an isolated rural area, and I felt like I was trying to learn another whole language. If I could have chosen one thing to have made my trip smoother, it would have been a better command of Pellegrini Spanish. I was able to get by, and came to understand some individuals fairly well, but often I found myself unable to communicate effectively.

It became clear to me that I needed to break out of my comfort zone and rely on others. Doing so was very hard for me, as I tend to be extremely independent and am often unwilling to delegate. I set unreasonably high standards, and few, including myself, can live up to them. However, I was clearly not succeeding on my own; I needed people that could get me to the places I had to see. It turned out that the English teacher just so happened to have a motorcycle, and graciously agreed to take me out to survey points in the afternoons when he had free time. He also introduced me to a local teenager, who, despite his age, proved to be a worthy guide, as he knew the area and some English. His grandfather also had a truck, which helped us get around.

In working with these guides, I quickly came to learn that I was going to have the best 


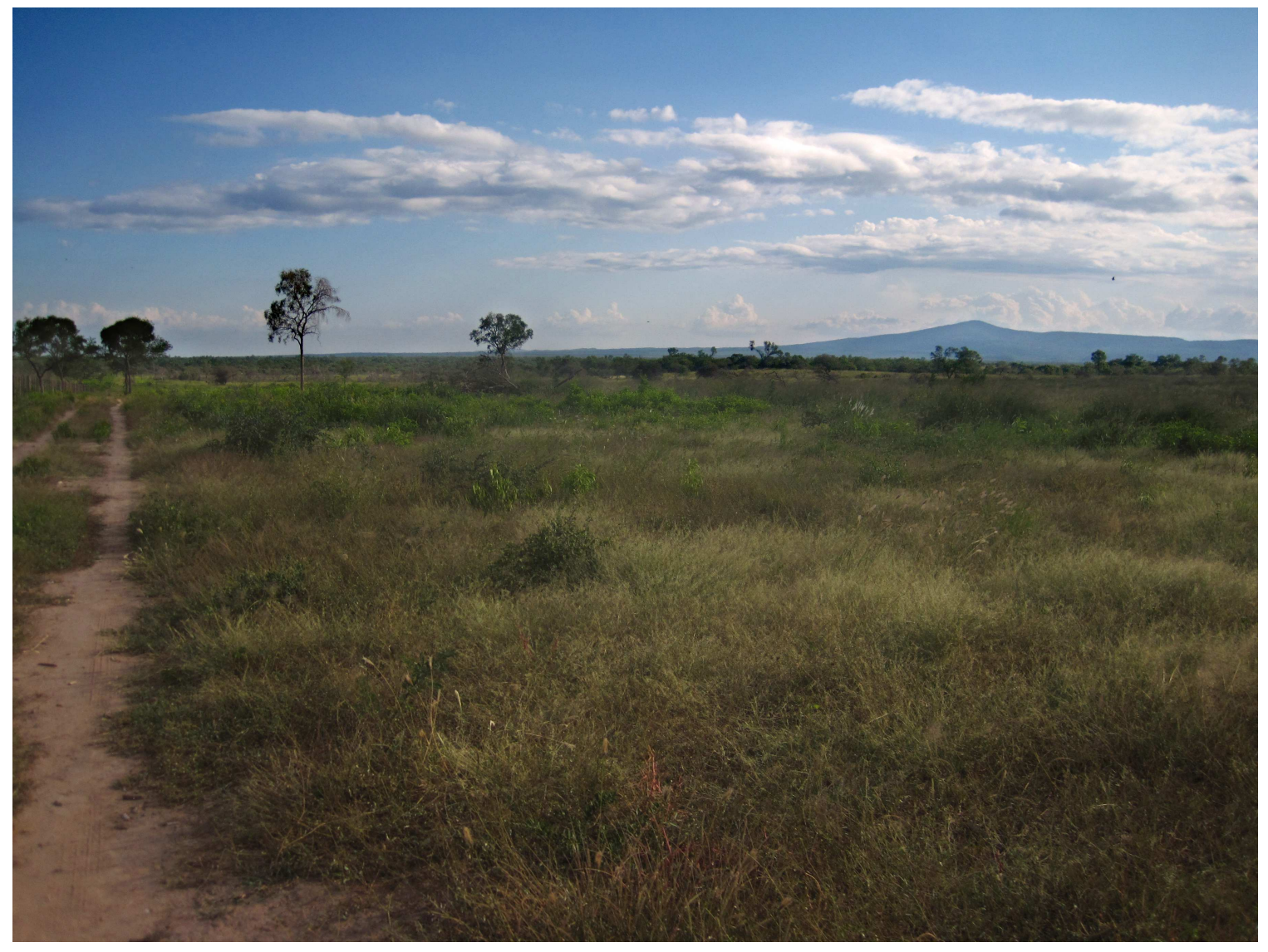

Figure A.5. Large Area Recently Cleared

I came across this area on one of my first days out. The huge area before me had just recently been deforested. What is visible here is only a small part of the whole area cleared. I was unable to find anyone who could tell me if this area was to be used for agriculture, or was cleared for other reasons.

success not in going to every survey point myself, but in talking with local farm hands and landowners. Even with the right vehicle, many places were still inaccessible, primarily because many "roads" on the satellite imagery didn't connect, or were blocked by locked gates. Luckily, I was also introduced to a police officer, who was of particular value to my project because he was responsible to know everything and everyone in Pellegrini. Not only did he know what roads I could and couldn't drive on in my car, but he also had a way with people that allowed him to get much more information than anyone else I worked with. By 


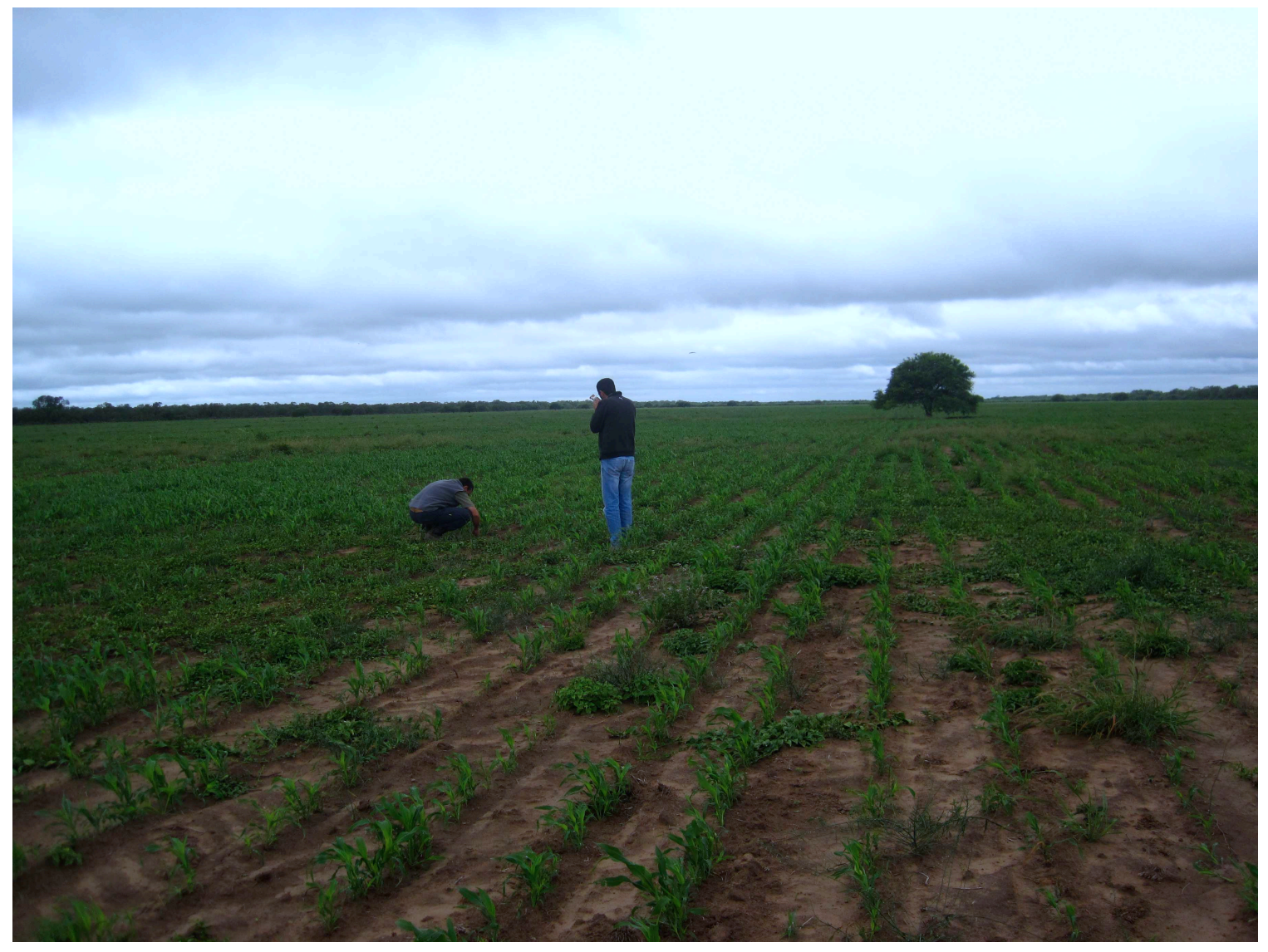

Figure A.6. Checking on Sorghum at Estancia La Armonia

I met with some agricultural engineers at a farm called Estancia La Armonia. They primarily had pasture and sorghum fields, as they raise cattle. The engineers took me out to see all their sorghum fields as they needed to check on the condition of the plants.

far, the connections I made through him supplied the majority of the data I collected. One such connection was with his cousin. His cousin was not only exceptionally knowledgable about agriculture in Pellegrini and managed quite a number of fields, but actually took it upon himself to gather some of my data for me, visiting some extremely remote fields and talking with a number of other producers he knew.

I suppose I knew, intellectually, that I would need to rely on local help, but knowing and doing are not the same. Trusting people - especially people I do not know - with a 


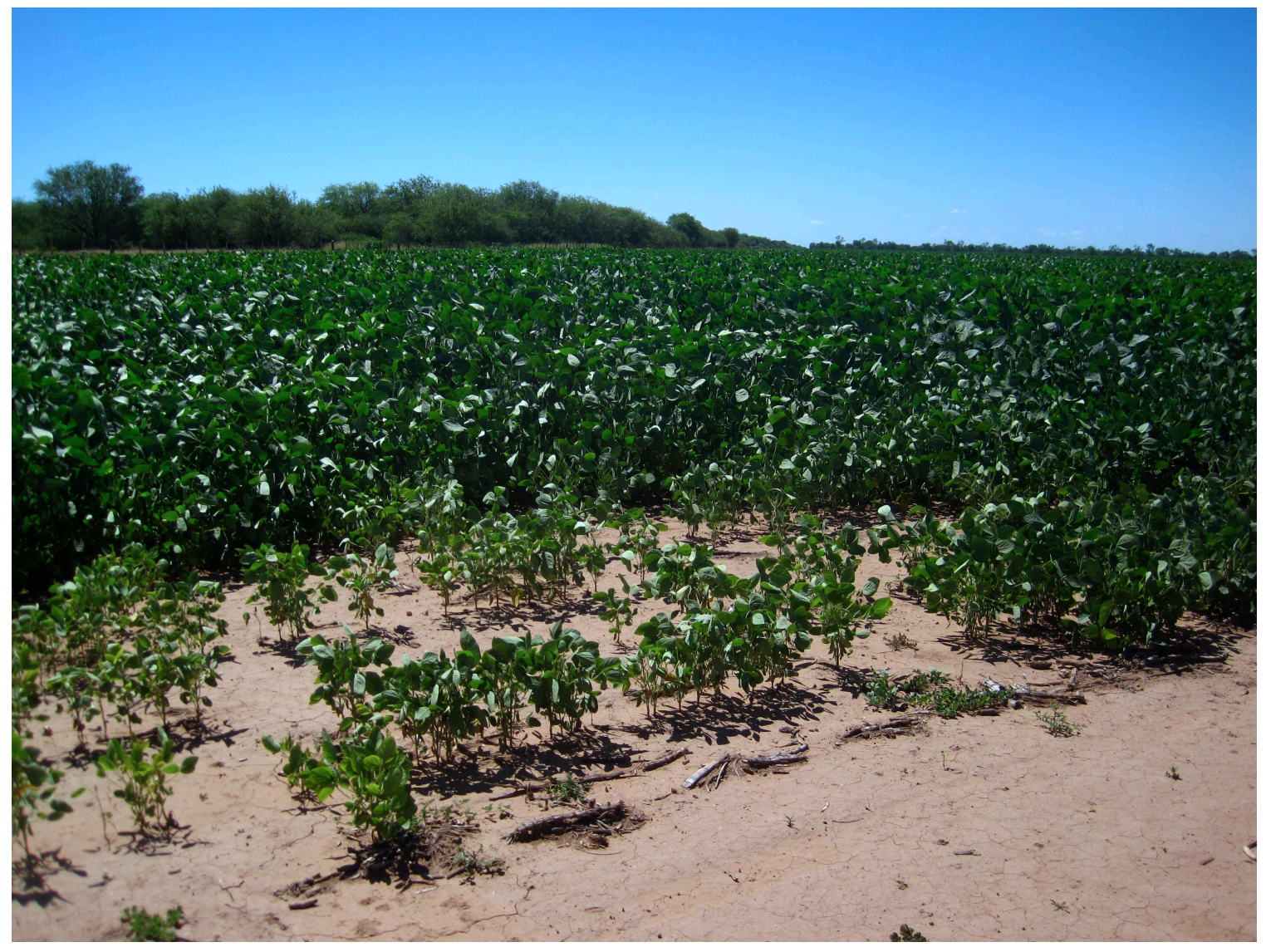

Figure A.7. A field of Pellegrini Soy

project as big and important as my master's thesis took an intentional act of letting go. I had to realize I needed skills and knowledge I did not have, but could get from those around me. This was doubly hard considering my inadequate lingual skills that, at times, caused communication breakdowns. What's more, who helped me was not my decision: the people I preferred to work with were not always available, so I had to turn to others I would not necessarily have chosen. Anyone doing fieldwork must be prepared for this reality: you can't pick the people that will be willing to help you.

The letting go and trusting did not come easy, and often didn't really happen; I merely internalized my uncertainty in others as stress. ${ }^{1}$ Yet, despite the overwhelming stress I in- 


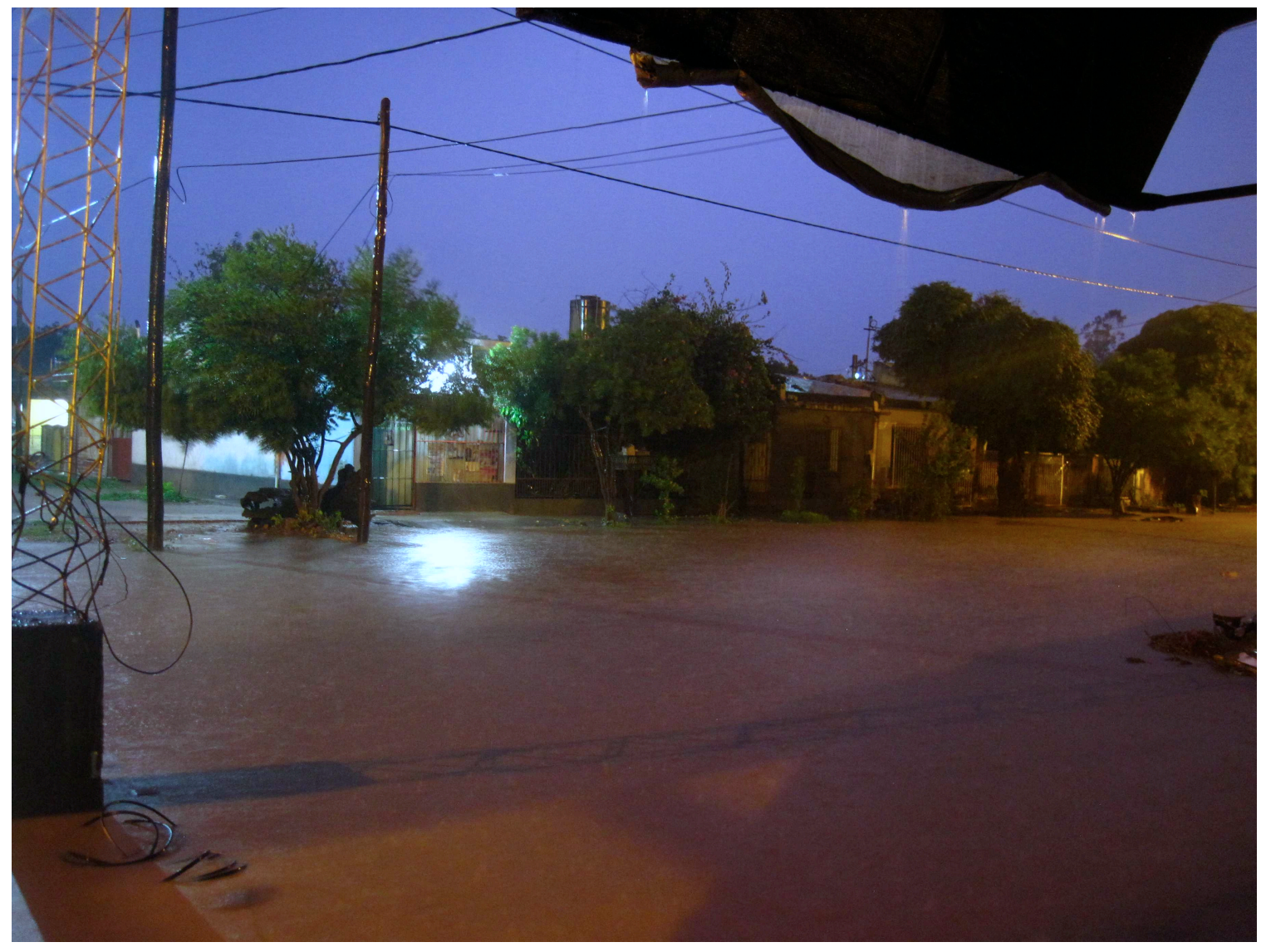

Figure A.8. Flooding Outside my Hotel During a Large Thunderstorm

One morning I awoke to the thunderous roar of down-pouring rain on the metal roof of my hotel room. I jumped out of bed and quickly picked my things off the floor as water streamed in through multiple leaks. In other parts of the hotel the ceiling had saturated and fallen in. This view from the front door shows the whole street flooded; water was lapping at the threshold.

flicted on myself during some particularly "trusting" moments, nothing bad happened. I got my data. I was never robbed. I was never left stranded in the middle of nowhere (except of my own doing). My car got repaired when it broke down and I didn't get ripped off (but that's another story...). I survived.

Another realization: you never know what someone might be able to offer you. That is, I found it important to talk with everyone around me, as hard as that was. Sometimes it was 
merely a different perspective or insight, while other times it was information which enabled me to check off a few sample points. Everyone had something to tell me. I am an introvert and not outgoing, so I tend to shy away from most people, yet I was forced to interact with everyone. Many people I honestly would have avoided under different circumstances. I even found myself doing things that made me uncomfortable just to build my credibility, such as going to the boliche at three in the morning and trying (and failing) to dance to the popular music. Surprisingly, I ran into a couple landowners in the club that night, and I could tell their impression of me was positively affected just by me being there. Joining in the cultural customs builds a rapport better than anything else. And it turned out to be fun, despite my discomfort.

These activities, and having to build relationships I would normally have avoided, pushed me outside my comfort zone and were a great opportunity for personal growth. Reflecting back on the trip and my life since returning, I see that I possess greater social confidence. I am still shy and introverted, but I no longer feel completely unable to put myself out there when meeting new people. Moreover, some of the relationships I might have otherwise written off turned into good friendships.

As is evident, I was overly confident in my abilities, and consequently made a number of incorrect assumptions about how my work would go. Thankfully, of all things, the data collection maps I made worked very well. If I were to have to plan such a project again, I would struggle to identify any changes I would make to them. I will say that I overestimated the usefulness of the maps for navigation; my GPS receiver with a satellite image and my sample points loaded onto it proved to work much better, as I didn't have to find my location 


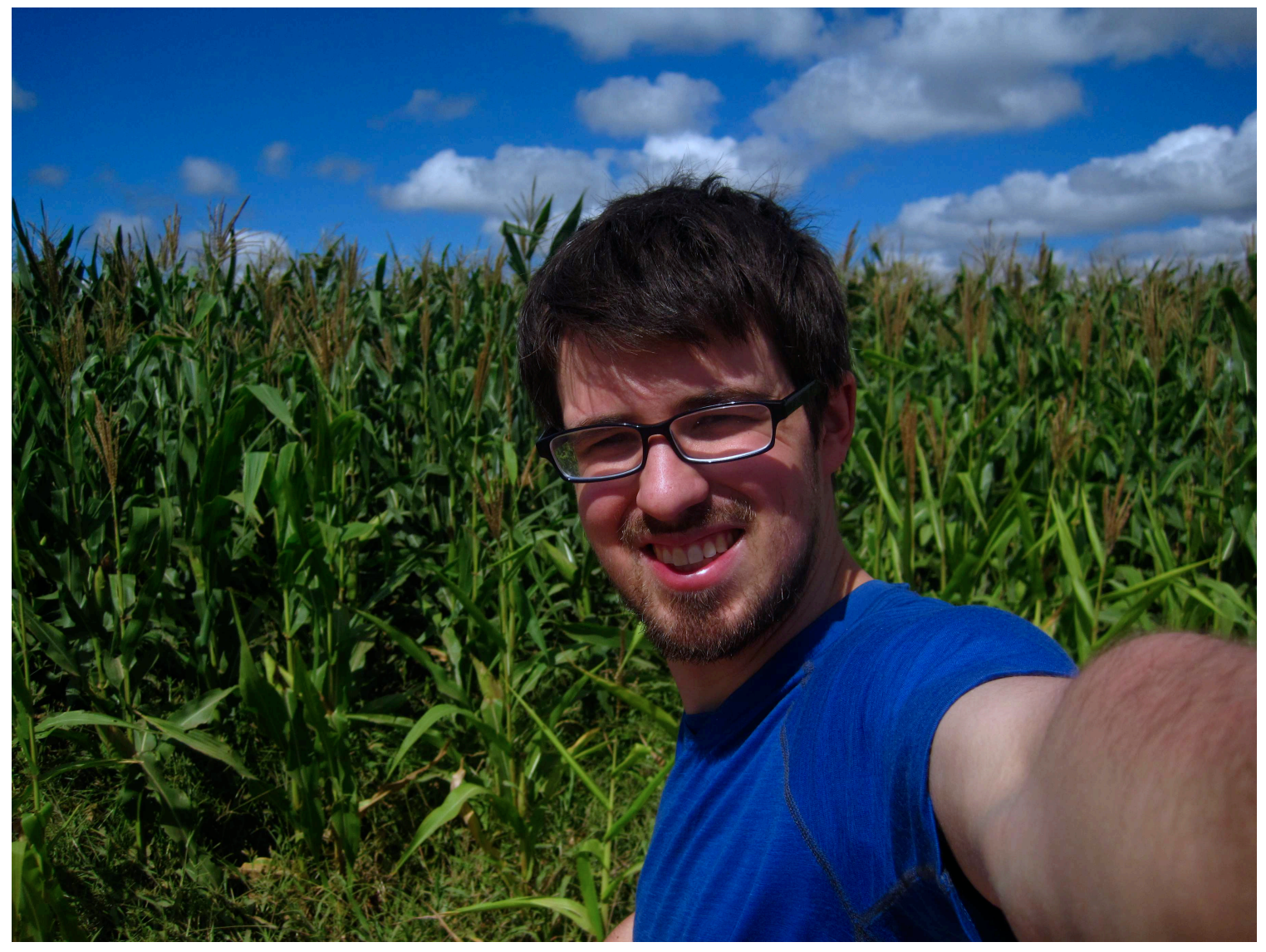

Figure A.9. Hanging Out in a Cornfield

Everyone in Pellegrini went out of their way to help. One time, I was talking to a farmer at his house when another farmer drove up to ask about something. He started talking to me and I explained why I was in Pellegrini. He said I needed to see his farm, and told me to get in my car and follow him. We drove for probably 50 kilometers, in a direction I didn't want to go, and at a speed way too fast for my poor little rental car. But we ended up at his farm, which was predominately corn, and he told me I could drive around and see each of his fields.

on the map before identifying the next turn in the road. The obviousness of this strikes me now; I am just grateful that I was able to download the necessary software, despite my phone's seemingly nonexistent data connection, to make such a solution possible. Next time I will be sure to have my GPS setup beforehand.

To reiterate: one must trust in others. They will help. I expected them to not. Perhaps 
Argentine culture is more relational, or perhaps I am simply too untrusting. In any case, it is foolish to think that one can go into another culture without the expert knowledge the locals have of the place and customs ${ }^{2}$ and be able gather any data, whether those data are of the physical geography, of technical practices, of cultural customs, or of anything else. I had to rely on wonderfully helpful people to do the actual data collection; I felt little more than an observer.

Pellegrini is now a special place to me. I was often asked by locals if I would want to move to live there. My answer has not changed - it is still too dust and flat for me - but I think of returning quite often. I hope that someday I will be able to go back and see Nueva Esperanza, how it has changed, and reunite the friends I made during my visit. I will never forget my experience in Pellegrini and its impact on my life will always remain. 


\section{Notes}

${ }^{1}$ Cultural differences were not helpful in this regard; everyone is extremely laid back. I felt as though few understood the time constraints of my work. However, I even found myself with such an attitude. Likely because of the effects of siestas and eating dinner well into the night, getting much work done after midday was hard. Additionally, the food was generally not my favorite. A lack of calories and sleep conspired to keep my energy levels depressed, so I was often content just to sit around and abide the relaxed atmosphere. Under other circumstances, I would have greatly appreciated this un-busyness. The constant assault of work is, I believe, a severe plight of the American culture, and the Argentine contentedness with leisure is refreshing. Under the looming pressure of a thesis, however, the inability of this environment to foster progress became problematic, and increased my stress levels.

Even when I was full of energy and vigor and wanted to get things done, I was often unable to do so, because of my reliance on others who were often occupied. While I felt as though I was not doing enough, I believe they felt like they and I were doing too much. Near the end of my trip, with unfinished work looming before me, I was often told that I needed to stop stressing and relax, yet the relaxing was exactly the cause of my stress! Of course they were right though, as everything was finished in time, thank in no small part to all those who worked to help me complete my project.

${ }^{2}$ Even the simple, and apparently not universal, act of knocking on the door when visiting someone's home: what is one to do when fences, dogs, and even sometimes the absence of a front door prevents knocking? Glap of course. While clapping seems an entirely logical 
course of action after the fact, it was not initially obvious to me. My ability to collect data was severely limited until I understood this and a few other basic rules and customs regarding social interactions. 


\section{Appendix B}

\section{Developing the Processing Tools}

Development has been a very iterative process, and has been primarily driven by testing requirements (see Appendix G). Many of the core functions began as simple proofof-concepts. As the codebase grew, it underwent significant refactoring. As this is my first major development project, I had to learn, the hard way, how to properly structure a project of this nature. I arrived at many key design principles quite late; some pieces of the project, consequently, were rewritten multiple times. Simultaneously, testing necessitated better ease of use and increased functionality; many features, such as the command line interface to the tools, were added as the need arose and better code organization made implementation possible. With the code as it currently stands, I believe my tools are just as easy to use as the Geographic Data Abstraction Library (GDAL) command line tools.

\section{B.1 Review of the classification process}

To reiterate, classifying imagery is a multi-step process. To do so is roughly as follows:

1. Build a multi-date image stack or time series image (TSI) from single-date images.

2. Find "pure" or mostly "pure" TSI pixels (eliminate mixels). 
3. Obtain a reference temporal signature for each of the crops to be identified in TSI.

4. Run the fit algorithm using the phenological reference curves to generate RMSE rasters for each of the input reference signatures.

5. Use the threshold tool to find the optimal RMSE threshold for each of the RMSE rasters (requires ground truth data for accuracy assessment). This process outputs the final classified image.

Steps 1, 3, 4, and 5 have been implemented as command line tools, each of which is detailed below. Step 2 is currently a manual process, the procedure for which is detailed in section subsection 4.3.3 on page 34; how this step was established is explained in section C.2 on page 124. A few other command line tools, such as to plot signatures or to create masked rasters, were also developed, but are not described here. The full source code for the project is hosted on github: https://github.com/jkeifer/pyHytemporal.

\section{B.2 Creating Time Series Images}

Before I could complete any testing, I had to first determine a way to create a chronological multi-date image stack - a time series image (TSI) - in which the values of each pixel represent the temporal signature of its contents. A TSI can be thought of as the temporal equivalent of a hyperspectral data cube, and is the primary data structure used in the analysis.

Despite the fancy terminology, however, a TSI (or hyperspectral data cube, for that matter) is merely a multi-band raster file; each band is the image from a given date. Abstracting this concept a step further, a raster is simply a multi-dimensional array. A single-band raster is therefore a two-dimensional array where the columns and rows of the image are repre- 
sented by the columns and rows of the array, and the data are single-dimension values in each cell. Adding multiple bands, or in this case dates, to the image is easily accomplished by adding a third dimension to the array.

The GDAL Python bindings and the Numpy Python module include objects and functions which make opening spatially-enabled raster files as arrays, saving arrays to spatiallyenabled raster files, and manipulating arrays in memory trivial tasks. Thus, creating a tool to build a TSI from a selection of single-date raster files was straightforward, and did not require any extensive or involved testing.

The finished tool I call the Build Multidate Image tool. It simply requires the user to specify a directory containing the MODIS .hdf files that will be assembled into a TSI. Users can specify which VI the tool should extract from the .hdf files as an optional argument; the default is to use NDVI.

\section{B.3 Extracting Reference Temporal Signatures}

I hope future libraries of temporal signatures will allow researchers to use temporal classification tools without needing to derive their own signatures. Unfortunately, such resources are not yet available. The lack of these resources necessitated that I devise a tool to create such signatures. I named this tool the Extract Signatures Tool (EST).

I decided, in order to maximize ease of use, the tool should use a set of vector points as the input. For each point, the tool finds the TSI pixel coordinates, then extracts the temporal signature of the pixel at those coordinates. Averaging the signatures extracted from all the input points gives the reference signature for that class (this process is described 
in subsection 4.3.4), which is written to a file for later use.

To implement this solution, I created a module of vector functions. The module includes a function to take the geographic coordinates of each point in a shapefile and convert them into a list of pixel coordinates in a specified image. I wrote a function to read pixel values from each band of a multi-band image given a list of pixel coordinates. The extracted values are saved in a text file for later use and in memory for further processing. Another function finds the mean value for each band, writing the result to another file with the format shown in Figure B.1. Together, these functions allow a user to read in the values of a class of pixels in a TSI defined by a series of points stored in a shapefile. Then, the user can find the average values across those points, which is the reference temporal signature of that class. Each of the text files is stored in plain-text ASCII format with the extension .ref.

I based the formatting of the .ref files on the .sig files used by ENVI for hyperspectral signatures. The plain-text file-based data format currently seems to be the best solution for storing reference signatures, as the data are simply structured and text files are highly portable. However, future implementations of the EST may benefit from a more rigid or better contained data format. In particular, a format that supports storing multiple values per date would allow multi-date, multi-band analyses.

\section{B.4 The Fit Algorithm}

Developing the fit algorithm and the corresponding tool was the most complex problem I had to solve. As described in section 2.4 (page 11), the basis of the algorithm is Equation 2.3. The equation finds the average difference (the RMSE) between a pixel signature and a 


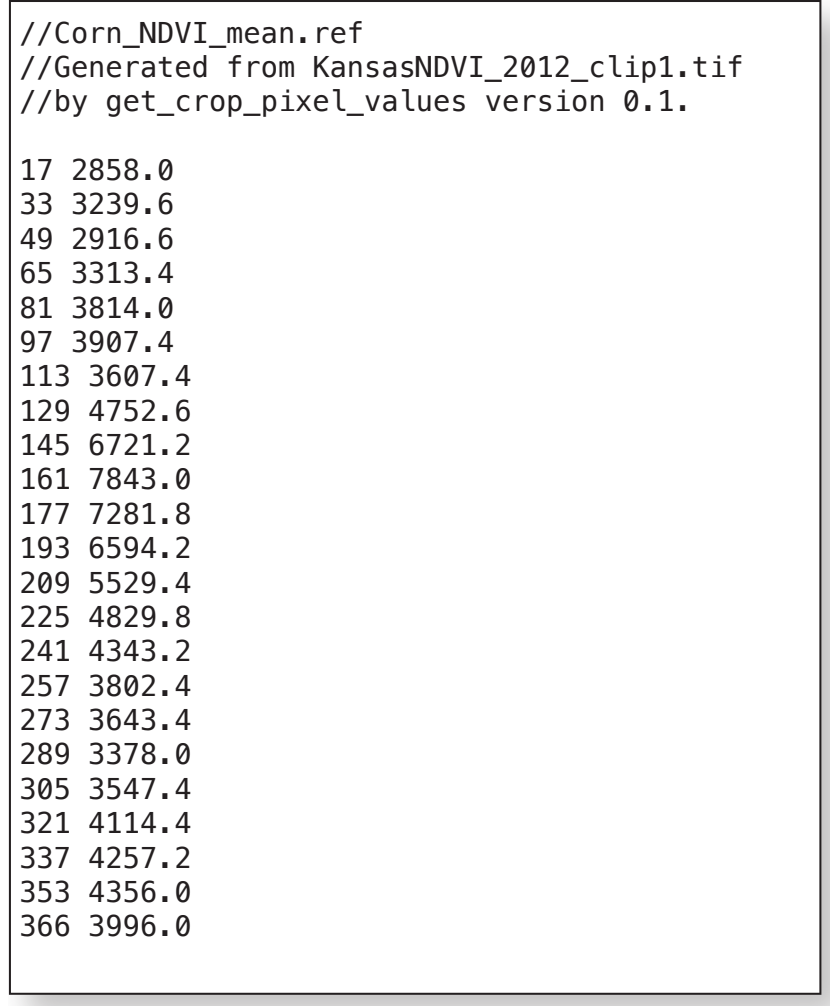

Figure B.1. An Example .ref File Used to Store Reference Temporal Signatures Comments are marked by // and each non-comment row represents a VI value (right column) for a given DOY (left column), separated by a space.

reference signature, while allowing the reference be transformed within predefined bounds. Minimizing the equation enables the degree of fit between a reference signature and a pixel signature to be quantified. To implement the algorithm, I used the minimize function in the Scipy Python package. I began by building the simplest implementation possible, testing artificial data hard-coded into the script. When that worked, I begin converting as many parameters as possible into function arguments to allow future testing of each. I continued building functionality until I had a tool capable of reading in a TSI from a user-specified file path and reference temporal signature .ref files in a user-specified directory. The tool could 
then process TSIs using signature ref files, and output a RMSE raster corresponding to each signature. The value of a pixel in a RMSE raster is the RMSE between the reference temporal signature and the same pixel in the TSI.

One clear problem early on was speed. Python's global interpreter lock (GIL), intended to increase the security and reliability of running python code, also has the consequence of limiting code execution to a single processor core. With current multicore processor designs, the GIL prohibits python from using much of the available processing resources. For example, in my eight-core computer, I was limited to using only 12.5 percent of its processing capabilities. I could only process a single signature file at a time, using just one core; consequently, the total execution time was quite lengthy. Processing five reference signatures required each RMSE raster to be produced consecutively, despite idling cores in my CPU.

To get around the GIL restrictions, I redesigned the tool to allow the use of the Python multiprocessing module. Using multiprocessing, I was able to spawn a new worker process for each reference signature (limited to a maximum number of processes as specified by the user). Each process can use up to an entire core to produce an RMSE raster. At first, this seemed to be a great solution: when using five reference signatures, I could produce all five RMSE rasters simultaneously in one-fifth the time. However, the parallel use of resources is not as straightforward as it seems.

In the later stages of testing, I began getting a serious error when attempting to generate the RMSE rasters. I am unsure why the problems started; it may be related to some code refactoring. I know that it had not occurred in earlier testing as the issue resulted in a fatal 
error: the program would try to read in a pixel from the TSI and would get a null value. Strangely, this issue would always happen on the twentieth row of the TSI. Even stranger, printing pixel values to standard out before the offending line in the program would "fix" the problem and the program would continue without errors. However, careful investigation revealed that the value returned from problem pixels was invalid (often being zero for every band, or a repeating pattern of negative numbers).

As a test, I eliminated parallelism without refactoring by using just a single worker process. Thus, the same code would run, but only a single process would access the GDAL raster object in memory. Removing concurrent access to that object also removed the errors, proving this was the problem. I tried using the multiprocessing lock construct to prevent multiple processes from reading the image object simultaneously, but this had no effect. Finally, after scouring the multiprocessing documentation yet again, I tried reading the entire TSI into a three-dimensional array in memory, as arrays seemed to be safer in concurrent applications. With this change, the problem disappeared, even using multiple processes. Additionally, this solution had the benefit of providing a moderate speed boost. Unfortunately this solution also raises the memory requirements of the program: the entire TSI must be read into memory, and all the arrays for the output RMSE rasters are also in memory. The memory footprint, consequently, is roughly equal to $s(n+1)$ where $s$ is the size, in bytes, of the TSI image, and $n$ is the number of worker processes.

Another problem I had throughout development involved pixel coordinates. Numpy arrays use matrix-style coordinates in row-column order, while GDAL functions require coordinates in terms of x-offset and y-offset, which is actually column-row order. This prob- 
lem was especially pervasive during refactoring, because in many places I switched from GDAL raster objects to arrays to boost performance. If I failed to change all the other calls to that object, I would end up accessing pixels with the wrong coordinate order. ${ }^{1}$

Using the fit algorithm is easy, as it has a command line interface through the Find Fit Tool. Due to the numerous parameters required by the algorithm, the command has many options. However, it only requires that the user specify the path to the TSI image, the TSI's start day-of-year, the TSI's day-of-year interval, and the path to the directory containing the .ref reference signature files to be fit. All of the other options require user input only if the user wants to use non-default values.

\section{B.5 Creating a Classification From the RMSE Rasters}

As described in subsection 4.3.6 on page 38, one must threshold the RMSE rasters produced by the fitting process before making a classification. To find an optimized classification (one of high accuracy), this currently involves iterating through combinations of thresholds, creating a classification and assessing the accuracy of each.

In order to automate the thresholding/classification process, I created a command line tool called the Classify Tool. The tool requires the user to specify the RMSE rasters to be classified, a truth raster, and RMSE threshold parameters. The threshold parameters allow the user to specify the starting RMSE threshold value, the number of RMSE threshold steps to test, and a RMSE threshold step value (how much to increase the threshold each step). The truth raster is ground truth for the entire classified area, and is assumed to match the RMSE rasters' pixel grids exactly and cover the same geographic extent (such 
that every pixel coordinate in the RMSE rasters and truth raster will describe the same geographic location and extent). From these parameters, the tool will automatically generate every possible threshold combination. Then, the tool will brute force through those combinations, creating a classification with each and checking the accuracy against the truth raster. Once completed, the tool outputs the classification raster with the highest accuracy, a boolean raster showing accurately and inaccurately classified pixels, and a report detailing each threshold combination tested with a confusion matrix for each. I plan to implement a method to generate an uncertainty raster (see Eastman 2012, pages 190-191) in future releases. However, it is unclear if such a raster would be meaningful, and requires testing. 


\section{Notes}

${ }^{1}$ One piece of advice to anyone developing raster tools: do not use square test rasters. Doing so hides many such bugs. For example, if the pixel coordinates are accidentally supplied in row-column format when a function is expecting column-row order, a square image will never throw an error, whereas a rectangular image will result in an error when the index of the array is out of bounds. Many otherwise subtle programming errors can be caught this way. 


\section{Appendix C}

\section{A Breakdown of all Completed Testing}

The following outlines much of the initial testing steps I took to get to the methods as presented in the body of this study. I completed five rounds of testing; this appendix is broken into sections for each round. The first section reviews my initial testing questions, my basic testing procedure, and Round 1's results and implications. Round 2 is presented in the second section, where I discuss the problems of mixels, how I eliminated them from the classification, and the results of doing so. In the third section, the Round 3 testing, I refined my reference signatures; the results of that are discussed. Round 4 investigates different date ranges for the TSI, to see how changing the dates classified affects the accuracy. The last

section briefly covers Round 5, the procedure and results of which are used and presented in the body of this study. 
Appendix C. A Breakdown of all Completed Testing

\section{C.1 Round 1 Testing: Initial Classifications}

\section{Testing Considerations}

I began testing the toolset (explained in Appendix B) with three main questions. I wanted to know how the accuracy of classification is affected by:

- The spatial distribution of pixels chosen to create the reference curves.

- The temporal distribution of pixels chosen to create the reference curves.

- The VI used for the classification.

To test these factors, I chose six small study sites dispersed across Kansas, each 100 MODIS pixels square, or about 2.3 square kilometers (Figure C.1). Using the USDA CDL as reference, I identified areas containing a mix of corn, soy, sorghum, winter wheat, and winter wheat/soybean double crop pixels. I did my best to distribute the study sites across the state to capture a wide variety of growing conditions. This task was surprisingly difficult, given the large extent of the state and the concomitant variation in growing conditions. The crops favored tended to change from one area to another. For example, few areas in western Kansas had little more than corn and wheat.

Next, I assembled a TSI for all of Kansas from 2012 MODIS 16-day NDVI composite imagery, as described in subsection 4.3.2 on page 32, except I used twenty three composites covering a date range from DOY 17 to DOY 1 of 2013. I also used this same procedure to create a Kansas TSI using the MODIS EVI composites. I clipped smaller, individual NDVI and EVI TSIs for each of the six study sites from the larger Kansas image. 


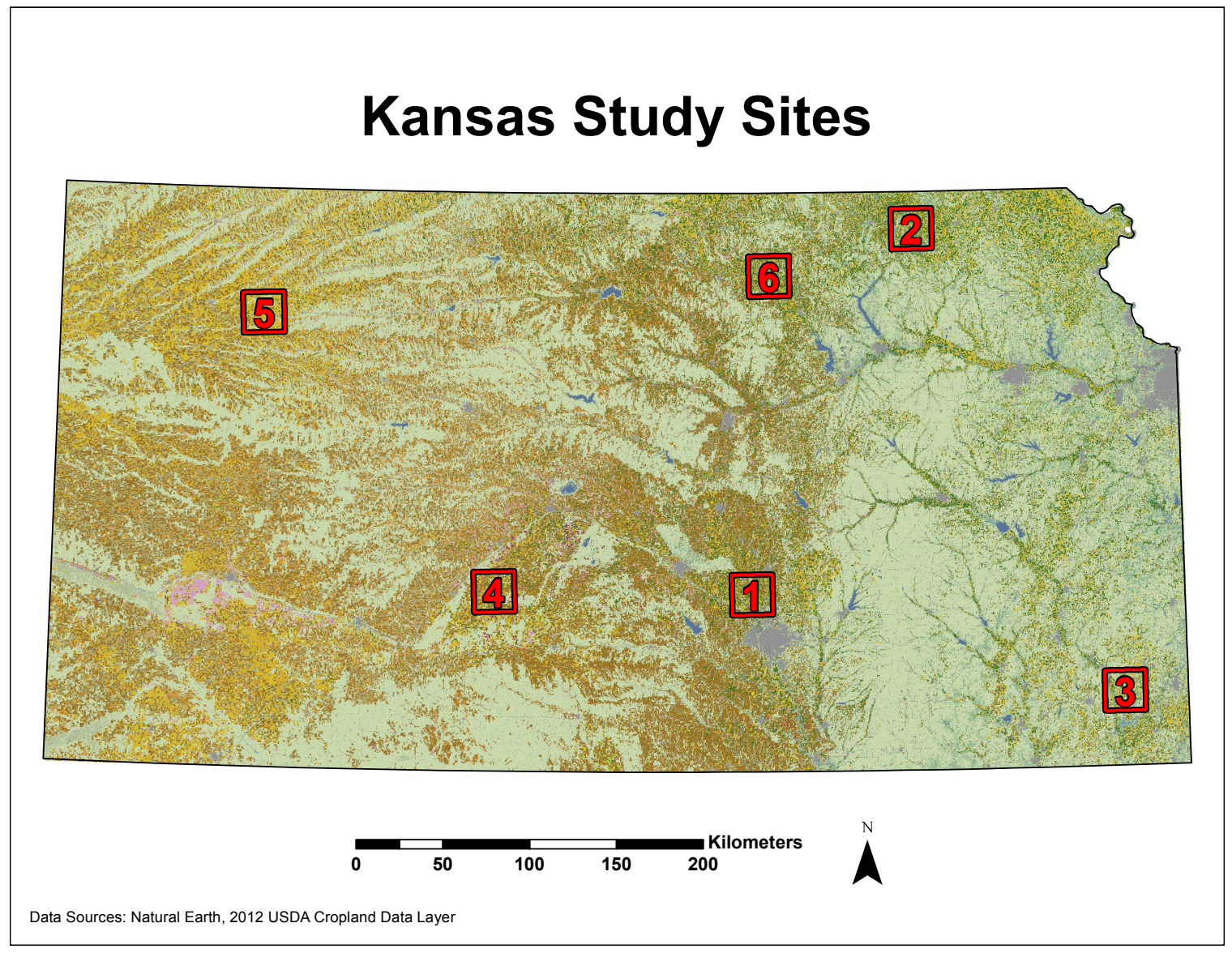

Figure C.1. The Six Kansas Study Sites

Within each study site, I found four to eight TSI pixels of corn, soy, sorghum, winter wheat, and winter wheat/soy double crop. I took care to choose only pixels in the center of fields, under the assumption such pixels would be more representative of each crop's true temporal signature. On each chosen pixel, I digitized a vector point feature (see Figure C.2 for an example from study site 1). I separated the points into separate shapefiles for each crop in each study site. I used these shapefiles as inputs to the RSG. Both NDVI and EVI reference temporal signatures were extracted for each study site TSI. Calculating the mean of the six extracted NDVI reference signatures for each crop gave me NDVI reference tem- 


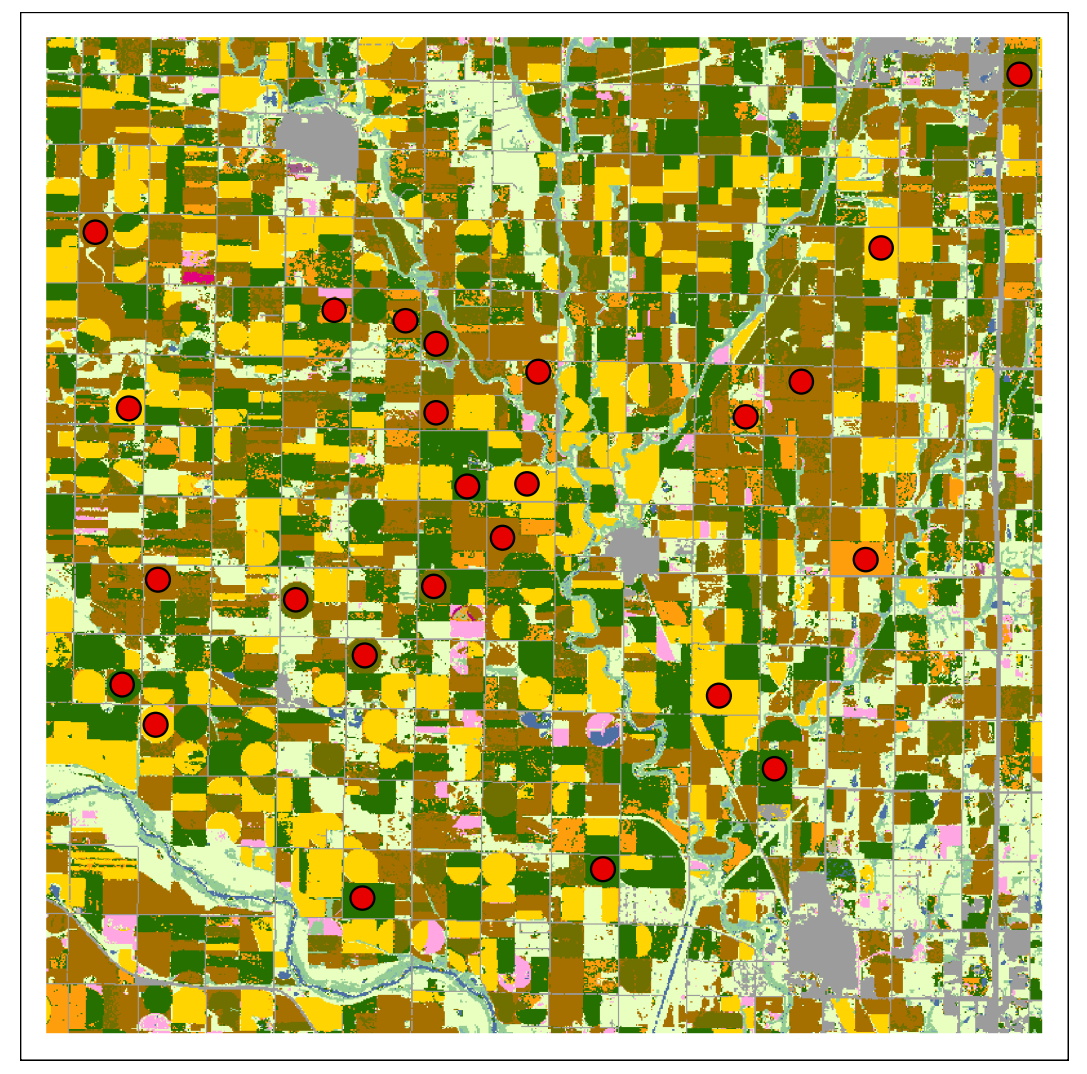

Figure C.2. Points Marking Pixels Used to Extract Reference Signatures in Study Site 1

poral signatures averaged across all six study sites. I also did the same averaging of the EVI signatures.

I created seven classifications of the EVI TSIs for each of the study sites: one classification using the study site's own reference signatures; five classifications of the study site, each one using the reference signatures derived from one of the other study sites; and one classification using the mean reference signatures averaged across all of the study sites. I repeated this procedure to produce an additional seven classifications of the NDVI TSIs of each study site. For all of these classifications I used only the corn, soy, and winter wheat reference signatures. 
By assessing the accuracy of these classifications I could test two of my initial questions: how the spatial distribution of pixels used to construct reference signatures affects the accuracy of classification, and which of the VIs had better performance. For the spatial distribution testing, I expected one of four possible outcomes:

1. Reference signatures are usable between study sites, but averaging multiple sites increases classification accuracy.

Classification accuracies will be largely independent of the reference signature set used. However, the mean reference signatures will produce a higher classification accuracy than those derived from single study sites.

2. Reference signatures are usable between study sites, but averaging multiple sites decreases classification accuracy.

Classification accuracies will be largely independent of the reference signature set used. However, the mean reference signatures will produce a lower classification accuracy than those derived from single study sites.

3. Reference signatures are not useable between study sites.

Classifications using reference signatures from different study sites will have consistently lower accuracies than the study site's own reference signatures. The mean reference signatures will perform somewhere between those of the study site in question and those of the other study sites.

4. Spatial distribution has no effect.

The classification accuracies will be relatively consistent no matter which reference signature set is used.

I initially hypothesized that averaging signatures across multiple sites would decrease the "truthfulness" of the reference signatures. That is, geographical discrepancies in season start date, maximum VI intensity, and/or season length would skew the resultant mean reference signature away from a "true" reference signature. Such skewing should negatively affect classification accuracy. I therefore expected outcome two. 
As for my third question (about temporal variation in the construction of reference temporal signatures), I decided to wait and see what results I got from these tests. If I found a wider spatial distribution of pixels negatively affected the classification accuracies, then I could reasonably conclude adding a temporal component would have a similar outcome: temporal variance, like spatial variance, would introduce discrepancies in season start date, maximum VI intensity, and/or season length.

\section{Round 1 Results and Discussion}

The accuracies of the fourteen classifications testing the spatial distribution of reference signatures and the performance of the two MODIS VIs is shown in Table C.1. Some clear patterns are immediately obvious. First, none of the classifications had a very high degree of accuracy; study site 3 stands out with much higher accuracies than the rest. Second, NDVI resulted in a higher top accuracy for every study site. Third, aside from study site 5 in the EVI-based classifications, each site's highest accuracy occurred when its own signatures were used for the classification. Last, all of the mean reference signature classifications are between the lowest and highest accuracies for each study site.

A more detailed examination of of study site 3's results shows that the increased accuracy is due to the fact that relatively few of the pixels in the study site are crop pixels (Table C.2). A higher accuracy thus results because so many pixels were left unclassified as "other."

As for NDVI versus EVI, the results show that NDVI consistently has higher classification accuracies. For this reason, I chose to continue all the following tests using NDVI. However, the EVI results were not far behind, so I am hesitant to conclude that future opti- 
Table C.1. Overall Percent Accuracy for Each Round 1 Classification, by Study Site (SS). Green cells indicate highest accuracy for each SS.

\begin{tabular}{|c|c|c|c|c|c|c|c|}
\hline \multicolumn{8}{|c|}{ EVI } \\
\hline & \multicolumn{7}{|c|}{ Reference Signatures Source } \\
\hline & SS 1 & SS 2 & SS 3 & SS 4 & SS 5 & SS 6 & Mean \\
\hline SS 1 & 55.61 & 45.44 & 45.34 & 54.36 & 43.83 & 49.06 & 49.63 \\
\hline SS 2 & 53.11 & 64.93 & 50.00 & 47.86 & 40.79 & 42.60 & 53.69 \\
\hline SS 3 & 73.87 & 69.40 & 75.23 & 73.53 & 70.57 & 71.86 & 73.71 \\
\hline SS 4 & 50.42 & 45.54 & 49.26 & 53.46 & 45.30 & 49.66 & 52.54 \\
\hline SS 5 & 42.05 & 45.62 & 56.00 & 54.68 & 55.06 & 49.02 & 40.29 \\
\hline SS 6 & 47.78 & 48.66 & 38.43 & 47.53 & 41.60 & 49.55 & 48.44 \\
\hline
\end{tabular}

Table C.2. Round 1 Testing: Study Site 3 Best Accuracy, Using NDVI Data

\begin{tabular}{|c|c|c|c|c|c|c|c|}
\hline \multicolumn{8}{|c|}{ Reference Data } \\
\hline & & Corn & Soy & Wheat & Other & Total & User Acc. \\
\hline \multirow{6}{*}{ 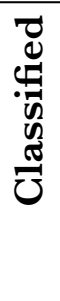 } & Corn & 861 & 133 & 0 & 334 & 1328 & $64.83 \%$ \\
\hline & Soy & 28 & 558 & 13 & 198 & 797 & $70.01 \%$ \\
\hline & Wheat & 2 & 4 & 23 & 37 & 66 & $34.84 \%$ \\
\hline & Other & 884 & 424 & 74 & 6427 & 7809 & $82.30 \%$ \\
\hline & Total & 1775 & 1119 & 110 & 6996 & 10000 & \\
\hline & cer Acc. & $48.51 \%$ & $49.87 \%$ & $20.91 \%$ & $91.87 \%$ & & \\
\hline
\end{tabular}

Overall Accuracy: 78.69\%

Kappa: 0.49 
mizations could not make EVI-based classifications as or more accurate than NDVI-based classifications. Further testing is required in this regard.

That each study site had its highest accuracy classification using its own references signatures was probably the most significant finding of the test. This result was not wholly unexpected: even if temporal signatures are largely location-independent, there is likely to be some location-specific phenomena influencing the shape of the signature curves. In some cases, it appears that some classifications using other study site reference signatures were of similar accuracy. For instance, the study site 1 NDVI classification using study site 4's signatures has an accuracy of 60.7 percent, versus 61.1 percent with study site 1's own signatures. However, in all other cases (using signature from study sites 2, 3, 4, 5, and 6), the study site 1 NDVI classification accuracies are about 10 percent lower.

The accuracies of the mean reference signature classifications are generally low. They are never the worst, which may suggest that it is better to average a greater number of pixels together if the representative-ness of the chosen pixels cannot be established. However, this conclusion would support a more selective and refined approach to creating reference signatures: don't try to average out bad pixels, eliminate them in the first place.

Looking back on the outcomes I outlined above, I actually found none of them completely captured the behavior shown in the results. I did not see relatively consistent classification accuracies independent of the set of reference signatures used, but I also found that the reference signatures from some study sites did well at classifying others. The mean signatures were also somewhat in the middle: generally they did not do terribly well, but sometimes came close. The best interpretation I could make of these results is that, under 
the right circumstances, reference signatures can be used to classify other areas. However, the cases where the reference signatures were not portable were concerning, as were the low overall accuracy levels. I began to consider that I might not be able to answer the initial testing questions. Instead, I realized I needed to take a step back and better explore what factors affect the classification process.

\section{C.2 Round 2 Testing: Eliminating Mixels}

\section{Pre-testing Investigation}

I began my Round 2 testing by diving back into my Round 1 results. I wasn't sure exactly what I needed to test, but I knew my previous results held more clues. For the sake of simplifying my investigation, I decided to focus solely on study site 1 (SS1) for the remainder of my testing. If I could boost the accuracy of its classification, I would identify some of the factors influential in the classification process. I chose SS1 over the others as it has the best variety of crops in which I am interested, and also includes some large non-crop areas of different land cover types. This mix seemed to offer the best testing environment of the six initial study areas.

First, I studied the classification results for SS1 from Round 1 produced with its own reference signatures (Figure C.3). I noticed that the major patterns generally matched the CDL fairly well. If the classification looks correct, however, where were the errors? Obviously there should be many incorrect pixels, as this classification only had an accuracy of 61.1 percent. Yet they weren't obvious at first glance. 


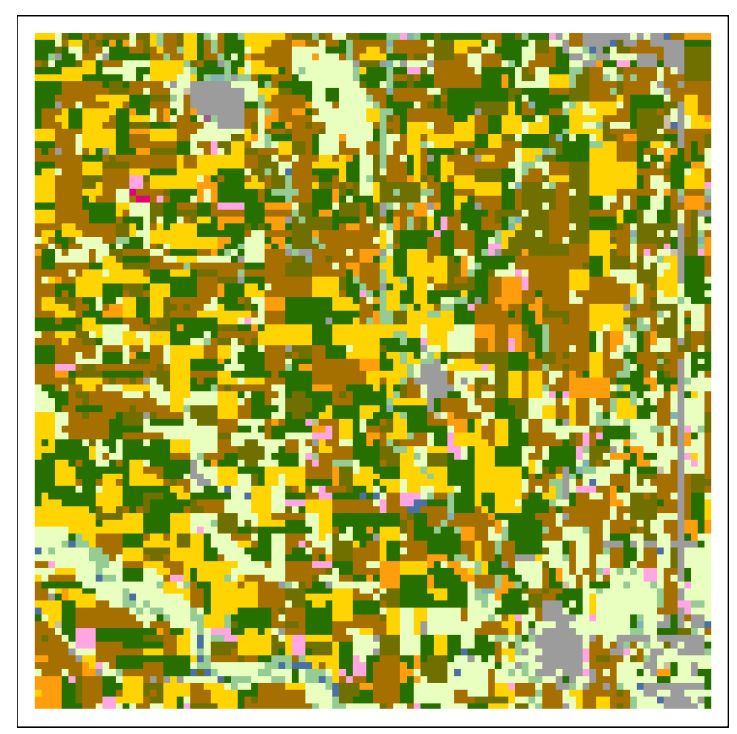

(a) The 2012 CDL for SS1

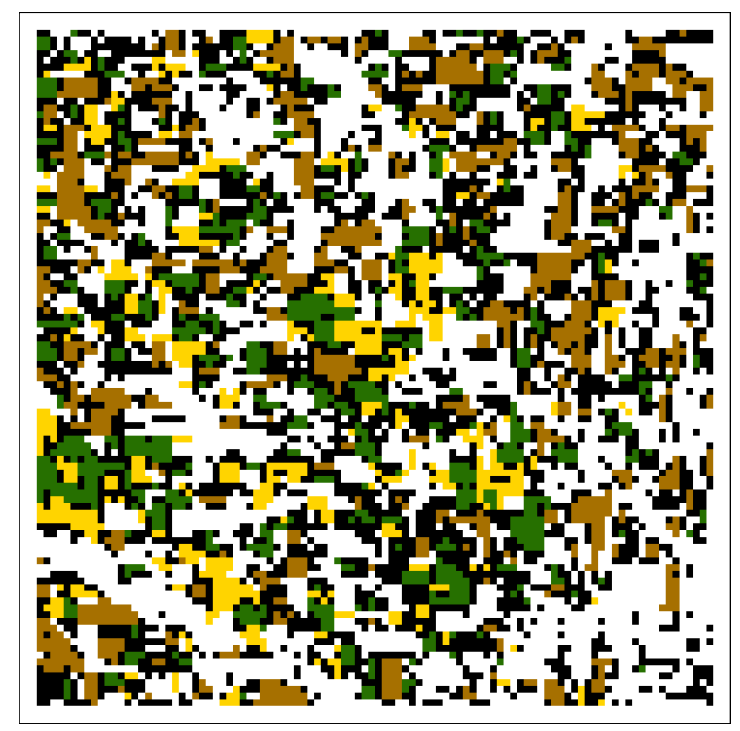

(c) Correctly classified pixels

Incorrect pixels are black

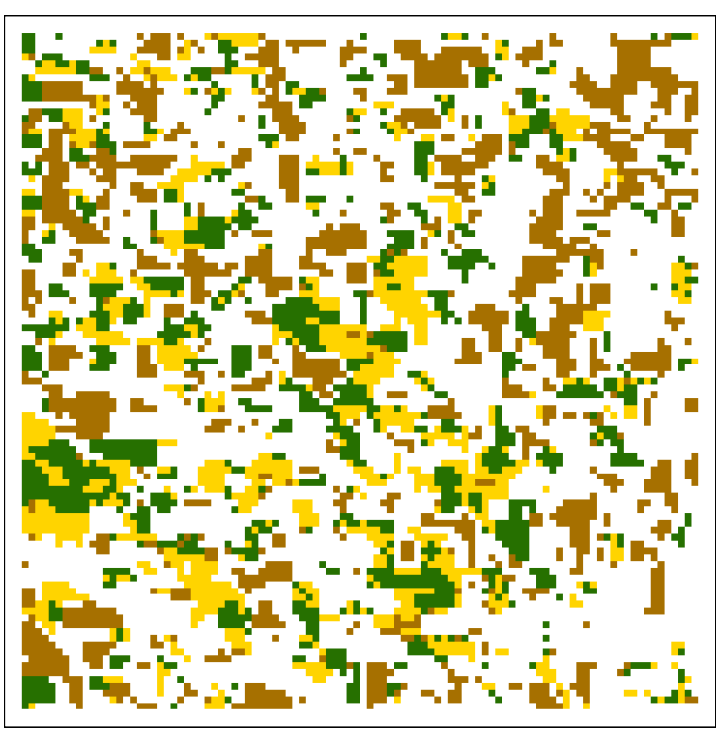

(b) Round 1 classification using SS1 signatures

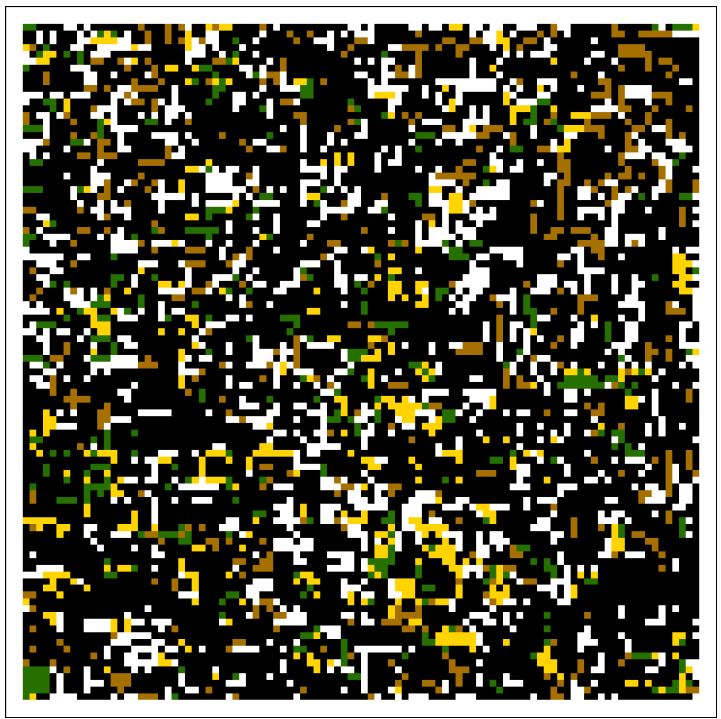

(d) Incorrectly classified pixels Correct pixels are black

Figure C.3. Round 1 Testing: Study Site 1 Classification.

Corn pixels are shown in yellow, while soy pixels are dark green, and winter wheat pixels are brown. Notice that the classification in (b) looks to do a decent job of capturing where the different crops occur in (a), but (c) and (d) show numerous errors on the edges of fields, and some class confusion. 
Table C.3. Round 1 Testing: Study Site 1 Best Accuracy, Using NDVI Data

\begin{tabular}{|c|c|c|c|c|c|c|c|}
\hline \multicolumn{8}{|c|}{ Reference Data } \\
\hline & & Corn & Soy & Wheat & Other & Total & User Acc. \\
\hline \multirow{7}{*}{ 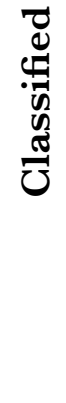 } & Corn & 657 & 299 & 16 & 174 & 1146 & $57.33 \%$ \\
\hline & Soy & 121 & 863 & 27 & 268 & 1279 & $67.47 \%$ \\
\hline & Wheat & 137 & 95 & 1250 & 379 & 1861 & $67.17 \%$ \\
\hline & Other & 688 & 803 & 885 & 3338 & 5714 & $58.42 \%$ \\
\hline & Total & 1603 & 2060 & 2178 & 4159 & 10000 & \\
\hline & Producer Acc. & $40.99 \%$ & $41.89 \%$ & $57.39 \%$ & $80.26 \%$ & & \\
\hline & & & & & \multicolumn{3}{|c|}{$\begin{array}{r}\text { Overall Accuracy: } 61.08 \% \\
\text { Kappa: } 0.43\end{array}$} \\
\hline
\end{tabular}

To find these incorrect pixels, I created an image with of the correct pixels and an image of the incorrect pixels (Figure C.3c and Figure C.3d). In the former, I noticed that many of the black incorrect pixels seemed to fall on the edges of fields. In the latter, I noticed some class confusion, a finding reinforced by the confusion matrix for this classification (Table C.3).

The class confusion seemed to be a problem, but how to begin to remedy it was not obvious. That so many border pixels were incorrectly classified, conversely, suggested that this classification method struggles when pixels have more than one land cover. Such "mixedpixels" are often termed "mixels."

The problem with mixels is that each land cover in a mixel has a different temporal signature. The different signatures are aggregated at the pixel level and become mixed, creating a new signature representing that specific mixture of individual signatures. This problem is not unique to my temporal data; all raster land cover data have mixels. Users of spectral data even have spectral unmixing tools to extract subpixel spectral information.

In my case, the large size of the MODIS pixels increases their possible effect on classi- 
fication accuracy. Many different land covers can be included within a 231-square-meter area. The large pixel size also means that a much greater percentage of the study area is composed of mixels than if a smaller pixel were used.

For these reasons, I hypothesized the low classification accuracy was partially because mixels could not be processed accurately by the fit algorithm. In other words, if two (or more) crops are mixed within a pixel, the curve of that pixel's values will be a blend of both crops' phenological signatures, and neither of the two crops' references signatures will fit the pixel well. Moreover, the crop which may occupy the majority of the pixel's area may not be the largest contributor a pixel's values. That is, the relationship between land covers in a mixel may not be linear. For instance, a mature crop may drive up the VI values for a pixel, even if that crop is in the minority of the pixel. Consequently, I determined I needed to find a way to remove mixels from the classification.

\section{The Testing Process}

The first step in removing mixels was to create a vector grid matching the pixel grind of the SS1 MODIS TSI. Then, I converted the 30-meter CDL raster ground truth dataset to vector polygons. Intersecting the CDL features with the TSI pixel polygons combined the geometries of both. Consequently, pixel polygons that fell within a continuous land cover area were undivided, but mixels were split up into multiple polygons by each land cover class within them. To find all the non-mixels in the study area, I selected all features with an area close to that of a full MODIS pixel from the intersected polygon features. Specifically, I chose to select all features greater than or equal to 53,000 square meters in area (or 98 percent of 


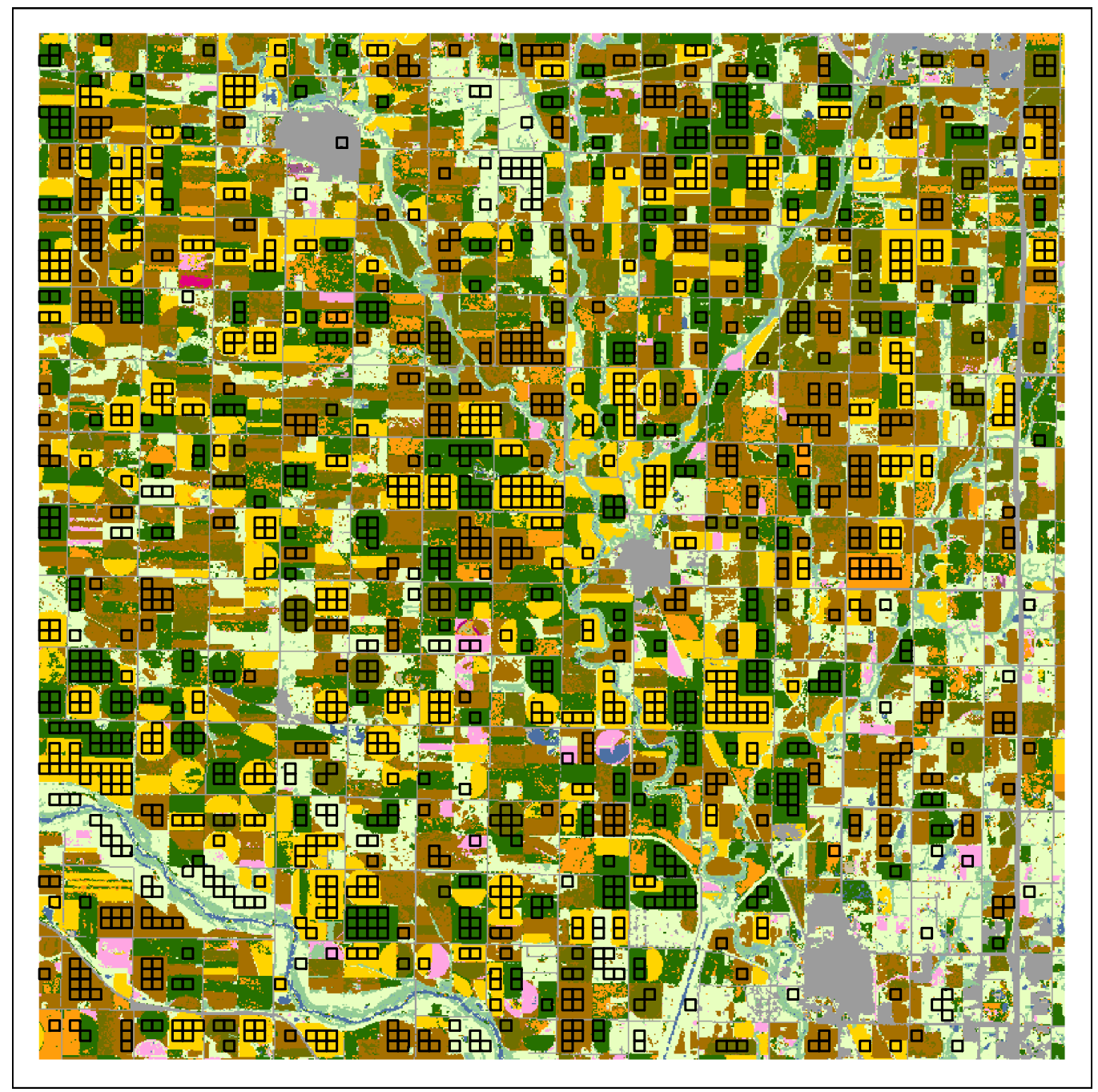

Figure C.4. Pure Pixels Delineated in Study Site 1

a full MODIS pixel, which is 53,824 square meters). I also manually added two sorghum pixel features that were not selected via this process because of the low number of sorghum pixels retained. The result, shown in Figure C.4, was 1,359 selected features. These features can be thought to represent MODIS pixels that have "pure" signatures: each pixel has only one land cover contributing to its temporal signature, so each should be representative of its class. 
To allow me to classify only these pure pixels, I found the centroid of each of the selected pixel polygon features. The subset option of the Find Fit Tool uses a shapefile of point features to create a list of pixel coordinates in the TSI to process. Only these 1,359 pixels were fit with the reference signatures. All the other pixels were assigned NoData (-3000 is the MODIS NoData value). Each of the other classification steps were the same as in Round 1, except the NoData values in the RMSE rasters were ignored by the Classify tool when considering accuracy.

\section{Round 2 Results and Discussion}

The pure-pixel-only classification is shown in Figure C.5, and its confusion matrix is Table C.4. The confusion matrix shows the vast majority of errors are errors of commission in the corn class. Almost one third of the soy pixels and close to half of the "other" pixels are classified as corn. A map with the incorrect pixels highlighted is shown in Figure C.6. That corn and soy have similar signatures may suggest that those crops will always have some confusion. In other words, because of the similar shape and close maximum dates of early soy and late corn, they may not be differentiable to the fit algorithm. However, if this hypothesis were true, I expected to see the confusion in both directions, with a greater number of corn pixels wrongly classified as soy. Additionally, this hypothesis does not explain why so many "other" pixels were classified as corn. Thus, I began to consider that the reference signatures I created might not be accurate.

To investigate this idea, I plotted the reference signatures I extracted from SS1 (Figure C.7). Comparing the plotted signatures to those shown in phenological classification 


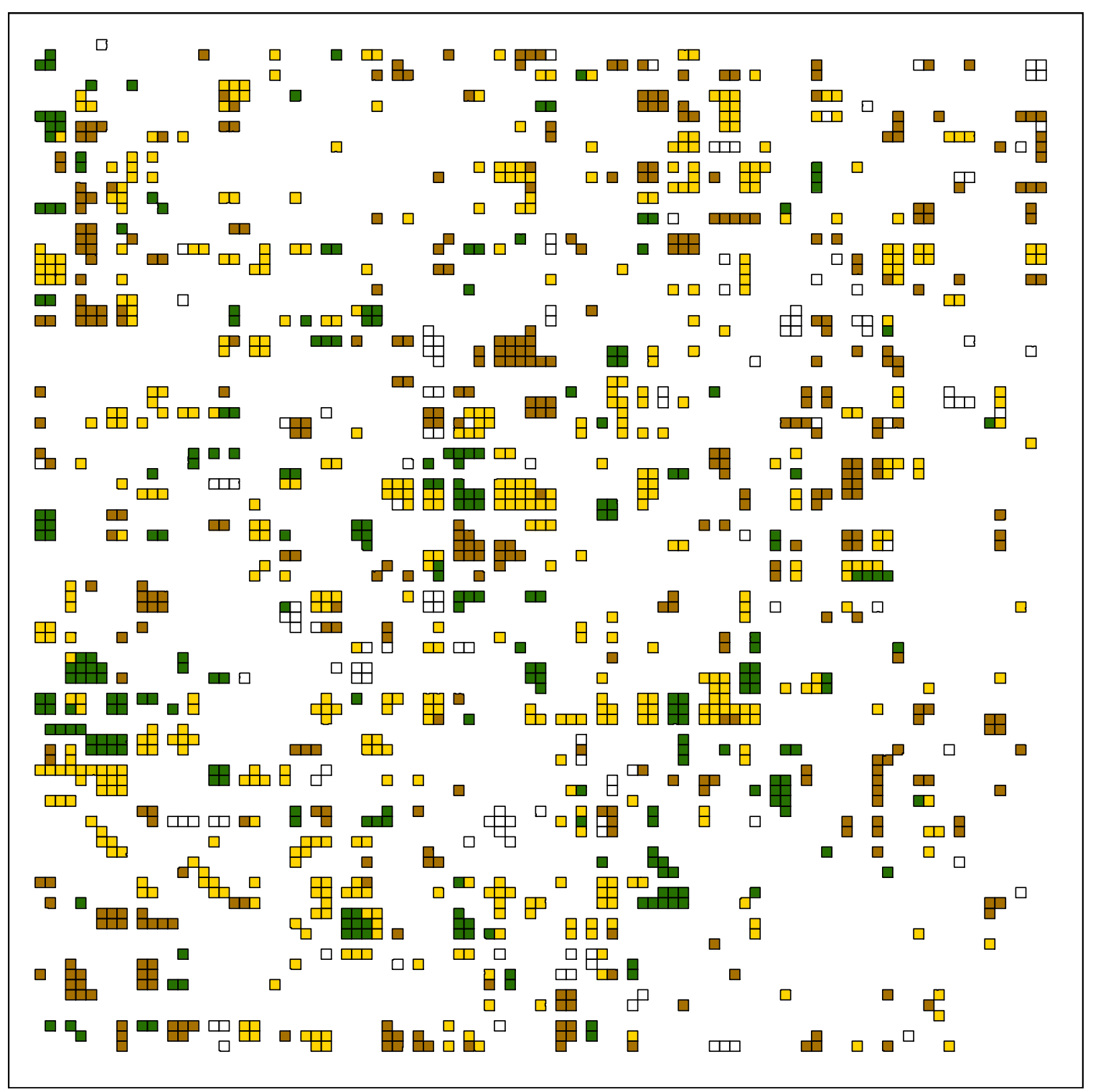

Figure C.5. Round 2 Testing: Classification of Study Site 1 Pure Pixels

The classified pixels are outlined in black. Green pixels are soy, yellow are corn, and brown are winter wheat. The outlined white pixels were classified as other. 


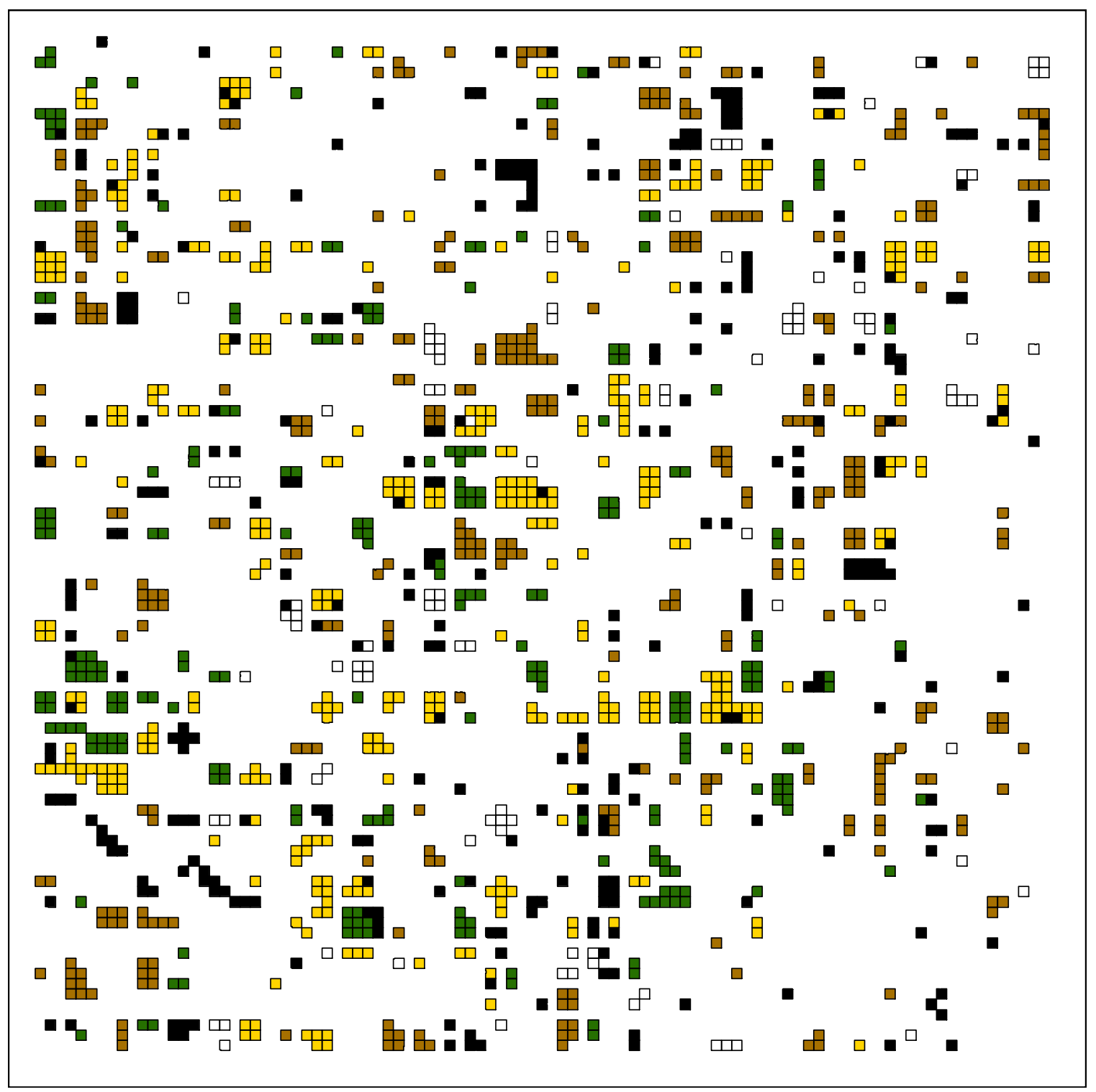

Figure C.6. Round 2 Testing: Correct Pixels in Study Site 1 Pure Pixel Classification

This is the same as Figure C.5, except all the incorrectly classified pixels are colored black to distinguish them from the correct pixels. 
Table C.4. Round 2 Testing: Study Site 1 NDVI Classification of Pure Pixels

\begin{tabular}{|c|c|c|c|c|c|c|c|}
\hline \multicolumn{8}{|c|}{ Reference Data } \\
\hline & & Corn & Soy & Wheat & Other & Total & User Acc. \\
\hline \multirow{6}{*}{ 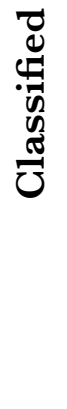 } & Corn & 358 & 108 & 3 & 79 & 548 & $65.34 \%$ \\
\hline & Soy & 10 & 236 & 0 & 11 & 257 & $91.83 \%$ \\
\hline & Wheat & 36 & 6 & 348 & 29 & 419 & $83.05 \%$ \\
\hline & Other & 10 & 4 & 20 & 101 & 135 & $74.81 \%$ \\
\hline & Total & 414 & 354 & 371 & 220 & 1359 & \\
\hline & Producer Acc. & $86.47 \%$ & $66.67 \%$ & $93.80 \%$ & $\begin{array}{c}45.91 \% \\
\text { Overall }\end{array}$ & $\begin{array}{r}\text { Accura } \\
\mathrm{K}\end{array}$ & $\begin{array}{l}\text { y: } 76.75 \% \\
\text { appa: } 0.68\end{array}$ \\
\hline
\end{tabular}

literature revealed numerous discrepancies (Wardlow and Egbert 2002, 2005; Wardlow, Egbert, and Kastens 2007; Wardlow and Egbert 2008; Masialeti, Egbert, and Wardlow 2010). To determine the cause of the differences, I plotted the signatures of the pixels sampled to generate each of the reference signatures (shown in Figure C.8 through Figure C.12). Some of these plots showed high variance between the sampled pixels and strange early and late season peaks inconsistent with the accepted temporal signatures for these crops. For example, one abnormally-low valued soy pixel was responsible for pulling down the peak of the soy reference signature. Corn had extremely variable pixel signatures which mangled its reference signature. Sorghum, among other problems, had very high early season peaks (I have since realized this is likely due to wheat/sorghum double cropping misclassified in the CDL). To correct these and other problems, I realized I needed to change my strategy for identifying the TSI pixels to sample for the reference signatures. Rather than simply finding pure pixels, I needed to ensure the signatures of sampled pixels were representative of the expected crop signature. 


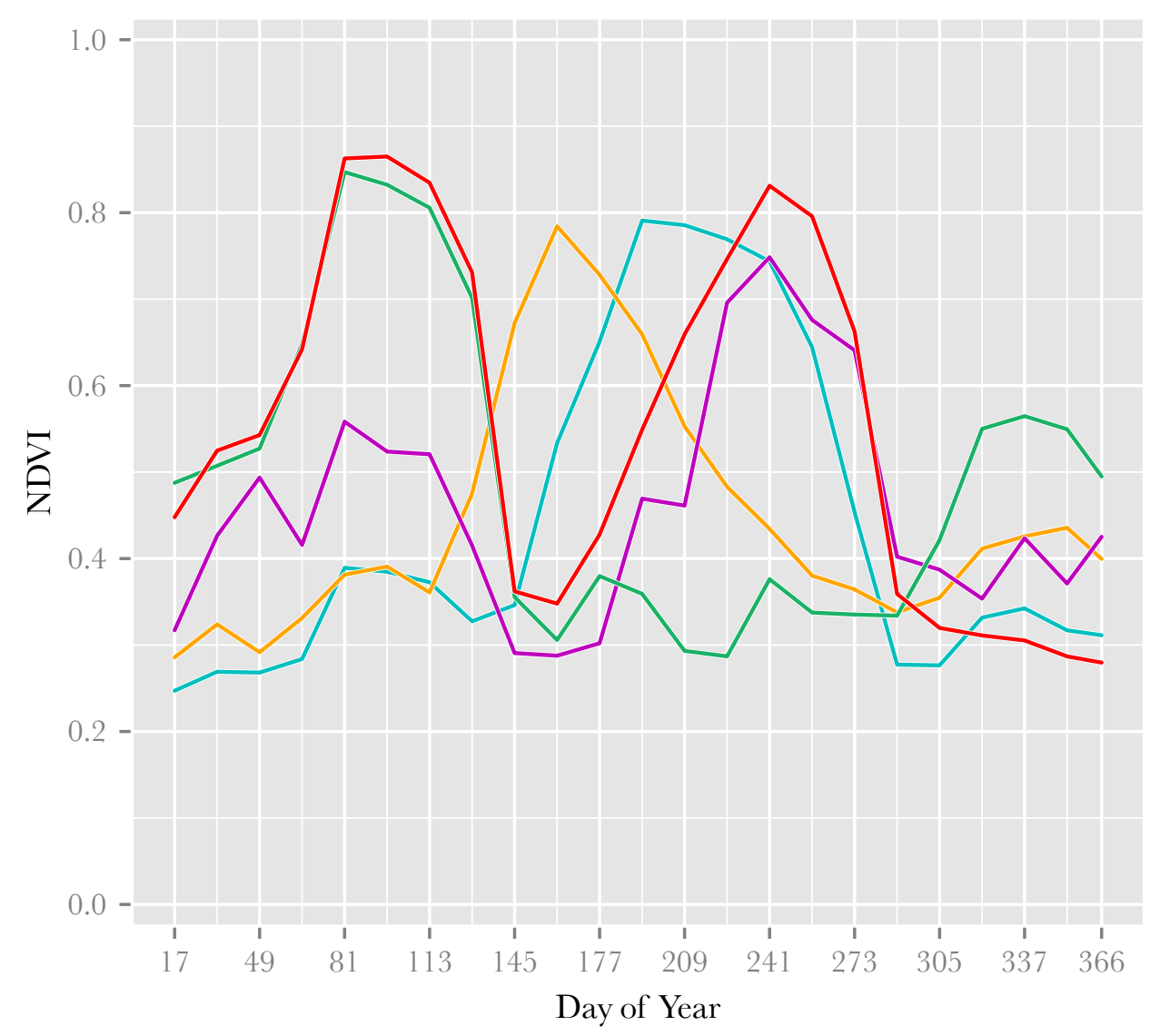

- Soy — Corn — Sorghum — Wheat — Wheat/Soy Double Crop

Figure C.7. Crop Reference Signatures Extracted from Study Site 1 


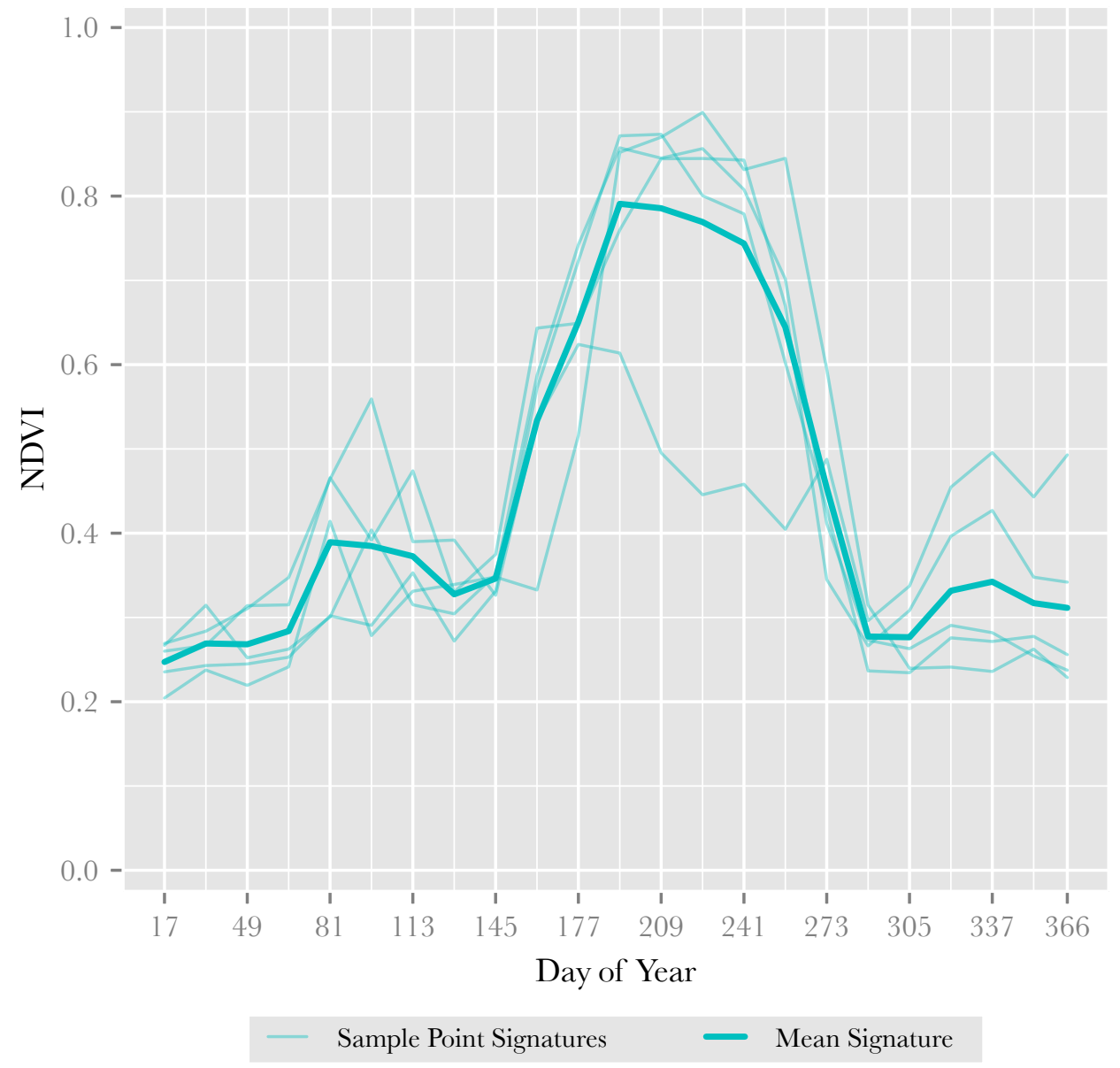

Figure C.8. Soy Sampled Pixel Signatures and Mean Signature 


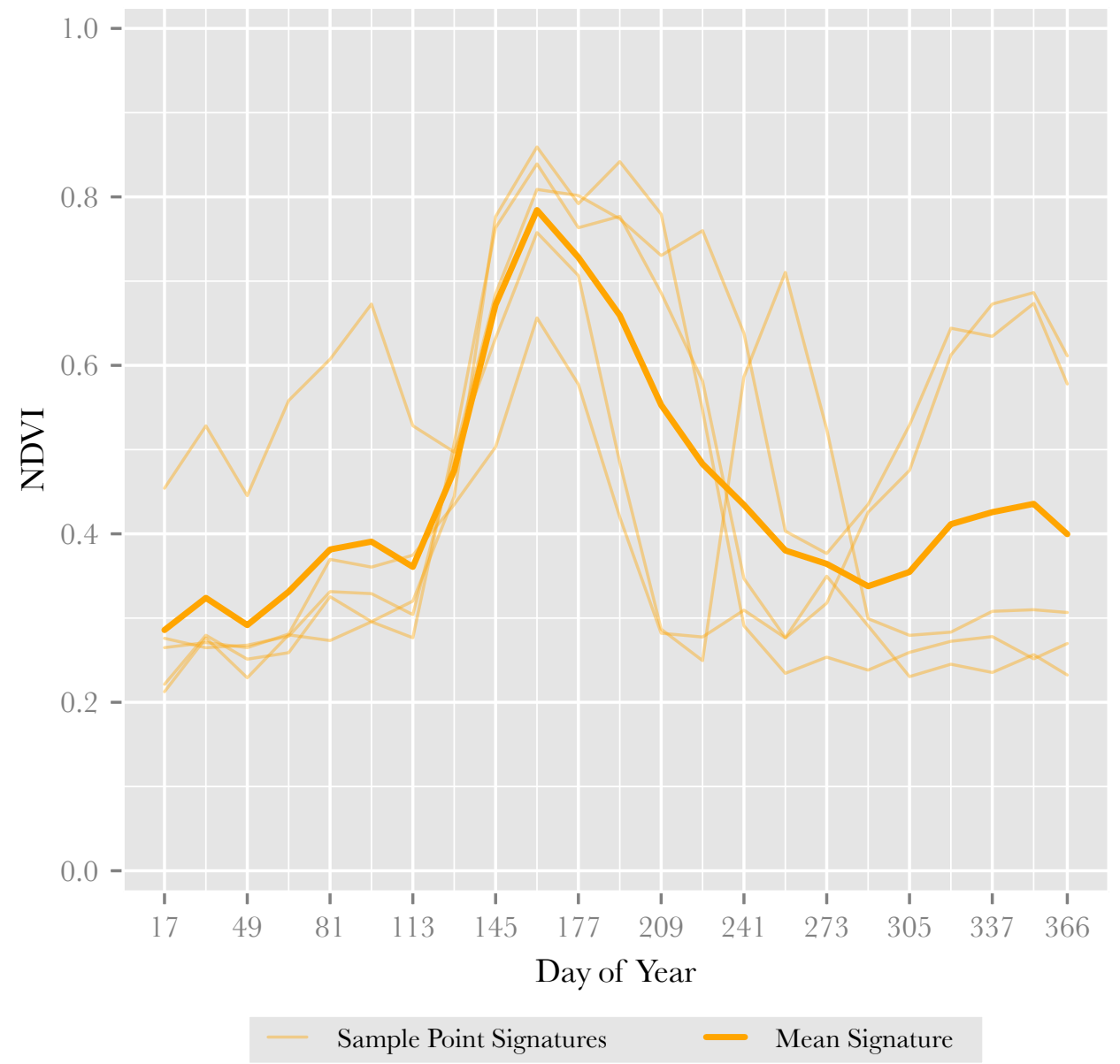

Figure C.9. Corn Sampled Pixel Signatures and Mean Signature 


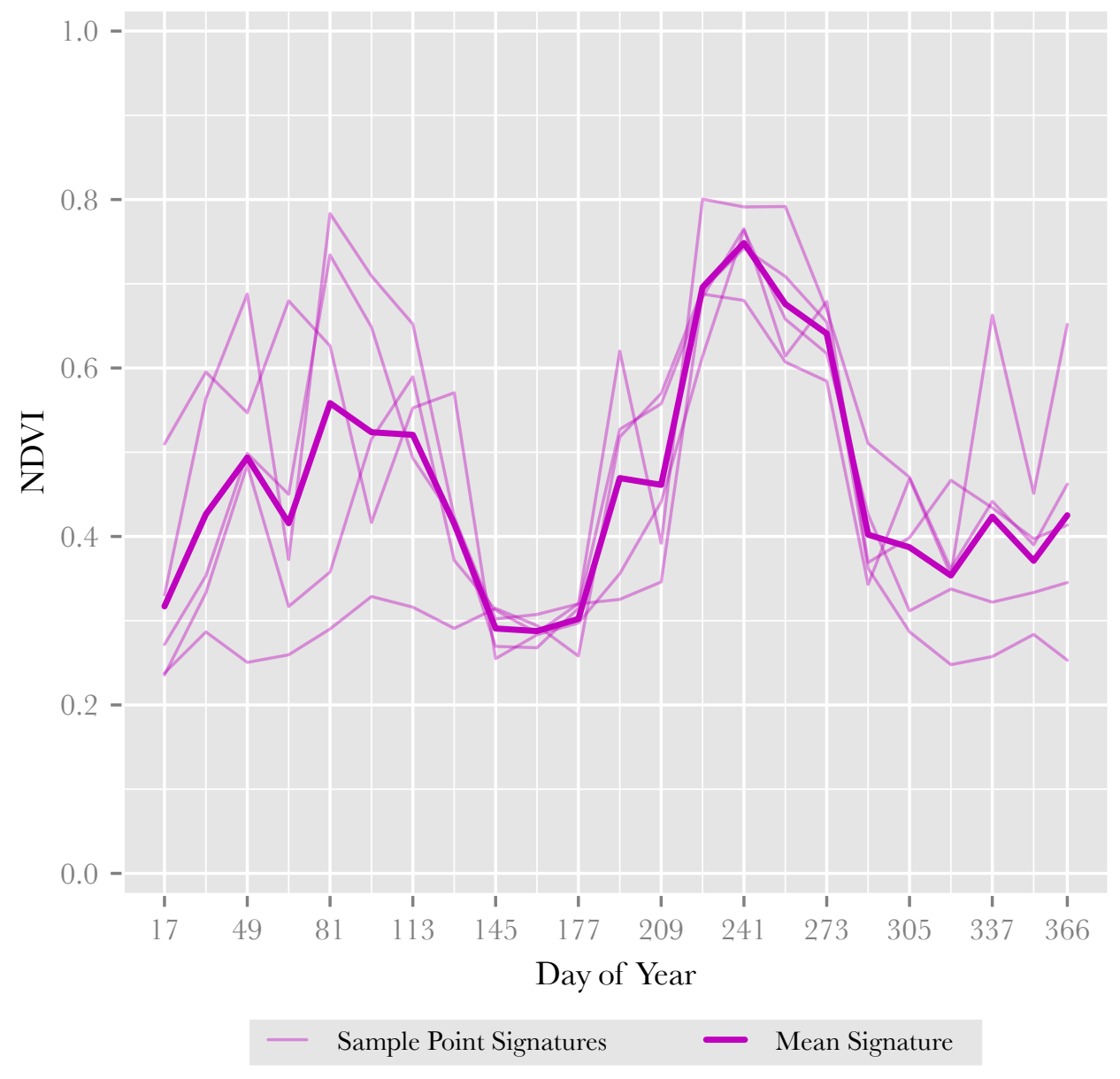

Figure C.10. Sorghum Sampled Pixel Signatures and Mean Signature 


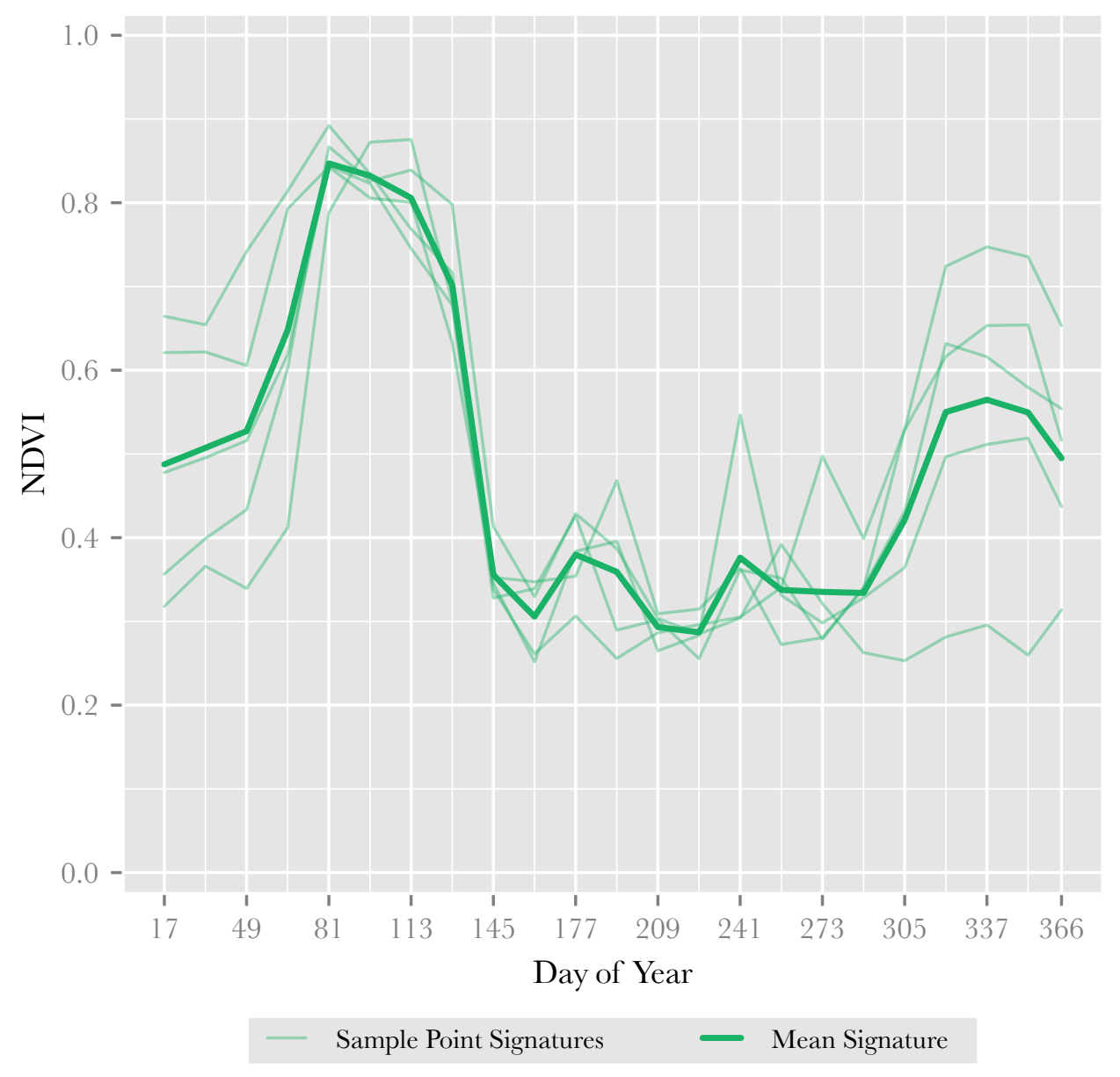

Figure C.11. Winter Wheat Sampled Pixel Signatures and Mean Signature 


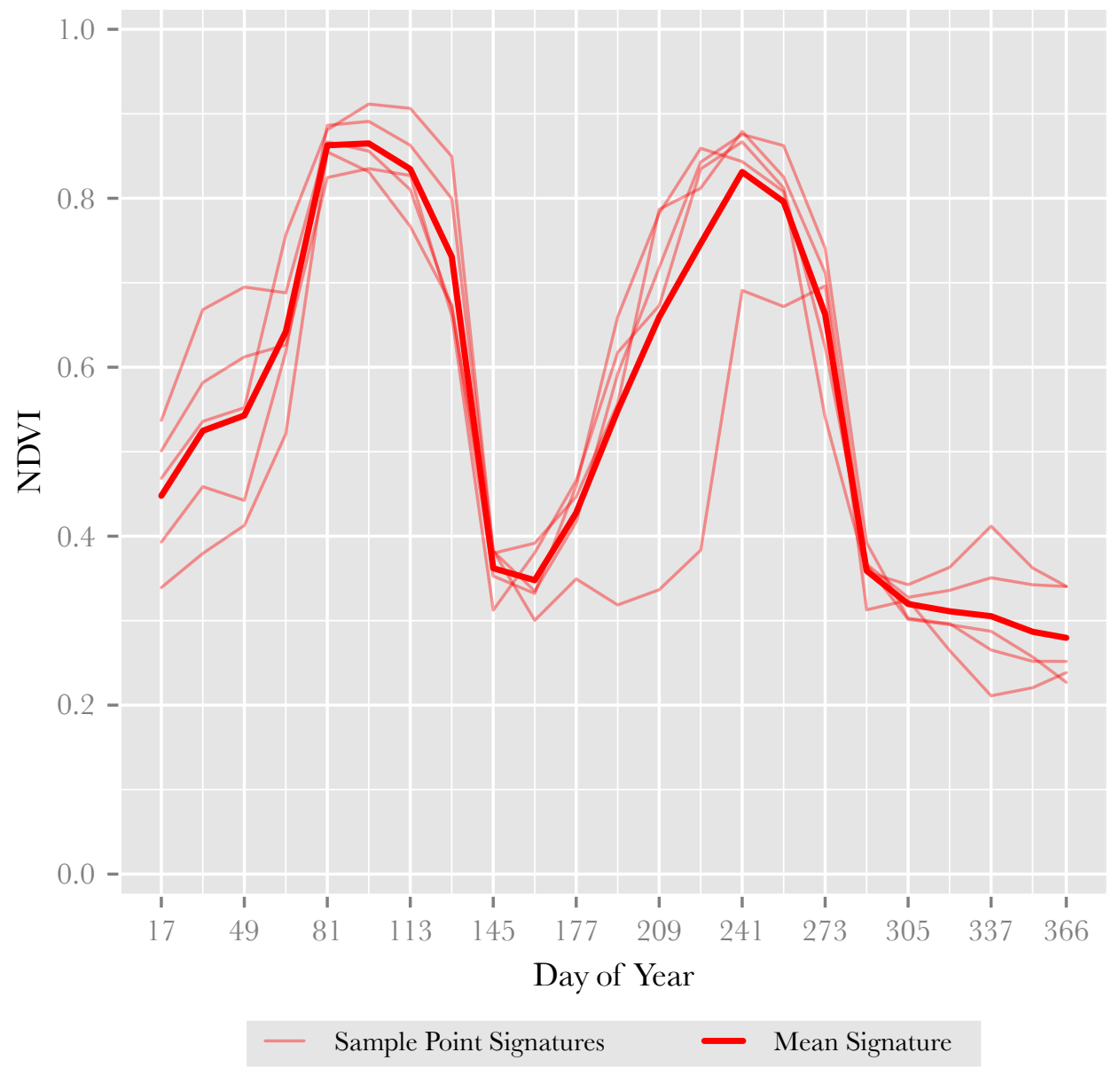

Figure C.12. Winter Wheat/Soy Double Crop Sampled Pixel Signatures and Mean Signature 


\section{C.3 Round 3 Testing: Refining the Reference Signatures}

The image analysis software ENVI (Exelis Visual Information Solutions 2014a) has a plotting tool that allows the user to interactively select pixels in a multi band raster and view plots of the pixel values. This tool proved perfect for refining the reference curves. Using it, I could ensure I only sampled crop pixels whose values appeared to match the expected crop signature. The new sample points are shown alongside the old points in Figure C.13. Figures C.14 to C.18 shows the individual signatures of the new sampled pixels for each crop, and the refined reference signatures made from those new sample pixels. In each figure, the original reference signature is shown in gray to illustrate the change. The new soy and corn reference signatures peak higher; soy exhibits its distinctive bell-shaped peak, while corn peaks early, remaining at high VI values before tapering off quickly at the end of its season. The new sorghum signature displays none of the early season peaks, and is much rounder compared to the jaggedness before. Unlike the others, however, the new winter wheat and winter wheat/soy double crop signatures do not differ greatly from the originals, though the originals did not exhibit many issues. Figure C.19 is combined plot of all the new reference signatures so they can be compared to one another. 


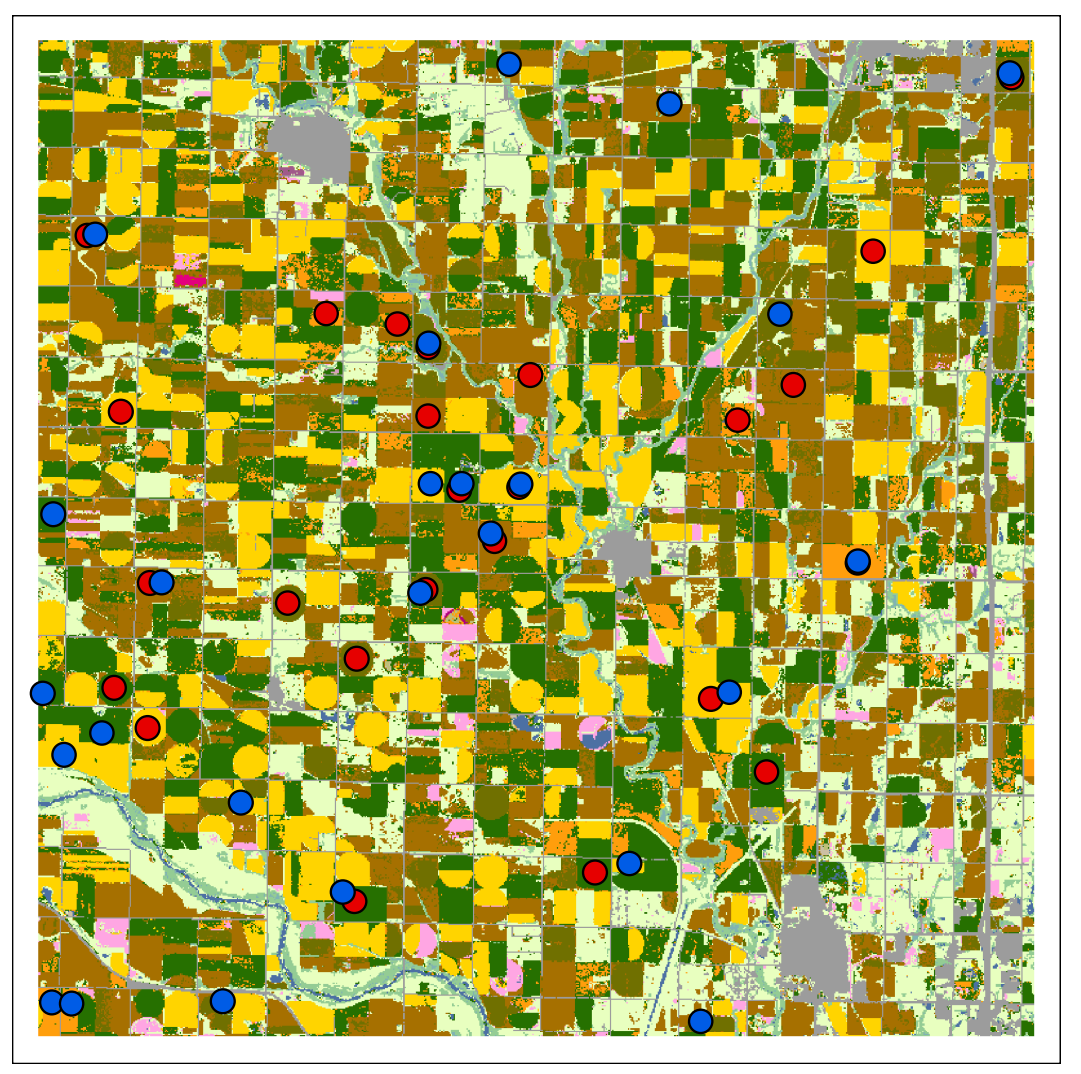

Figure C.13. Points Marking New Pixels Sampled to Create New Reference Signatures

The blue points represent the new pixels sampled to create the new crop reference signatures. The red points are the old points used to create the original crop signatures. Some of the original pixels had good signatures and were used again for the refined signatures. 


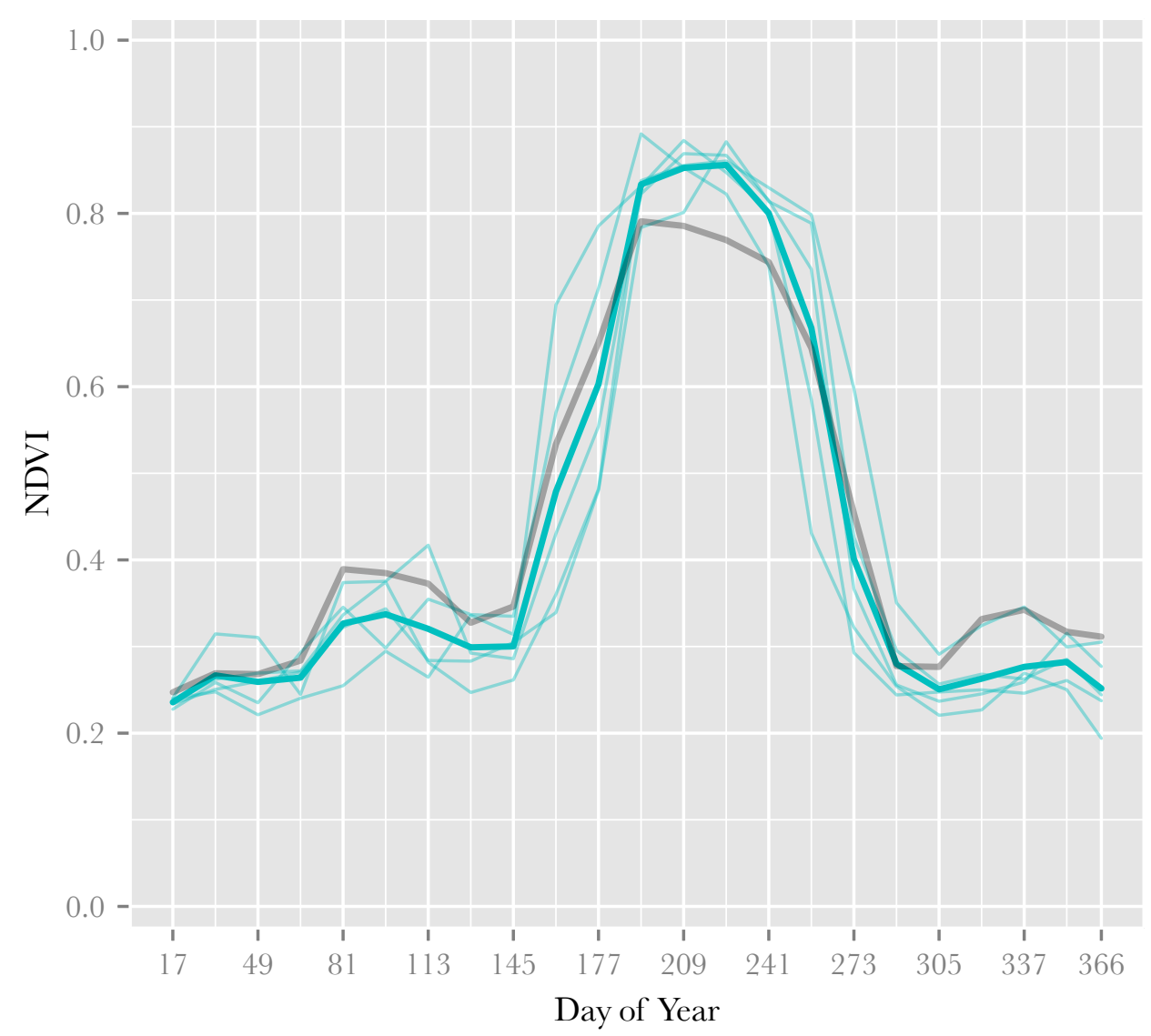

- Sample Point Signatures _ $\quad$ Mean Signature $\quad$ Previous Mean Signature

Figure C.14. Refined Soy Sampled Pixel Signatures and Mean Signature 


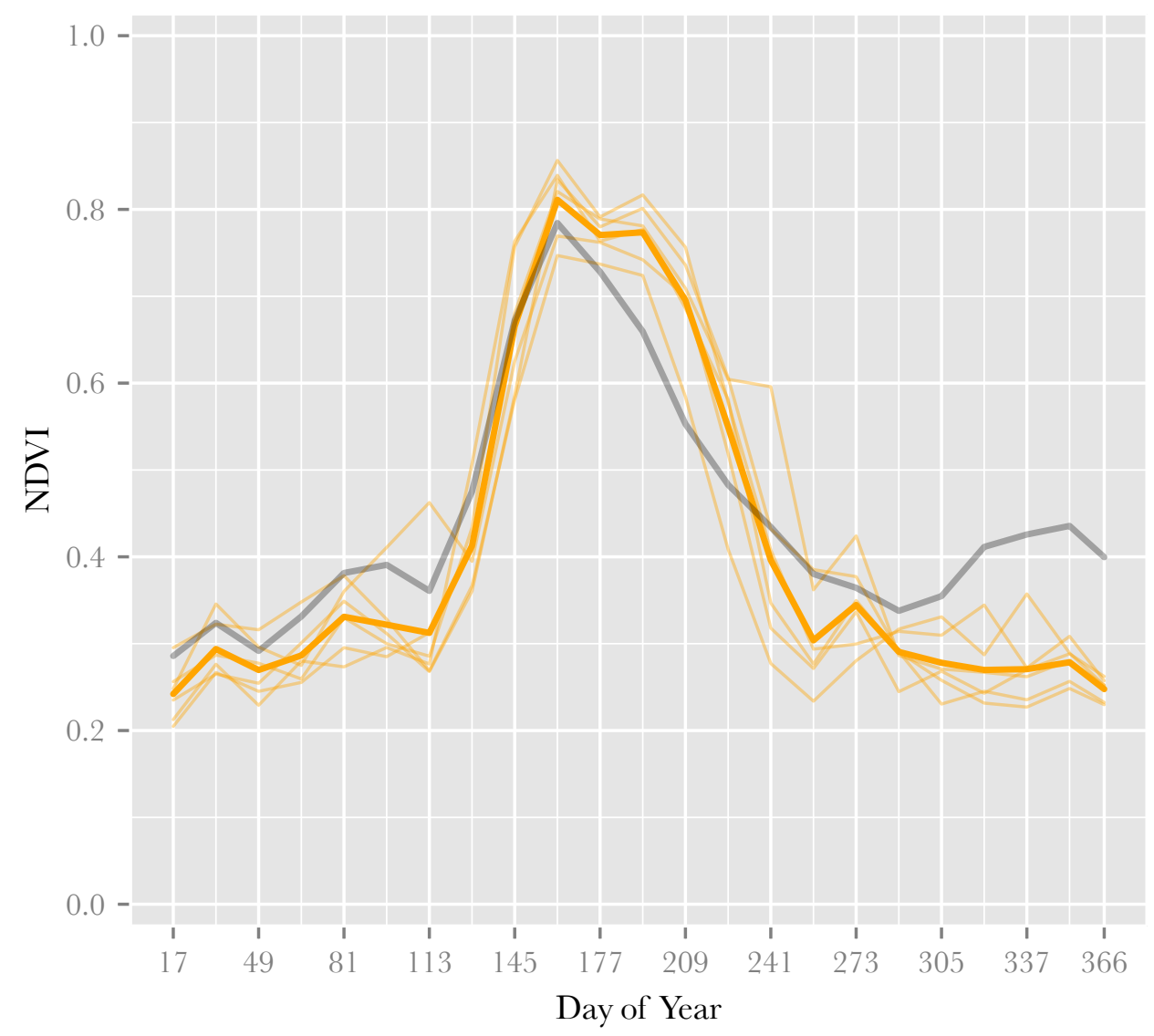

Sample Point Signatures

Mean Signature

Previous Mean Signature

Figure C.15. Refined Corn Sampled Pixel Signatures and Mean Signature 


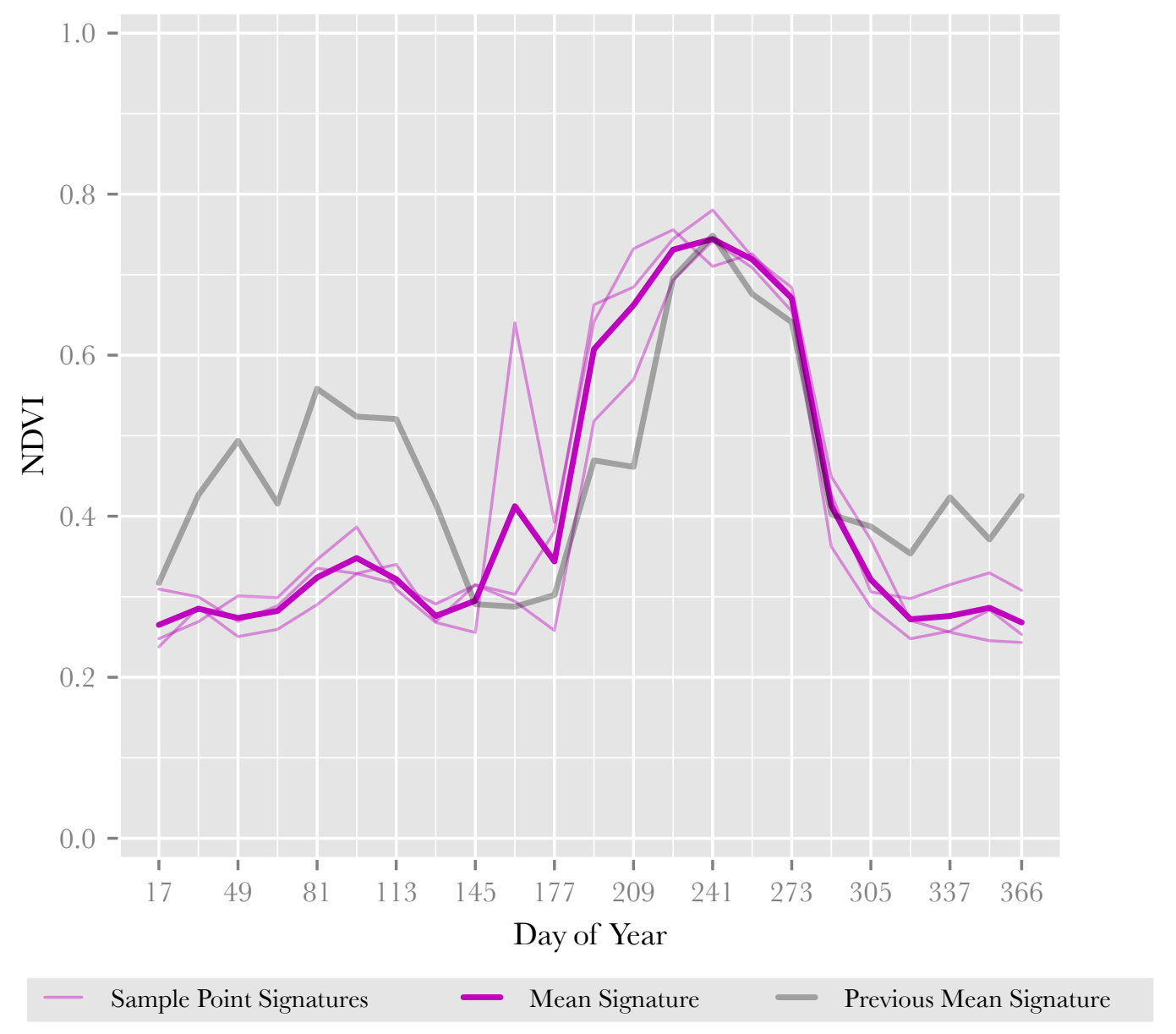

Figure C.16. Refined Sorghum Sampled Pixel Signatures and Mean Signature 


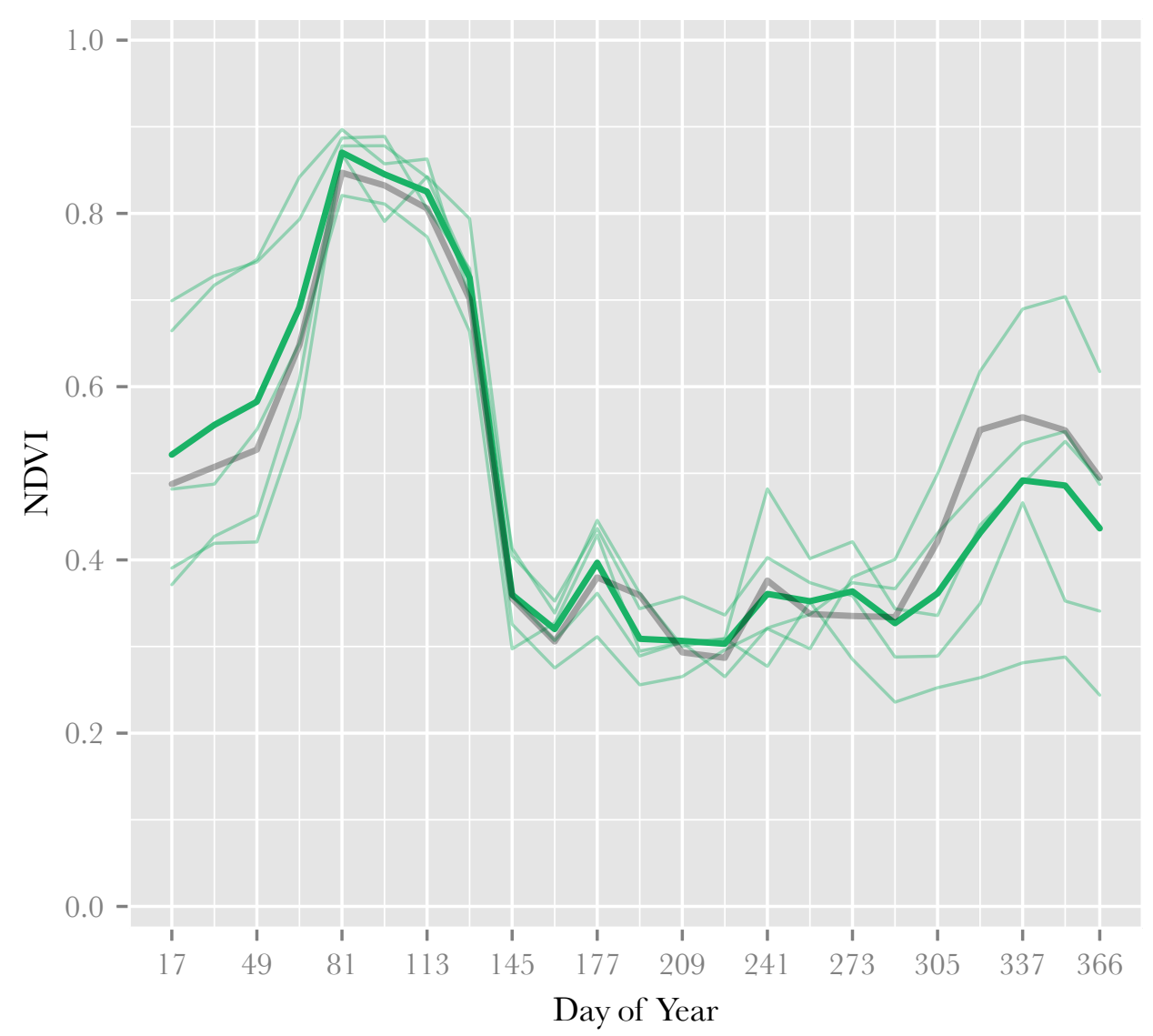

- Sample Point Signatures _ Mean Signature $\quad-$ Previous Mean Signature

Figure C.17. Refined Winter Wheat Sampled Pixel Signatures and Mean Signature 


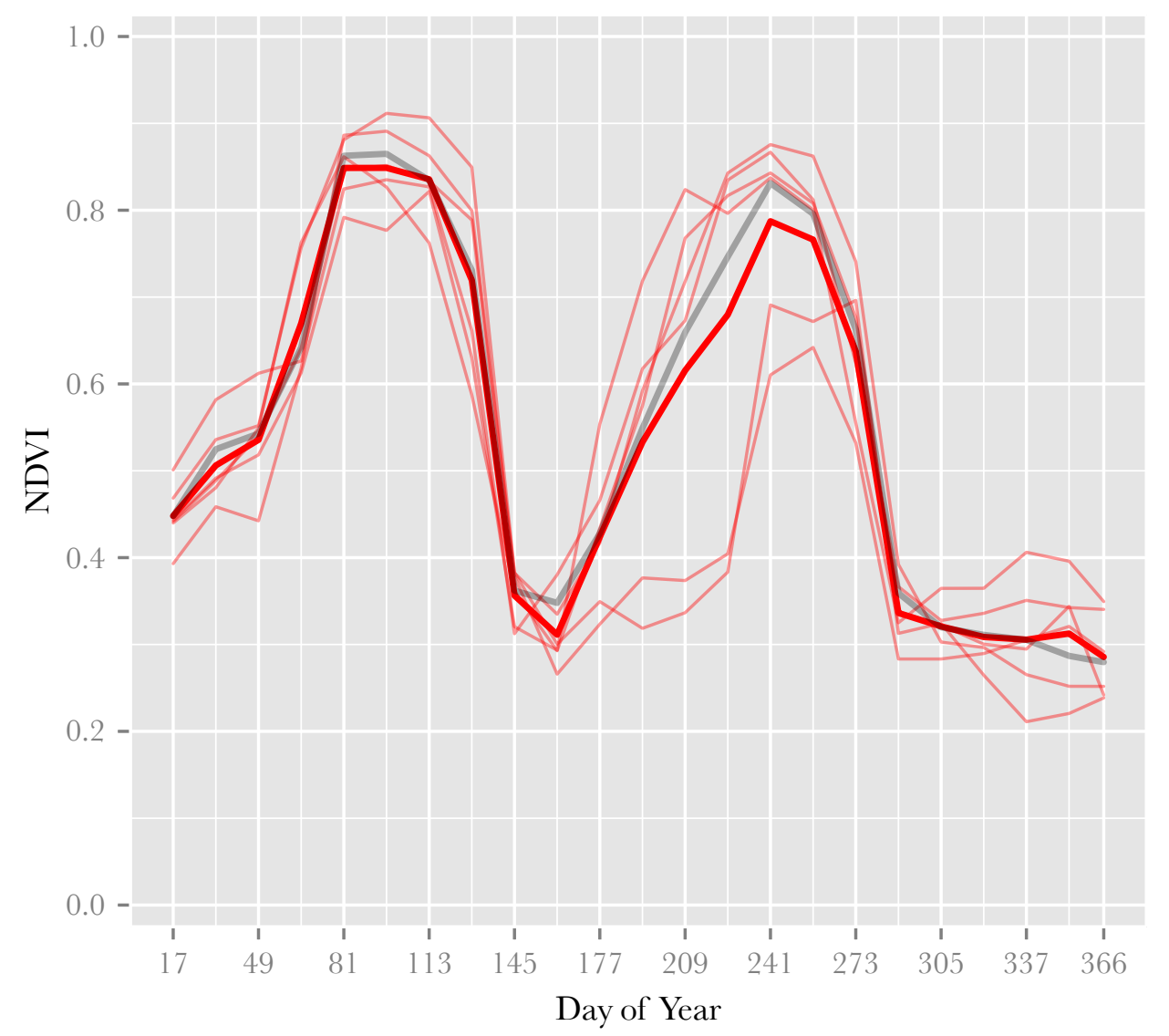

— Sample Point Signatures _ Mean Signature $\quad$ Previous Mean Signature

Figure C.18. Refined Winter Wheat/Soy Double Crop Sampled Pixel Signatures and Mean Signature 


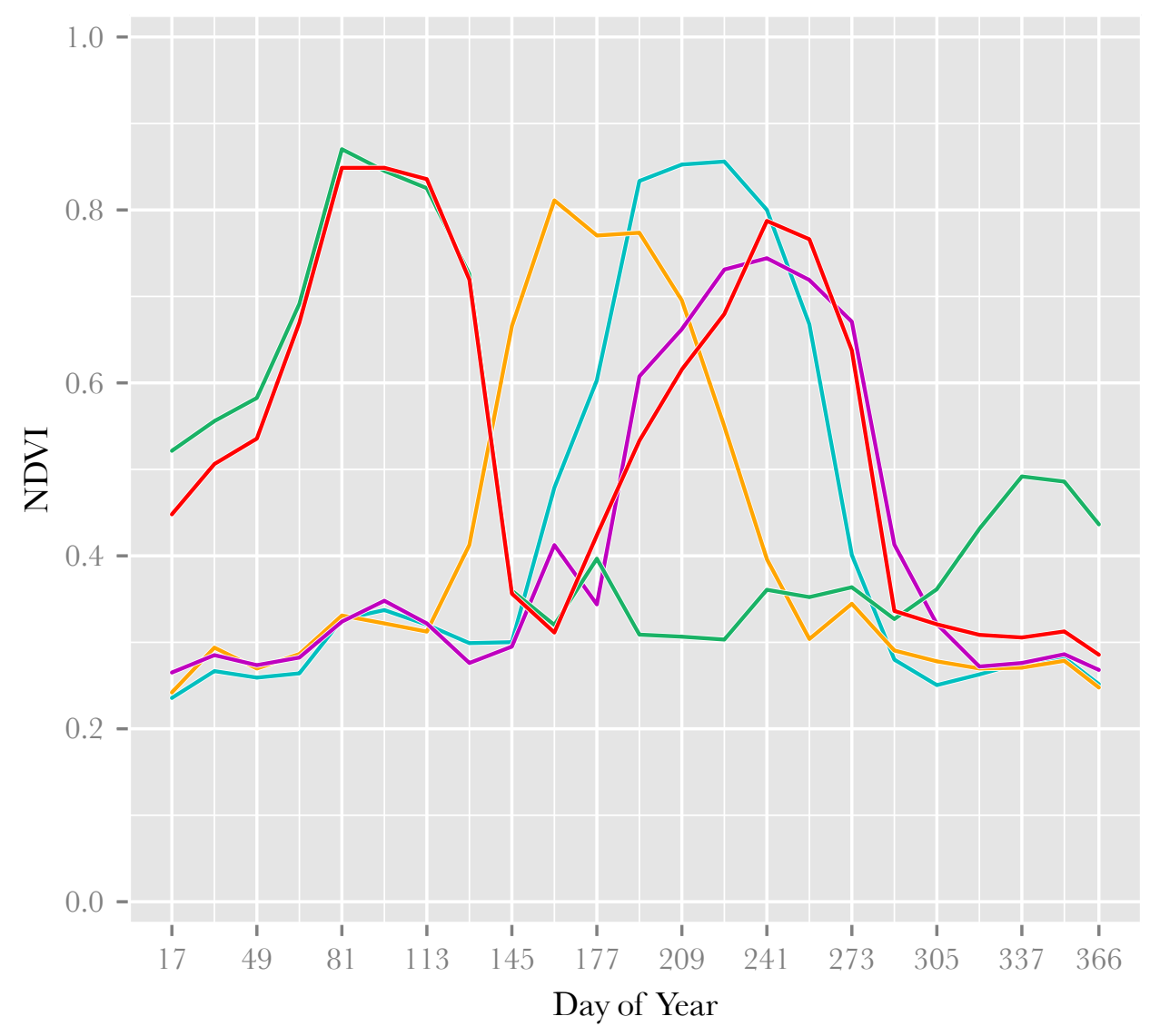

- Soy — Corn — Sorghum — Wheat — Wheat/Soy Double Crop

Figure C.19. Refined Crop Signatures Extracted from the 2012 Kansas TSI 
Table C.5. Round 3 Testing: Study Site 1 NDVI Classification of Pure Pixels Using Refined Reference Signatures

\begin{tabular}{|c|c|c|c|c|c|c|c|}
\hline \multicolumn{8}{|c|}{ Reference Data } \\
\hline & & Corn & Soy & Wheat & Other & Total & User Acc. \\
\hline \multirow{6}{*}{ 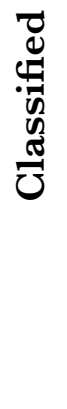 } & Corn & 201 & 117 & 0 & 7 & 325 & $61.85 \%$ \\
\hline & Soy & 1 & 196 & 0 & 16 & 213 & $92.02 \%$ \\
\hline & Wheat & 41 & 9 & 340 & 40 & 430 & $79.07 \%$ \\
\hline & Other & 171 & 32 & 31 & 157 & 391 & $40.15 \%$ \\
\hline & Total & 414 & 354 & 371 & 220 & 1359 & \\
\hline & Producer Acc. & $48.55 \%$ & $55.37 \%$ & $91.64 \%$ & $\begin{array}{l}71.36 \% \\
\text { Overall }\end{array}$ & $\begin{array}{r}\text { Accura } \\
\mathrm{K}\end{array}$ & $\begin{array}{l}\text { y: } 65.78 \% \\
\text { appa: } 0.55\end{array}$ \\
\hline
\end{tabular}

\section{Round 3 Results and Discussion}

To my surprise, refining the reference signatures actually reduced the classification accuracy to 65.8 percent (Table C.5). I did notice almost all of the "other" pixels were correctly classified, but also that, in contrast to the Round 2 testing, errors of omission were primarily responsible for the decrease in accuracy. That is, many corn pixels in the study were classified as other. The confusion between corn and soy also remained.

To further understand what had happened, I plotted the signature of every incorrectly classified pixel in the study site. A small selection of strange signatures from the many pixels labeled as corn by the CDL that were not accurately classified is shown in Figure C.20. Looking through the plots, I began to notice some patterns were repeated. Among the signatures in Figure C.20 there are many similarities and differences. Pixel signatures 1, 2, 3, and 5 all share an early season peak, but tend to diverge after the first dip in values around DOY 113. Pixel 4's signature does not appear distinctly different than the corn reference signature up until DOY 257, when it begins to climb steeply to a second peak. 


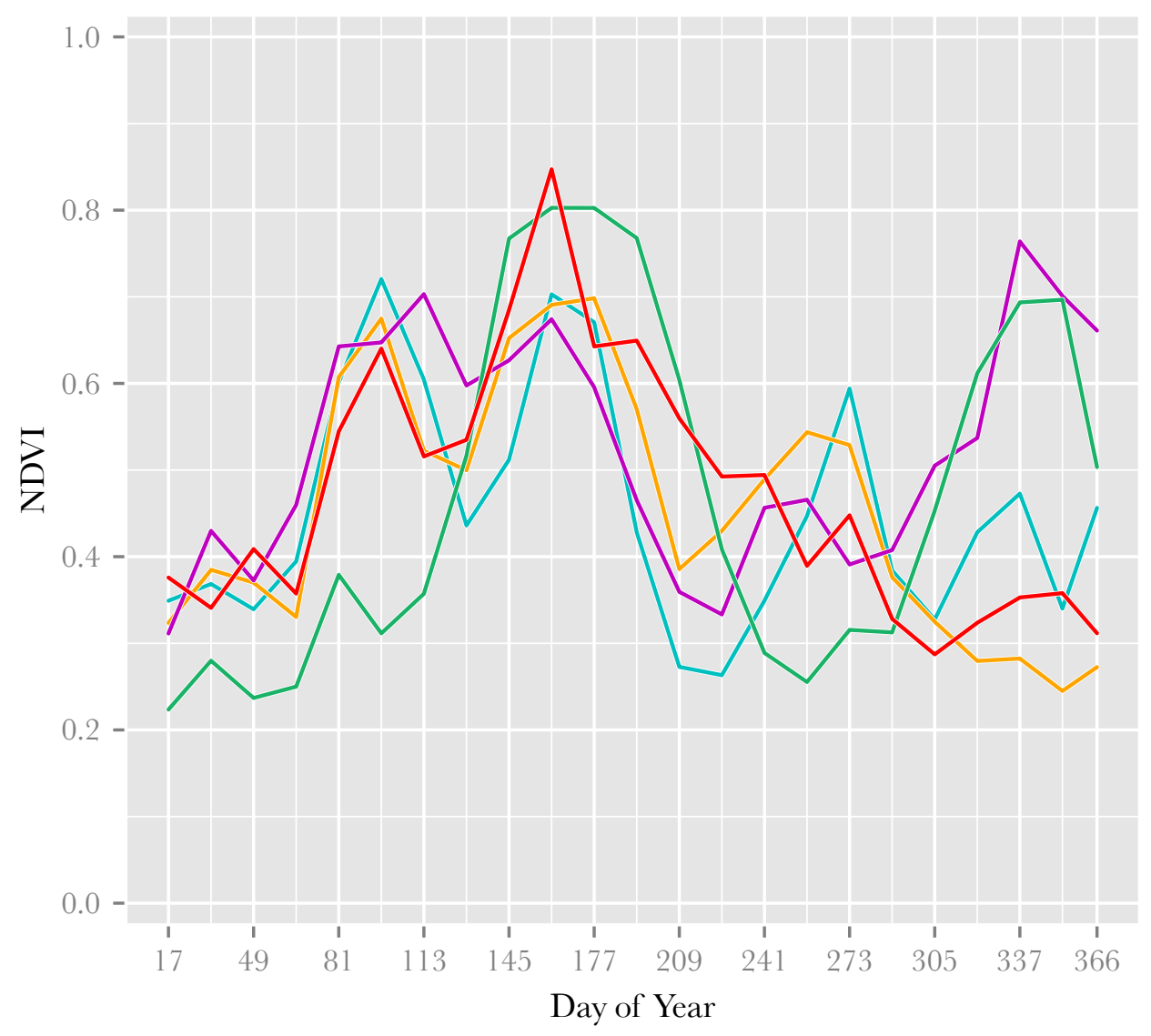

\section{Pixel $1-$ Pixel $2-$ Pixel $3-$ Pixel $4-$ Pixel 5}

Figure C.20. Selected Examples of Strange Signatures from Pixels Labeled Corn in the GDL

Each of these signatures was extracted from a pixel labeled corn by the GDL that was not accurately classified in the Round 3 testing. The signatures of pixels 1, 2, 3, and 5 share features on a few key dates, but diverge on others. None of these four is remotely similar in appearance to corn. In fact, the two peaks, around DOY 97 and DOY 161, suggest some sort of double crop rotation.

The only signature similar to corn is that of pixel 4, which departs from the corn reference signature around DOY 257. After that date pixel 4 increases sharply to an end-of-year peak, suggestive of winter wheat planting for the following year. 
Comparing the pixel coordinates of all the incorrect pixel plots, I found many adjacent pixels with similar plot shapes. This finding provides evidence that pixels in a field generally have the same signature and supports the overall theory behind this method. That is, if plants of a crop grow under the same conditions, they should have the same temporal signature.

However, the many different signatures I found within each crop class of the CDL is particularly troublesome. Assuming the truthfulness of the CDL, this suggests that each crop has multiple temporal signatures. Not only does such reasoning conflict with previous research into phenological classification, but is illogical considering the typical growth cycle for crops like corn and soy. The same crops within close proximity should be exposed to essentially equal growing conditions. Variations in planting date may account for slight differences in the temporal signatures. The use of irrigation or application of pesticides, fertilizers, or herbicides may also impart slight disparities between signatures (Wardlow and Egbert 2005; Wardlow, Egbert, and Kastens 2007; Wardlow and Egbert 2008; Sakamoto et al. 2010). However, none of these variables would likely be accountable for the vastly different crop signatures observed.

To get an expert opinion, on 31 May 2014 I e-mailed a few of the signatures plots of incorrectly classified pixels, labeled as corn in the CDL (similar to pixels 1, 2, 3, and 5 in Figure C.20), to Dana Peterson, a research assistant at the Kansas Applied Remote Sensing Program of the Kansas Biological Survey at University of Kansas. She and her colleagues have significant experience working with phenological classifications made using MODIS VI data and the Kansas CDL. Her reply of 1 June 2014 confirmed that the signature types 
I sent are likely attributable to double cropping, and that the CDL is not correct in these cases.

The remaining incorrectly classified pixels that did not have the double crop appearance were, predominately, similar to pixel 4 in Figure C.20. These pixel signatures all had an unusual bump in value at the end of the year. Reviewing typical crop signature plots in the phenological classification literature made me think the end-of-year increase in NDVI of many incorrectly classified pixel may be related to winter wheat planting for the next year's growing season.

To investigate this idea, I used the U.S. Geological Survey Landsat Look online imagery viewer to identify some of these incorrectly classified fields in multidate Landsat imagery to see how they appeared through time. Fields that increased in value at the end of the year featured vegetation throughout the winter and had significant vegetation growth early in the following year, consistent with winter wheat. Moreover, an analysis using the CDL for 2013 showed 172 of the incorrectly classified pixels were planted with winter wheat in fall 2012.

\section{C.4 Round 4 Testing: Different Time Ranges}

\section{Deriving the Date Ranges to Test}

As many pixels with 2013 winter wheat did not fit any reference signatures within the utilized RMSE thresholds, I wondered what would happen if I changed the date range of the TSI. Instead of beginning and ending the TSI at the start of January, I decided to create 
a TSI that began with the end-of-year winter wheat bump from 2011 and end before the bump in 2012. Specifically, I selected images from 2011 DOY 305 through 2012 DOY 289.

As by this point I had also returned from my field work in Argentina, I had a better idea of how my processing procedure would have to change to classify the Pellegrini imagery. In talking with the locals on Pellegrini, I found that wheat was just one of a number of different grains that were grown in the winter dry season. Moreover, given my visit was in the middle of the summer growing season, I did not have any good way to verify where nor what types of winter crops were grown. To compound the problem, I also learned that, due to the length and flexibility of the summer wet season in Pellegrini, farmers were not limited to double cropping only late summer crops with a winter crop. Instead, any summer crop could be grown with a winter crop. Having extracted only one double crop signature from the Kansas data, the winter wheat and soy signature, and a lack of winter wheat ground truth, I realized I would not be able to use my Kansas signatures to classify an entire agricultural year in Argentina. Rather, I could only classify summer crops. Consequently, I decided to also try classifying SS1 during the spring and summer months only, using MODIS imagery from DOY 97 through DOY 273.

\section{Classification Procedures}

The only difference in the processing procedure for these two classifications as compared to the previous procedure in Round 3 was the date ranges used to build the TSIs. I fit the same reference signatures as derived in Round 3, and classified only the pure pixels identified in Round 2. 
Table C.6. Round 4 Testing: Study Site 1 NDVI Classification of Pure Pixels Using Refined Reference Signatures, 2011 DOY 305 Through 2012 DOY 289

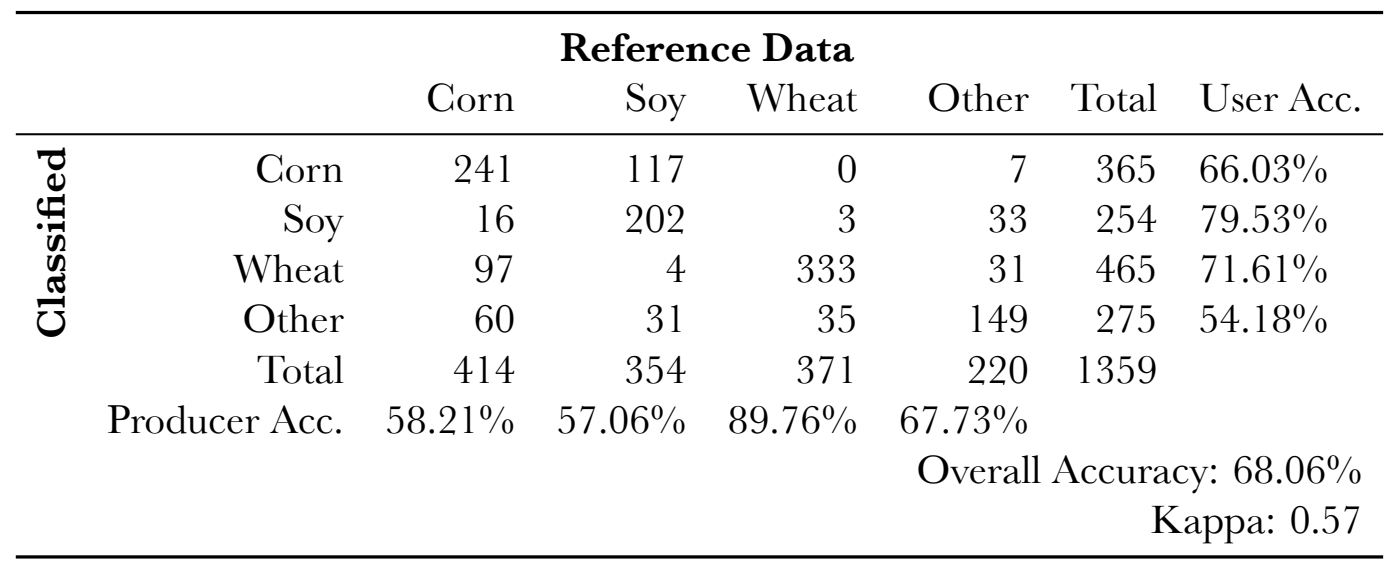

\section{Round 4 Results and Discussion}

Despite accounting for the winter wheat planting for the following year, my 2011-2012 classification of corn, soy, and winter wheat was only marginally better than the full 2012 classification. The overall accuracy was only 68.1 percent, as shown in Table C.6. From the classification results, it appears that a few of the winter wheat 2013 pixels were properly classified this time, but many remained incorrect. Evidenced by the percent accuracy, most improvements were offset by pixels now unable to be accurately classified. Given that I knew I would be focusing only on summer crops in Argentina, I did not further investigate why this was the result.

The 2012 summer-only classification fared slightly better. Given the date range, I classified the three main summer crops — corn, soy, and sorghum — finding an accuracy of 75.1 percent. Looking at the classification and its confusion matrix, I realized much of the error was due to confusion between soy and sorghum (Table G.7).

Considering that only 18 pixels in the study area were sorghum, I tried classifying the 
Table C.7. Round 4 Testing: Study Site 1 NDVI Classification of Pure Pixels Using Refined Reference Signatures, 2012 DOY 97 Through DOY 273

\begin{tabular}{|c|c|c|c|c|c|c|c|}
\hline \multicolumn{8}{|c|}{ Reference Data } \\
\hline & & Corn & Soy & Sorghum & Other & Total & User Acc. \\
\hline \multirow{6}{*}{ 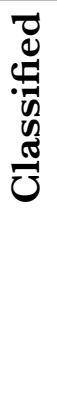 } & Corn & 394 & 120 & 0 & 27 & 541 & $72.83 \%$ \\
\hline & Soy & 0 & 76 & 4 & 5 & 85 & $89.41 \%$ \\
\hline & Sorghum & 6 & 135 & 12 & 3 & 156 & $7.69 \%$ \\
\hline & Other & 14 & 23 & 2 & 538 & 577 & $93.24 \%$ \\
\hline & Total & 414 & 354 & 18 & 573 & 1359 & \\
\hline & Producer Acc. & $95.17 \%$ & $21.47 \%$ & $66.67 \%$ & $\begin{array}{l}93.89 \% \\
\text { Overall }\end{array}$ & $\begin{array}{r}\text { Accura } \\
\mathrm{K}\end{array}$ & $\begin{array}{l}\text { cy: } 75.06 \% \\
\text { appa: } 0.63\end{array}$ \\
\hline
\end{tabular}

data again using the corn and soy signatures alone. However, this merely traded confusion between sorghum and soy for confusion between corn and soy, and the overall accuracy was practically unchanged at 75.3 percent.

In both summer-only classifications, the accuracy was higher than over the entire year classifications. However, I realized that these results were not actually comparable. Previously, I had always been finding winter wheat, corn, and soy. However, the summer-only classification found results classified corn, soy, and sorghum. To allow a direct comparison between the 2011-2012 and the summer 2012 classifications, I reclassified the 2011-2012 RMSE rasters, looking for corn, soy, and sorghum without wheat. To my surprise, I found the overall accuracy to be more or less the same as classifying just the summer months (Table C.8). However, some discrepancies appear after further examination. In the summer only classification, one can see a significant degree of confusion between sorghum and soy that is not present in the 2011-2012 classification. However, the producer accuracy for soy in the 2011-2012 classification is only marginally better, as soy is instead confused with 
Table C.8. Round 4 Testing: Study Site 1 NDVI Classification of Pure Corn, Soy, and Sorghum Pixels Using Refined Reference Signatures, 2011 DOY 305 Through 2012 DOY 289

\begin{tabular}{|c|c|c|c|c|c|c|c|}
\hline \multicolumn{8}{|c|}{ Reference Data } \\
\hline & & Corn & Soy & Sorghum & Other & Total & User Acc. \\
\hline \multirow{6}{*}{ 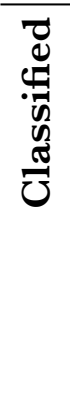 } & Corn & 389 & 211 & 7 & 69 & 676 & $57.54 \%$ \\
\hline & Soy & 0 & 124 & 3 & 2 & 129 & $96.12 \%$ \\
\hline & Sorghum & 0 & 4 & 6 & 0 & 10 & $60.00 \%$ \\
\hline & Other & 25 & 15 & 2 & 502 & 544 & $92.28 \%$ \\
\hline & Total & 414 & 354 & 18 & 573 & 1359 & \\
\hline & Producer Acc. & $93.96 \%$ & $35.03 \%$ & $33.33 \%$ & $\begin{array}{c}87.61 \% \\
\text { Overall }\end{array}$ & Accura & $\begin{array}{l}\text { y: } 75.13 \% \\
\text { appa: } 0.62\end{array}$ \\
\hline
\end{tabular}

corn. Looking through the other statistics in the tables, seeming any advantage of one classification over the other is balanced by additional inaccuracies. Without a specific reason to choose one classification over the other, however, they perform equally.

This result validates that restricting the classification to the summer months does not have a negative effect when classifying summer crops. In light of this result, and my experience in Argentina, I decided to use the summer-only approach for all subsequent testing.

\section{C.5 Round 5: A Last Ditch Effort to Match the CDL}

For my final test classification, I attempted to match the CDL as best as possible. To do so, I clustered each crop's pixels using k-means to try to isolate the different signatures I previously identified. This classification process and the subsequent results are those presented in the body of this thesis. To read about the methods, see Chapter 4 beginning on page 28 . The results are presented in section 5.4 on page 50 and discussed in section 6.2 on page 57, so I will only briefly summarize my findings here. 
Clustering each crop's pixels to find multiple signatures increased the classification accuracy to 84.4 percent. A map of the classification, Figure 5.5, is on page 51 . The confusion matrix is Table 5.4 on page 50. Corn and soy had class confusion. Sorghum was not well classified, which may have something to do with the date range used.

Also mentioned in the discussion, specifically section 6.1 on page 56 , one of the soy signatures had a strange, non-soy-like appearance (Soy_1 in Figure 5.4 on page 49). I reran the classifier as before, omitting this soy signature to test that signature's effect. The accuracy did drop to 81.5 percent, but when I visually analyzed the classification I could see that many previous errors where non-crop pixels were classified as soy disappeared. I interpret these results to mean one of two things: (1) some soy fields have signatures quite similar to grassland and pasture areas, or (2) the CDL inaccurately classifies some grassland or pasture as soy. From my understanding of crop phenologies, and given my experience looking at crop signatures, I believe the latter is more likely.

\section{C.6 Discussion and Conclusions}

Are the results still rather low because the GDL has class confusion? That is, might my inaccuracy be compounded because of inaccuracies in the CDL that my classification methods will never recreate? I must posit that my method might actually be more accurate than I can test given the problems with the CDL. However, even if the accuracy of the CDL is about 90 percent, as is published, what is a reasonable accuracy for me to achieve? If my classification were 100 percent accurate, comparing it to the CDL would only result in 90 percent accuracy. Thus, a classification of 80 percent accuracy may indeed be higher 
relative to the actual ground conditions. Only further testing with a 100 percent accurate ground truth dataset can truly confirm how well the method performs. 


\section{Appendix D}

\section{Supplemental Files}

The source code for the tools documented in Appendix B is included with this thesis. All of the source files are in plain-text format, and can be opened in any text editor. The tools were developed in version 2.7.8 of the Python programming language (Python Software Foundation 2014) on MacOS 10.8.5. Usage of the tools on any unix-based system should be similar; Windows users may encounter unforeseen problems. Installing the tools is a complex process due to the Geospatial Data Abstraction Library (GDAL) dependency. GDAL is available as a Python Package, but does not come with support for the MODIS HDF4 file format. To use GDAL with this file format, it must be built from source with the correct dependencies and the proper compile options (namely HDF4 support and the Python bindings). How to do this is outside the scope of this documentation; please consult resources specifically about compiling GDAL.

A virtual environment, or virtualenv in Python-speak, is a development environment running an isolated Python interpreter. The Python install is independent from the system install. Likewise, packages can be installed within the virtualenv, not at the system level. I highly recommend using Python within a virtualenv. However, when GDAL is installed, 
the Python bindings are installed to the system Python. Using the GDAL bindings within a virtualenv can be complicated. To do so, navigate to lib/python2.7/site-packages in the virtualenv's directory tree. Within this folder, create a symbolic link to your GDAL install's .egg-info directory, and a symbolic link to the osgeo directory within your system python's site-packages directory. Specifically, the osgeo directory should contain the gdal and ogr .py and .so files. With these links, GDAL should be available for the virtualenv.

The rest of the dependencies can then be installed using the Python package manager pip. With the virtualenv activated, run the command \$ pip install - $r$ requirements . txt, and all the other dependencies will be installed. To complete the installation, copy the included files into the project directory of the virtualenv.

To use the command line tools, ensure your virtualenv is activated. Then, cd into the pyhytemporal folder. At your command prompt, type \$ python commands.py - - help. This will list the available commands. To see how to use each command, type \$ python commands.py <command_name $>$ - -help. All of the arguments and options will be listed.

The full list of included files is below:

- LICENSE - contains the licensing info for the software

- README - contains information about the included software and instructions for installation and operation of the software

- requirements.txt - a pip-format file for installing the required Python dependencies

- pyhytemporal [directory]

- LICENSE - contains the licensing info for the software

_ _ _ init__.py - required file for python package 
- classify.py - python module with classification functions

- commands.py - python module with the command line tools

- constants.py - python module with the package constants

- core.py - python module with the object definitions for the main package objects

- fitting.py - python module with signature fitting functions

- imageFunctions.py - python module with functions for image operations

- plotting.py - python module with pixel and signature plotting functions

- signatureFunctions.py - python module with reference signature functions

- utils.py - python module with basic utility functions

- vectorFunctions.py - python module with functions for vector data operations

Any future updates to this software will be pushed to the project's github site: https: //github.com/jkeifer/pyHytemporal. Please check this site to ensure the software is up-todate before use. Any bugs can be reported to the project's issue tracker. If you would like to contribute to this project, pull requests are accepted. 